\author{
UNIVERSIDADE DE SÃO PAULO \\ FACULDADE DE CIÊNCIAS FARMACÊUTICAS \\ Programa de Pós-Graduação em Fármaco e Medicamentos \\ Área de Insumos Farmacêuticos
}

\title{
ANTICHAGÁSICOS POTENCIAIS: SÍNTESE E ESTUDO DO COMPORTAMENTO VOLTAMÉTRICO DE BIOISÓSTEROS DO NITROFURAL
}

CHARLES DE LIMA BRITO

Dissertação para obtenção do grau de MESTRE

Orientadora:Profa. Titular Elizabeth Igne Ferreira

São Paulo

2011 
Aos meus pais Antonio Brito e Maria , por ter conduzido com sabedoria a educação exemplar, a auto-estima, primando pela cultura da valorização da ética, do amor e do respeito, meu profundo reconhecimento e minha eterna gratidão pela minha formação como pessoa e ter sempre incentivado intensamente os estudos. 
$\mathcal{A}$ Carla de Lima Brito, o meu eterno agradecimento. Não são laços de sangue que nos unem, mas sim de amor, respeito, carinho e amizade. Você tem um papel fundamental em minha vida, muito obrigado por sempre estar ao meu lado.

À Ana Paula, minha namorada, amiga, companheira... Melhor, você, que eu amo. Esta conquista, sem dúvida, também é sua.

Aos meus parceiros Bruce, Tobby (em especial) e Brad, que me acompanham nos meus estudos noturnos e constituem assim o super time: "DE LIMA BRITO", por toda a vida estarem presentes na minha vida $A$ vocês é dedicado este trabalho. 
À prof. Elizabeth,

amiga, companheira... Pelo apoio incondicional em todos os momentos, palavras não são o suficiente para expressar a minha gratidão por todo o amor, carinho, incentivo, paciência e compreensão. 
Ao Prof. Mauro, pela oportunidade dessa experiência e a orientação de fato concedida, expresso meus sinceros agradecimentos. Fica aqui minha gratidão pela liberdade para executar esse trabalho, pelo conhecimento transmitido e além de tudo, a nossa amizade que se fortalecera ao logo desse período 


\section{AGRADECIMENTOS}

Gostaria de expressar minha profunda gratidão às várias pessoas que me deram sua ajuda e apoio durante o período em que desenvolvi este trabalho. Seria impossível mencionar a todas.

À FACULDADE DE CIÊNCIAS FARMACÊUTICAS que me possibilitou o desenvolvimento deste trabalho.

Em especial a prof. Dra. Daniela Rando, pessoa iluminada, amiga exemplar e por coincidência do destino foi a primeira pessoa que avistei quando entrei na Faculdade de Ciências Farmacêuticas. Obrigado por toda paciência e amizade, parceria, apoio, dedicação sempre demonstrada comigo. Desejo-te muito sucesso tanto na sua vida pessoal quanto profissional.

A profa. Dra. Carlota Yagui de Oliveira Rangel que também contribuiu significativamente para o meu crescimento acadêmico. Um ser humano fantástico, que tenho uma imensa gratidão, além dos ensinamentos valiosos na área de farmácia. Muito obrigado por esta nossa amizade que é regada pela amizade e cumplicidade.

Ao prof. Dr. Gustavo Trossini pelo apoio ao longo de todo caminho percorrido e pela amizade.

Aos colegas de trabalho que passaram pelo laboratório durante esse tempo: Hugo, Ana Dionéia, Bigatão, Ricardinho,, Jeanine, Vanessa, Soraya, Camila, Marcela, Zaim, Ronan (Bárbaro), Natanael (Farinho) e Marina. Colegas e amigos do Laboratório que por este período foram convivência diária, o meu muito obrigado pela amizade, parceria, conversa e apoio em todos os momentos desse período.

Aos funcionários da secretaria de pós-graduação e do departamento de farmácia da Faculdade de Ciências Farmacêuticas da USP.

Aos meus amigos da manutenção da Faculdade de Ciências Farmacêuticas João Cordeiro, João Ângelo e Abdias, pelo carinho e por acreditarem e torcerem por mim.

A todos da minha família que não foram citados, mas que sempre me incentivaram e me deram força para continuar estudando.

A todos os amigos que ficaram fora desta lista, mas que de alguma forma contribuíram com este trabalho. 
"A essência do sábio é como a água. Por assim ser, se nivela por baixo, penetra em todos os lugares e nada força, mas tudo alcança. Não será atingido e não agride o agressor, mas todo agressor se molha."

Lao Tsu

"Grandes realizações não são feitas por impulso, mas por uma soma de pequenas realizações."

Vicent Van Gogh

"As invenções humanas nunca são o resultado de uma casualidade, mas da intenção e do pensamento do homem."

Werner Heinsenberg

"O pensamento é um vento que vem de lugar nenhum, sopra onde quere não pode ser detido."

Heidegger

"Adquirir conhecimento é a única coisa de que a mente nunca se cansa, nunca tem medo e nunca se arrepende"

Leonardo Da Vinci 


\title{
BRITO, C. L. ANTICHAGÁSICOS POTENCIAIS: SÍNTESE E ESTUDO DO COMPORTAMENTO VOLTAMÉTRICO DE BIOISÓSTEROS DO NITROFURAL.
}

\author{
2011.115p. Dissertação (Mestrado)- Faculdade de Ciências Farmacêuticas, \\ Universidade de São Paulo, 2011.
}

\section{RESUMO}

\begin{abstract}
A compreensão do mecanismo de redução de compostos nitroheterocíclicos pode ser um parâmetro importante para correlacionar estudos entre a transferência eletrônica e a atividade biológica. O nitrofural (NF), fármaco pertencente ao grupo químico dos 5-nitroheterocíclicos é ativo contra o Trypanosoma cruzi, agente etiológico da doença de Chagas, mas sua toxicidade impede o seu uso no tratamento desta parasitose. Desta forma, realizaram-se estudos do comportamento eletroquímico de três bioisósteros de NF, com substituição ora no heteroátomo do anel $(\mathrm{O}$ e $\mathrm{S})$ ora na carbonila $(\mathrm{O}$ e $\mathrm{S})$. As técnicas eletroquímicas de voltametria cíclica (VC), voltametria de pulso diferencial (VPD) e cronoamperometria (CRO) em meio aquoso e empregando eletrodo de carbono vítreo (ECV) como eletrodo de trabalho. A finalidade deste estudo foi compreender a influência do efeito estrutural sobre a atividade redox dos bioisósteros, pois os respectivos comportamentos eletroquímicos podem estar correlacionados com a ação biológica. Todos os processos de redução foram controlados por difusão, com a formação de único pico de redução $\left(E c_{p, 1}\right)$, sendo os análogos NT e NTS reduzidos em potencial ligeiramente mais negativo. A comparação dos resultados voltamétricos de NF com os obtidos para cada análogo demonstraram que todos os compostos apresentaram mecanismo de redução similar, envolvendo quatro elétrons, sendo em meio ácido o derivado hidroxilmina (RNHOH) o principal produto formado. Os dados obtidos por VPD e CRO corroboraram com estes resultados. Em meio alcalino e com prévio tratamento do eletrodo de carbono vítreo, constatou-se a formação de um pico de redução reversível, com envolvimento de um elétron para todos os compostos. Este pico refere-se à formação do nitro radical aniônico $\left(\mathrm{R}^{-} \mathrm{NO}_{2}{ }^{-}\right)$, mostrando-se estável na escala de tempo de medida da técnica de VC. Ademais, realizou-se estudo comparativo do efeito do polimento mecânico no ECV, com diamante e alumina, onde os dois procedimentos não apresentaram efeitos significativos diferentes sobre 0 comportamento voltamétrico dos análogos estudados. $O$ nitro radical gerado eletroquimicamente em meio aquoso sofre reação de desproporcionamento com cinética de segunda-ordem, seguindo mecanismo $\mathrm{E}_{r} \mathrm{C}_{\mathrm{i}}$ (reação eletroquímica reversível seguida de uma reação química irreversível). Os valores da constante de velocidade $\left(k_{2}\right)$ desta reação mostraram-se dependentes do $\mathrm{pH}$, confirmando que o nitro radical aniônico é mais facilmente estabilizado em meio alcalino, uma vez que com a diminuição da acidez do meio, a protonação do radical torna-se mais difícil. O composto com a inclusão de dois átomos de enxofre (NTS) apresentou os menores valores de $k_{2}$ indicando uma cinética de reação de desproporcionamento mais lenta praticamente em toda faixa de $\mathrm{pH}$, com exceção em $\mathrm{pH} 8$, com o qual os valores de $k_{2}$ não apresentaram diferenças significativas. Portanto, os resultados obtidos neste estudo indicaram claramente a possibilidade de geração e detecção do nitro radical em meio aquoso a partir de compostos nitro-heterocíclicos, distinguindo-se de dados reportados na literatura em que se realizam estes estudos predominantemente em meio não aquoso ou misto.
\end{abstract}

PALAVRAS CHAVE: doença de Chagas, nitro-heterocíclicos, nitrofural, nitro-radical aniônico, voltametria cíclica, bioisósteros, hidroxilamina 


\title{
BRITO, C. L. POTENTIAL ANTICHAGASIC: SYNTHESIS AND STUDY OF VOLTAMMETRIC BEHAVIOR OF BIOISOSTERES OF NITROFURAZONE.
}

\author{
2011.115p. Dissertação (Mestrado)- Faculdade de Ciências Farmacêuticas,
}

Universidade de São Paulo, 2011.

\section{ABSTRACT}

The comprehension of the reduction mechanism of nitroheterocyclic compounds is an important study to know the parameters which can establish the correlation between electron transfer and biological activity. Nitrofural (NF), a drug containing the 5-nitroheterocyclic moiety, is active against Trypanosoma cruzi, which is the etiologic agent of Chagas disease. Unfortunately, as NF toxicity prevents its use for the treatment against this illness, studies on the electrochemical behavior of three NF bioisosteres were performed. These bioisosteres contained substitutions $(O$ and $S$ ) on either the heterocyclic atom or the carbonyl group. The electrochemical techniques herein used were cyclic voltammetry (CV), differential pulse voltammetry (DPV) and chronoamperometry (CRO) in aqueous medium employing a glassy carbon (GCE) as the working electrode. The purpose of this study was to understand the structural influence on the redox activity of these bioisosteres and to suggest the correlation possibilities between the electrochemical behavior and the biological activity. The reduction processes were all diffusion controlled in acidic medium, with the formation of a single peak reduction $\left(E c_{p, 1}\right)$, being the NT and NTS analogue reduced at a slightly less negative potential. The comparison between the NF voltammetric results and those obtained with each analogue showed that all compounds presented a similar reduction mechanism, involving four electrons, being the hydroxylamine derivative the main product formed. The obtained data by DPV and CRO corroborated these results. Additionally, in alkaline medium and with previous GCE treatment by polishing a reversible reduction peak formation was observed with the involvement of one electron for all compounds. This peak refers to the nitro-radical anion formation $\left(\mathrm{R}^{-\mathrm{NO}_{2}}{ }^{-}\right)$, being stable in the $\mathrm{CV}$ time scale. Moreover, a comparative study was carried out on the mechanical effect in the GCE by polishing with diamond and alumina, showing that both procedures had no significant effect on the voltammetric behavior of the compounds. The nitro-radical electrochemically generated in aqueous medium undergoes disproportionation reaction with secondorder kinetics, following the $\mathrm{E}_{\mathrm{r}} \mathrm{C}_{i}$ mechanism (reversible electrochemical reaction followed by an irreversible chemical reaction). The constant rate values $\left(k_{2}\right)$ for this reaction proved to be $\mathrm{pH}$ dependent, confirming that the nitro-radical anion is more easily stabilized in alkaline medium, since the decreasing acidity of the medium hinders the radical protonation. Complementarily, NTS compound showed the lowest values of $k_{2}$, indicating a slower disproportionation reaction in almost all $\mathrm{pH}$ values, except at $\mathrm{pH} 8$, in which the $k_{2}$ values had no significant difference among all bioisosteres. Therefore, the obtained results in this study clearly showed that nitroradical anion can be detected and formed in aqueous solution in contrast to what is reported in literature, in which it is predominantly stabilized in non-aqueous solution or in solvent mixture.

KEYWORDS: Chagas disease, nitroheterocyclic, nitrofurazone, nitro-radical anion, voltammetry cyclic, bioisosters, hidroxylamine 


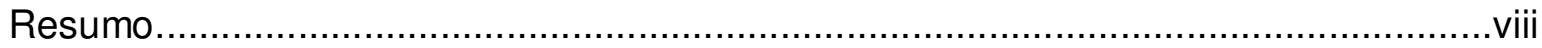

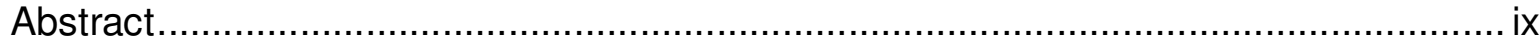

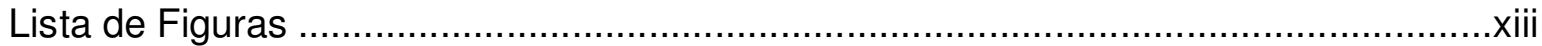

Lista de Esquemas e Tabelas................................................................................ii

Lista de Abreviaturas, Siglas e Símbolos .................................................................. vviii

\section{Capítulo 1: Introducão e Objetivos}

1.1 Introdução

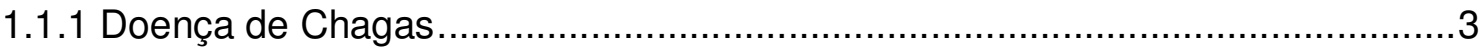

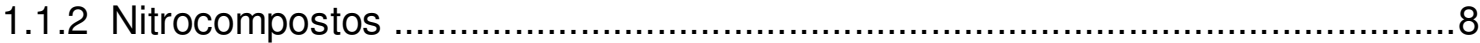

1.1.3 Mecanismo de ação dos nitrocompostos com atividade antichagásica............10

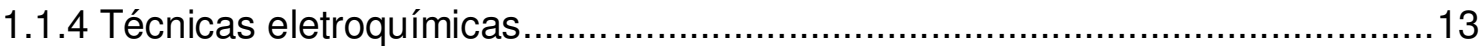

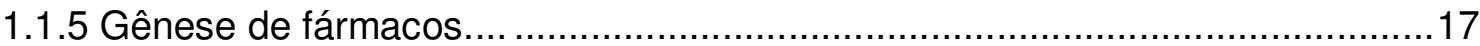

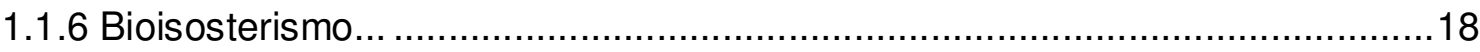

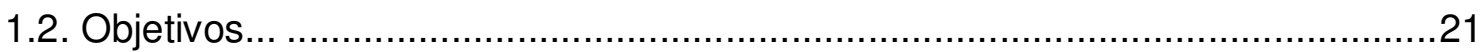

\section{Capítulo 2: Parte Experimental}

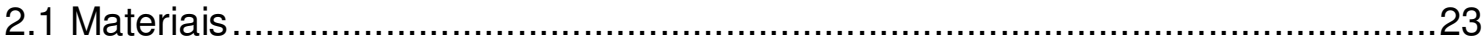

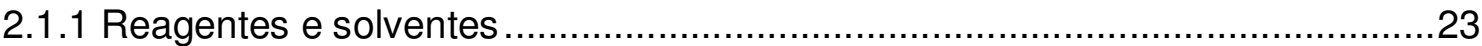

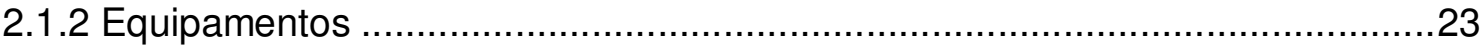

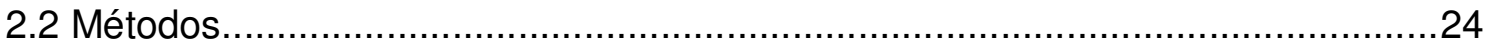

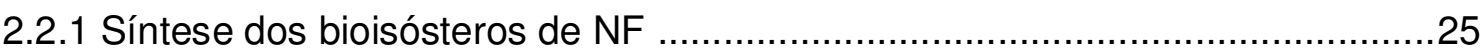

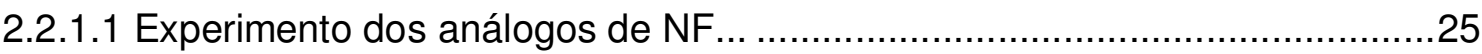

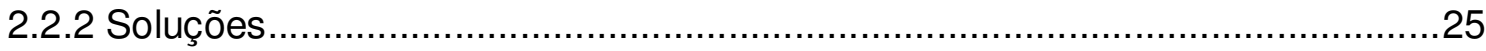

2.2.2.1 Soluções estoques de tampão universal pH 2,03-12,01 .........................25

2.2.2.2 Soluções estoques de 5,0 mmol/L d e NF e bioisósteros ..........................25

2.2.2.3 Solução estoque de $1,0 \mathrm{mmol} / \mathrm{L}$ de ferricianeto de potássio $\left(\mathrm{K}_{3} \mathrm{Fe}(\mathrm{CN})_{6}\right.$

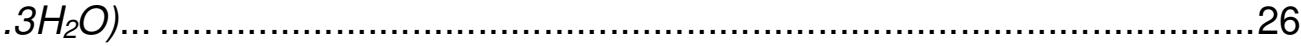

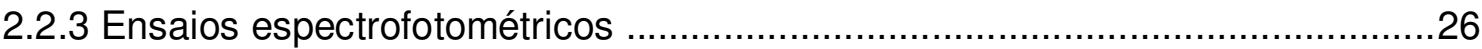

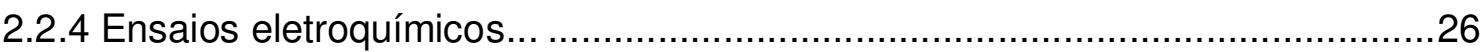


2.2.4.1 Pré-tratamento do eletrodo de carbono vítreo..........................................27

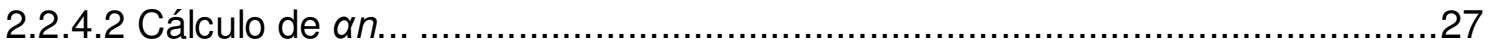

2.2.4.3 Cálculo do coeficiente de difusão $(D)$ de NF e de seus análogos................27

2.2.4.4 Procedimento para estimar a área efetiva do eletrodo ECV usando voltametria cíclica a partir de solução de $0,1 \mathrm{mmol} / \mathrm{L}$ de ferricianeto de

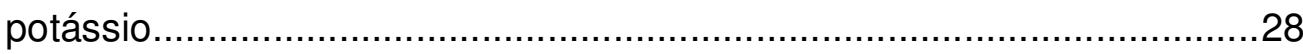

2.2.4.5 Estimativa do número de elétrons correspondente ao pico de redução

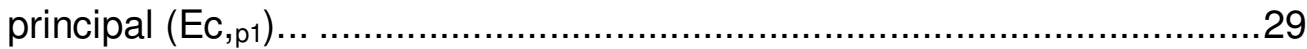

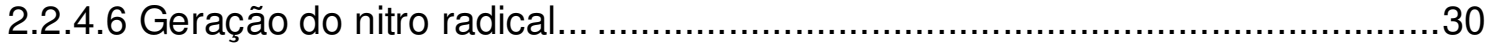

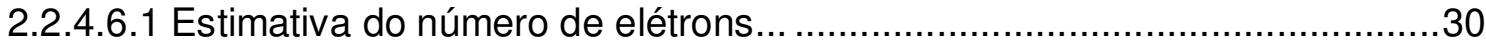

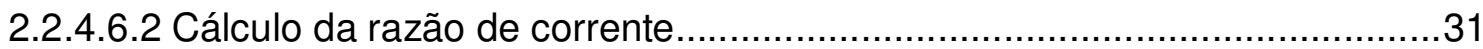

2.2.4.6.3 Cálculo da constante de velocidade $\left(k_{2}\right)$ e do tempo de meia-vida $\left(\mathrm{t}_{1 / 2}\right)$

\section{Capítulo 3: Resultados e discussão}

3.1 Estudo da estabilidade de NF e seus análogos ...............................................34

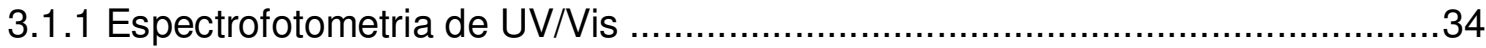

3.2 Comportamento Voltamétrico de NF e seus bioisósteros....................................36

3.2.1 Estimativa do número de elétrons envolvidos na redução de NF e seus

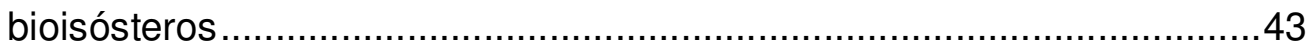

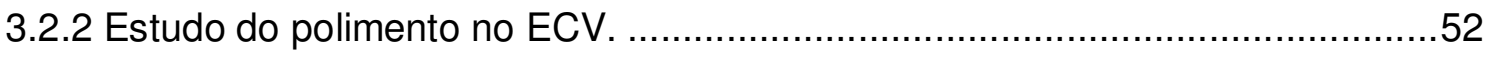

3.2.3 Estudo do efeito do $\mathrm{pH}$ no comportamento voltamético de NF e de seus

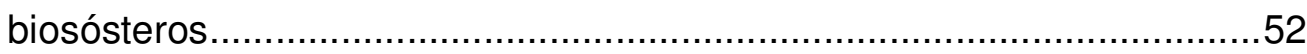

3.3 Geração nitro radical ânion $\left(\mathrm{R}-\mathrm{NO}_{2} / \mathrm{R}^{-\mathrm{NO}_{2}}{ }^{-}{ }^{-}\right)$em meio aquoso. ........................57

3.3.1 Aplicação dos critérios de reversibilidade.........................................................61

3.3.2 Estimativa do número de elétrons envolvidos na redução voltamétrica do nitro radical ânionico $\left(\mathrm{R}-\mathrm{NO}_{2} / \mathrm{R}^{-\mathrm{NO}_{2}}{ }^{\bullet}\right)$ ) de $\mathrm{NF}$ e seus análogos......................65

3.3.3 Avaliação dos parâmetros que podem influenciar as razões de corrente de NF

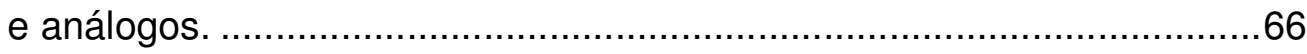

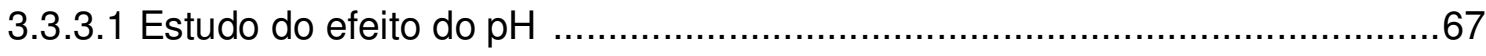




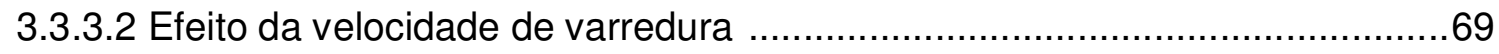

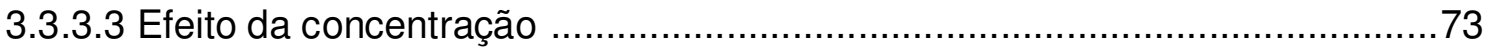

3.3.3.4 Cálculo das constantes de velocidade $\left(k_{2}\right)$ e tempo de meia-vida $\left(t_{1 / 2}\right)$........75

\section{Capítulo 4: Conclusões}

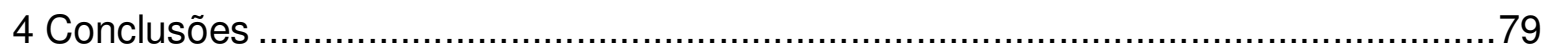

\section{Capítulo 5: Perspectivas}

5 Perspectivas

\section{Capítulo 6: Referências bibliográficas}

6 Referências bibliográficas .82

\section{Capítulo 7: Anexos}

7.1 Curriculum vitae 92

7. 2 Ficha do aluno. 96 


\section{LISTA DE FIGURAS}

Figura 1- Células sanguíneas infectadas pelo Trypanosoma cruzi...................................

Figura 2- Distribuição geográfica da doença de Chagas ..................................................

Figura 3- Estrutura química dos fármacos atualmente empregados no tratamento da doença de Chagas ........................................................................

Figura 4- Redução de tripanotiona dissulfeto para tripanotiona ditiol pela enzima tripanotiona redutase... .............................................................................

Figura 5- Comparação entre as estruturas da glutationa redutase e tripanotiona redutase. 8

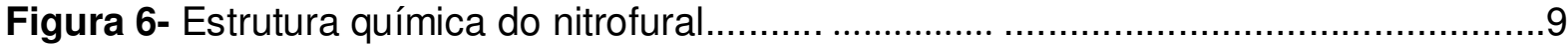

Figura 7- (A) Excitação típica do sinal para voltametria cíclica, potencial na forma de onda triangular, (B) gráfico da corrente vs potencial característica de VC obtido de dez ciclos 16

Figura 8- Análogos de NF ... .20

Figura 9- Espectros de UV/Vis de NF e bioisósteros. [Composto]= 0,1 mmol/L, em meio (1:1) DMF e água ultrapura, scan de 200-500 nm, velocidade de scan 2400 $\mathrm{nm} \min ^{-1}$ .35

Figura 10- Voltamogramas cíclicos registrados em pH 4,02. [Composto] $=0,5 \mathrm{mmol} / \mathrm{L}, v=$ $0,1 \mathrm{~V} / \mathrm{s}$. Condições experimentais: $E_{\text {inicial }}=0,0 \mathrm{~V}, \quad \mathrm{E}_{\lambda} \quad 1=-1,0 \mathrm{~V}$, $E_{\lambda 2}=+0,80 V, E_{\text {final }}=0,0 \mathrm{~V}$ 38

Figura 11- Voltamogramas cíclicos registrados em pH 4,02 com janela de potencial restrita em relação a Figura 10 . [Composto] $=0,5 \mathrm{mmol} / \mathrm{L}, v=0,1 \mathrm{~V} / \mathrm{s}$. Condições experimentais: $E_{\text {inicial }}=0,0 \quad V, E_{\lambda_{1}}=-0,35 \quad V, E_{\lambda 2}=+0,8 \quad V$; $E_{\text {final }}=0,0 \mathrm{~V}$ 
Figura 12- Variação de $-\mathrm{Ic}_{\mathrm{p}, 1}$ vs $v^{1 / 2} \mathrm{em} \mathrm{pH}$ 4,02. Dados obtidos usando ECV em [Composto] $=0,5 \mathrm{mmol} / \mathrm{L}$.

Figura 13- Voltamogramas de pulso diferencial obtidos em pH 4,02 usando eletrodo de carbono vítreo. [Composto] $=0,1 \mathrm{mmol} / \mathrm{L}, v=0,05 \mathrm{~V} / \mathrm{s}$. Condições experimentais: amplitude de pulso $=0,05 \mathrm{~V}$, intervalo de pulso $=0,5 \mathrm{~s}$, duração de pulso $=0,05 \mathrm{~s}$, tempo de equilíbrio $=5 \mathrm{~s}, \mathrm{E}_{\text {inicial }}=0,0 \mathrm{~V}, \mathrm{E}_{\text {final }}=-$ $0,7 \mathrm{~V}$. 45

Figura 14- Voltamogramas de pulso diferencial obtidos em $\mathrm{pH} \mathrm{4,02} \mathrm{usando} \mathrm{eletrodo} \mathrm{de}$ carbono vítreo. [Composto] $=0,1 \mathrm{mmol} / \mathrm{L}, v=0,05 \mathrm{~V} / \mathrm{s}$. Condições experimentais: amplitude de pulso $=0,05 \mathrm{~V}$, intervalo de pulso $=0,5 \mathrm{~s}$, duração de pulso $=0,05 \mathrm{~s}$, tempo de equilíbrio $=5 \mathrm{~s}$, Einicial $=0,0 \mathrm{~V}$, Efinal $=-0,7 \mathrm{~V}$ .46

Figura 15- Variação de $\mathrm{ld}$ em função de $\mathrm{t}^{-1 / 2}$. Dados obtidos em ECV, em $\mathrm{pH} 4,02$, [Composto]= 0,5mmol/L. Número de pulsos de potencial (3): nível (1) potencial $0 \mathrm{~V}$, duração: $0.2 \mathrm{~s}$, tempo de amostragem: $0,05 \mathrm{~s}$, nível (2) potencial $-0,7 \mathrm{~V}$, duração: $15 \mathrm{~s}$, tempo de amostragem: $0,05 \mathrm{~s}$, nível (3) potencial $0 \mathrm{~V}$, duração: $0.2 \mathrm{~s}$, tempo de amostragem: $0,05 \mathrm{~s}$

Figura 16- Variação de Id em função de $\mathrm{t}^{-1 / 2}$. Dados obtidos em ECV, em $\mathrm{pH} 7,41$, [Composto]= 0,5mmol/L. Número de pulsos de potencial (3): nível (1) potencial $0 \mathrm{~V}$, duração: $0.2 \mathrm{~s}$, tempo de amostragem: 0,05, nível (2) potencial $-0,7 \mathrm{~V}$, duração: $15 \mathrm{~s}$, tempo de amostragem: 0,05, nível (3) potencial 0V, duração: $0.2 \mathrm{~s}$, tempo de amostragem: $0,05 \mathrm{~s}$ .50

Figura 17- Variação dos potenciais de pico catódico $\left(\mathrm{Ep}_{, \mathrm{c} 1}\right.$ e $\left.\mathrm{Ep}, \mathrm{c}_{2}\right)$ vs $\mathrm{pH}$ usando eletrodo de carbono vítreo como eletrodo de trabalho [Composto] = $0,5 \mathrm{mmol} / \mathrm{L} v=0,10 \mathrm{~V} / \mathrm{s}$ .54 
Figura 18- Variação do potencial do primeiro pico anódico $\left(\mathrm{Ea}_{\mathrm{pp} 1}\right) v s \mathrm{pH}$. Dados obtidos usando ECV a $v=0,10 \mathrm{~V} / \mathrm{s}$, [Composto] $=0,5 \mathrm{mmol} / \mathrm{L}$.

Figura 19- Voltamogramas cíclicos obtidos em pH 7,01 usando eletrodo de carbono vítreo. [Composto] $=0,5 \mathrm{mmol} / \mathrm{L}, v=0,1 \mathrm{~V} / \mathrm{s}$. Condições experimentais: $E_{\text {inicial }}=\quad 0,0 \mathrm{~V}, \quad \mathrm{E}_{\lambda 1}=\quad-1,2 \mathrm{~V}<\mathrm{E}_{\lambda}<-0,80 \mathrm{~V} \quad \mathrm{E}_{\lambda 2}=\quad+0,2 \mathrm{~V}$; $\mathrm{E}_{\text {final }}=0,0 \mathrm{~V}$ 59

Figura 20- Voltamogramas cíclicos obtidos em pH 7,41 usando eletrodo de carbono vítreo. [Composto] $=0,5 \mathrm{mmol} / \mathrm{L}, v=0,1 \mathrm{~V} / \mathrm{s}$. Condições experimentais: $\mathrm{E}_{\text {inicial }}=$ $0,0 \mathrm{~V}, \mathrm{E}_{\lambda 1}=-1,2 \mathrm{~V}<\mathrm{E}_{\lambda}<-1,5 \mathrm{~V}, \mathrm{E}_{\lambda_{2}}=+1,0 \mathrm{~V} ; \mathrm{E}_{\text {final }}=0,0 \mathrm{~V}$

Figura 21- Voltamogramas cíclicos obtidos em pH 10,01 usando eletrodo de carbono vítreo, spray de diamante para polimento. [Composto] =0,5mmol/L. Condições experimentais: $E_{\text {inicial }}=-0,2 \mathrm{~V},-0,60 \mathrm{~V}<\mathrm{E}_{\lambda}<-0,70 \mathrm{~V}$, $\mathrm{E}_{\text {final }}=-0,2 \mathrm{~V}$. Intervalo de $\quad 100 \leq v \leq 1000 \mathrm{mV} \mathrm{s}^{-1}$. Área do $\mathrm{ECV}=0,035 \pm 0,004 \mathrm{~cm}^{2}$

Figura 22- Variação de $\mathrm{Ec}_{\mathrm{c}, \mathrm{p} 2 \mathrm{R}}$ e $\mathrm{Ea}_{\mathrm{p} \text { p3R }}$ em pH 10,1 como função de $v$, usando eletrodo de carbono vítreo,

[Composto] $=0,5 \mathrm{mmol} / \mathrm{L}$. .63

Figura 23 - Variação de $\mathrm{Ic}, \mathrm{p} 2 \mathrm{R} / \mathrm{C} v^{1 / 2}$ (função de corrente) como função de $v$. Dados obtidos dos voltamogramas mostrados na Figura 21 64

Figura 24 - Variação de $\mathrm{Ic}$,p2R em função de $v^{1 / 2}$. Dados obtidos a partir dos voltamogramas apresentados na Figura 21 [Composto] $=$ $0,5 \mathrm{mmol} / \mathrm{L}$ .65

Figura 25- Efeito do $\mathrm{pH}$ nos valores de Ec,p2R para o par redox $\mathrm{R}-\mathrm{NO}_{2} / \mathrm{R}-\mathrm{NO}_{2}{ }^{\bullet-}$ gerado eletroquimicamente. [Composto] $=0,5 \mathrm{mmol} / \mathrm{L} ; \quad v=1,0 \vee \mathrm{s}^{-1}$; $E_{\lambda}=-0,7 \mathrm{~V}$. 68 
Figura 26- Efeito do $\mathrm{pH}$ sobre os valores de $1 \mathrm{a}_{\mathrm{p}, 3 \mathrm{R}} / \mathrm{l}_{\mathrm{p}, 2 \mathrm{R}}$. [Composto] $=0,50 \mathrm{mmol} / \mathrm{L}$, $v=1,0 \mathrm{Vs}^{-1}$. $\mathrm{E}_{\text {inicial }}=-0,2 \mathrm{~V},-0,60 \mathrm{~V}<\mathrm{E}_{\lambda}<-0,70 \mathrm{~V}, \mathrm{E}_{\text {final }}=-0,2 \mathrm{~V}$ .68

Figura 27- Relação entre as razões de $\mathrm{la}_{\mathrm{p}, 3 \mathrm{R}} / \mathrm{I}_{\mathrm{p}, 2 \mathrm{R}}$ e $\log v$. [Composto] $=0,5 \mathrm{mmol} / \mathrm{L}(\boldsymbol{\nabla})$ $\mathrm{pH} 8 ;(\Delta) \mathrm{pH} 9,(0) \mathrm{pH} 10$, (a) $\mathrm{pH}$ 12. Condições experimentais: Einicial=$0,2 \mathrm{~V},-0,60 \mathrm{~V}<\mathrm{E}_{\lambda}<-0,70 \mathrm{~V}, \mathrm{E}_{\text {final }}=0,2 \mathrm{~V}$. .71

Figura 28- Dependência de $\mathrm{Ec}_{, \mathrm{p} 2 \mathrm{R}}$ em função de $\log v$. Dados obtidos em pH 10 usando ECV, velocidade de varredura de $1,0 \mathrm{~V} \mathrm{~s}^{-1}$. Condições experimentais: $E_{\text {inicial }}$ $=-0,2 \mathrm{~V}, \quad E_{\lambda_{1}}=-0,70 \mathrm{~V}, \mathrm{E}_{\text {final }}=-0,2 \mathrm{~V}$ .72

Figura 29- Variação de la,p3R/lc,p2R em função da concentração. Dados obtidos em pH 10 usando ECV, velocidade de varredura de $1,0 \mathrm{~V} / \mathrm{s}$. Condições experimentais: $E_{\text {inicial }}=-0,2 \mathrm{~V}, \mathrm{E}_{\lambda 1}=-0,70 \mathrm{~V}, \mathrm{E}_{\text {final }}=-0,2 \mathrm{~V}$

Figura 30- Gráfico dos parâmetros cinéticos, $\boldsymbol{\varpi}$ como função da constante de tempo, $\tau$. [Composto]= 0,50 mmol/L. ( $\bullet$ ) pH 8; ( $\boldsymbol{\nabla}$ ) pH 9, ( $\Delta$ ) pH 10, ( ○ ) pH 12. Condições experimentais: $\quad E_{\text {inicial }}=-0,2 \mathrm{~V}, \quad-0,60 \mathrm{~V}<\mathrm{E}_{\lambda}<-0,70 \mathrm{~V}$, $E_{\text {final }}=-0,2 \mathrm{~V}$. .77 


\section{LISTA DE ESQUEMAS E TABELAS}

Esquema 1. Síntese de análogos do NF. Reação geral da síntese dos bioisósteros de $N F$ .24

Tabela 1. Parâmetros voltamétricos obtidos na redução de $0,5 \mathrm{mmol} / \mathrm{L}$ de NF e NFS em $\mathrm{pH} 4,0$ usando ECV em $0,01 \mathrm{~V} / \mathrm{s} \leq v \leq 1,0 \mathrm{~V} / \mathrm{s}$ .37

Tabela 2. Parâmetros voltamétricos obtidos na redução de $0,5 \mathrm{mmol} / \mathrm{L}$ de NF e NFS em $\mathrm{pH} 4,0$ usando ECV em $0,01 \mathrm{~V} / \mathrm{s} \leq v \leq 0,5 \mathrm{~V} / \mathrm{s}$

Tabela 3. Valores de coeficiente de difusão e do volume molar dos compostos estudados em pH 4,02 e 7,41, em $v=0,01 \mathrm{~V} / \mathrm{s}$ usando ECV... .48

Tabela 4. Número de elétrons ( $\mathrm{n}$ ) para a redução de $0,5 \mathrm{mmol} / \mathrm{L}$ de $\mathrm{NF}$ e de seus análogos de NF e seus análogos em pH 4,02 usando ECV e a Equação de Randles-Sevick 51

Tabela 5. Número de elétrons ( $\mathrm{n}$ ) para a redução de $0,5 \mathrm{mmol} / \mathrm{L}$ de $\mathrm{NF}$ e de seus análogos de NF e seus análogos em pH 4,02 e 7,41 usando ECV e a Equação de Cottrell .51

Tabela 6. Equações das retas obtidas a partir das regiões lineares dos gráficos $\mathrm{Ec}_{\mathrm{p} 1}$ vs. $\mathrm{pH}$.[Composto] $=0,5 \mathrm{mmol} / \mathrm{L}, \mathrm{v}=0,1 \mathrm{~V} / \mathrm{s}$ .55

Tabela 7. Equações das retas obtidas a partir dos gráficos $\mathrm{Ea}_{\mathrm{p}, 1}$ vs. pH . Dados obtidos em ECV e concentração de $0,5 \mathrm{mmol} / \mathrm{L}$ .57

Tabela 8. Valores de coeficiente de difusão e do número de elétrons (n) dos compostos estudados, bem como as equações de reta em $\mathrm{pH}$ 10,01, referentes à redução do pico Ec,p2R

Tabela 9. Valores de $k_{2}$ e $t_{1 / 2}$ para a reação de desproporcionamento do radical aniônico em diferentes valores de $\mathrm{pH}$; [Composto] $=0,5 \mathrm{mmol} / \mathrm{L}$ 


\section{LISTA DE ABREVIATURAS, SIGLAS E SÍMBOLOS}

\begin{tabular}{|c|c|}
\hline TR & Tripanotiona redutase \\
\hline NF & Nitrofural \\
\hline NFS & 5-nitro-2-furfurilideno tiosemicarbazona \\
\hline NT & 5-nitro-2-tiofeno semicarbazona \\
\hline NTS & 5-nitro-2-tiofeno tiosemicarbazona \\
\hline ECV & Eletrodo de Carbono Vítreo \\
\hline VC & Voltametria Cíclica \\
\hline VPD & Voltametria de Pulso Diferencial \\
\hline CRO & Cronoamperometria \\
\hline GR & Glutationa redutase \\
\hline DMF & N-N Dimetilformamida \\
\hline ECS & Eletrodo de calomelano saturado \\
\hline$\alpha$ & Coeficiente de transferência de carga \\
\hline $\mathrm{R}-\mathrm{NO}_{2} \bullet-$ & Nitro radical aniônico derivado do $\mathrm{R}-\mathrm{NO}$ \\
\hline $\mathrm{R}-\mathrm{NHOH}$ & Hidroxilamina derivada do $\mathrm{R}-\mathrm{NO}_{2}$ \\
\hline Ar-NO & Nitroso derivado do $\mathrm{R}-\mathrm{NO}_{2}$ \\
\hline D & Coeficiente de difusão \\
\hline
\end{tabular}




\begin{tabular}{|c|c|}
\hline$E_{i}$ & Potencial inicial \\
\hline$E_{f}$ & Potencial final \\
\hline$E_{\lambda}$ & Potencial de inversão de varredura em voltametria cíclica \\
\hline$E c, p$ & Potencial de pico catódico \\
\hline $\mathrm{Ea}, \mathrm{p}$ & Potencial de pico anódico \\
\hline $\mathrm{la}_{\mathrm{,p}}$ & Corrente de pico anódica \\
\hline IC, & Corrente de pico catódica \\
\hline $\mathrm{la}, \mathrm{p} / \mathrm{lc}, \mathrm{p}$ & Razão de corrente \\
\hline$k_{2}$ & Constante de velocidade para reação de desproporcionamento \\
\hline$t_{1 / 2}$ & Tempo de meia-vida \\
\hline SOD & Superóxido dismutase \\
\hline$n$ & Número de elétrons \\
\hline V & Volumes moleculares \\
\hline UV & Espectro na região do UV \\
\hline Vis & Espectro na região do visível \\
\hline AM1 & Método Hamiltoniano \\
\hline$\Delta \mathrm{E}_{\mathrm{p}}$ & $\mathrm{Ea}_{, \mathrm{p}}-\mathrm{Ec}_{\mathrm{p}, \mathrm{p}}$ \\
\hline$v$ & Velocidade de varredura \\
\hline Id & $\begin{array}{l}\text { Corrente difusional obtida nos ensaios voltamétricos e } \\
\text { cronoamperompétricos }\end{array}$ \\
\hline $\mathrm{E}_{\mathrm{r}} \mathrm{C}_{\mathrm{i}}$ & $\begin{array}{l}\text { Reação de transferência de carga reversível seguida de reação } \\
\text { química irreversível }\end{array}$ \\
\hline
\end{tabular}


Capítulo 1

Introdução e Objetivos 


\subsection{INTRODUÇÃO}

\subsubsection{Doença de Chagas}

A doença de Chagas ou tripanossomíase americana descoberta em 1909 por Carlos Chagas é uma doença infecciosa parasitária causada pelo protozoário Trypanosoma cruzi (Figura 1), que é um hemoflagelado digenético e eucarionte, pertencente à ordem Kinetoplastida, família Trypanosomatidae e gênero Trypanosoma (DIAS et al., 2009; Coura \& Castro, 2002). A doença é assim chamada em homenagem a Carlos Chagas, talvez o maior pesquisador brasileiro do século XX. Além de identificar o T. cruzi, Carlos Chagas efetuou descobertas em todos os aspectos da doença, tais como: anatomia patológica, epidemiologia, etiologia, formas clínicas, meios de transmissão, patogenia, profilaxia e sintomatologia, o que é considerado um feito único na história da medicina (DIAS, 2002; AMATO NETO, 1950).

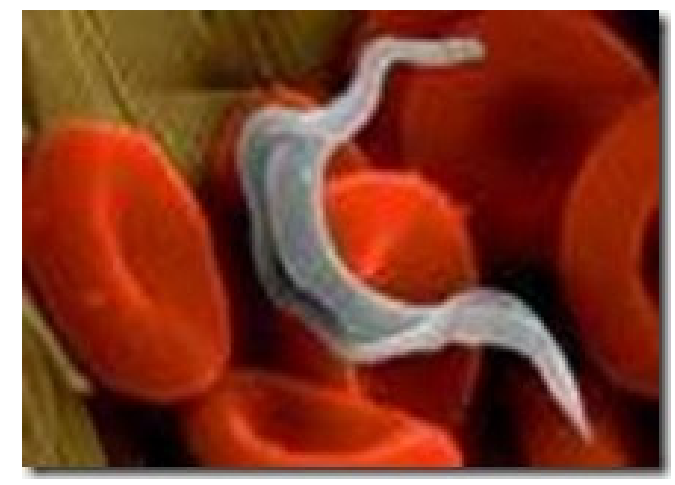

Figura 1 - Células sanguíneas infectadas pelo Trypanosoma cruzi. Fonte: www.who.int/tdr/diseases/chagas/files/chagas-postes.pdf. Acesso 03/10/2010.

O vetor para este protozoário é o Triatoma, principalmente o $T$. infestans e $T$. dimidiata, que são conhecidos popularmente no Brasil como "barbeiros", devido ao hábito de picarem os indivíduos na região do rosto, onde a pele é mais fina (DIAS, 2002). Dentre outras formas de transmissão estão à transfusão sanguínea, sendo a segunda forma de transmissão mais relevante do $T$. cruzi com prevalência de contaminação sanguínea maior que HIV, hepatites B e C (WHO, 2008). A transmissão por via oral também deve ser considerada, assumindo a terceira forma mais incidente, por meio da amamentação, pois o T.cruzi já foi encontrado em leite materno na fase aguda da infecção, como também pela ingestão de alimentos 
contaminados - como açaí ou caldo de cana-de-açúcar - com fezes ou urina de triatomíneos infectados com o parasita (MAEGAWA et al., 2003; ROJAS et al., 2005). É válido ressaltar os relatos de consumo de caldo de cana contaminado em Santa Catarina em 2005, e de açaí no Pará em 2005 (Informativos das Secretarias de Saúde de Santa Catarina e do Pará, 2005). Além destes modos de transmissão consta-se também a transmissão por transplante de órgãos infectados, acidentes laboratoriais e a transplacentária (LANA \& TAFURI, 2005).

A doença de Chagas é um dos principais problemas socioeconômicos enfrentados na América Latina, pois afeta 10 milhões de pessoas a partir do sul dos Estados Unidos até a Patagônia, perfazendo um total de 21 países endêmicos, na qual 2 milhões estão na fase crônica da doença e correm risco de morrer (WHO, 2011). Estima-se que esta patologia causa aproximadamente 50.000 mortes por ano e que apenas 0,5\% recebem tratamento. Ao todo 100 milhões de indivíduos vivem em áreas de risco e estão ameaçados pela doença (GELB \& HOL, 2002; ENGELS \& SAVIOLI, 2006). Esta endemia é tão negligenciada que sequer há números oficiais sobre a doença no mundo, todavia estimativas da Organização Mundial de Saúde indicam que o Brasil concentra $23 \%$ dos infectados, com o maior número de casos dentre todos os países endêmicos (WHO, 2011). A Figura 2 mostra a distribuição geográfica da parasitose.

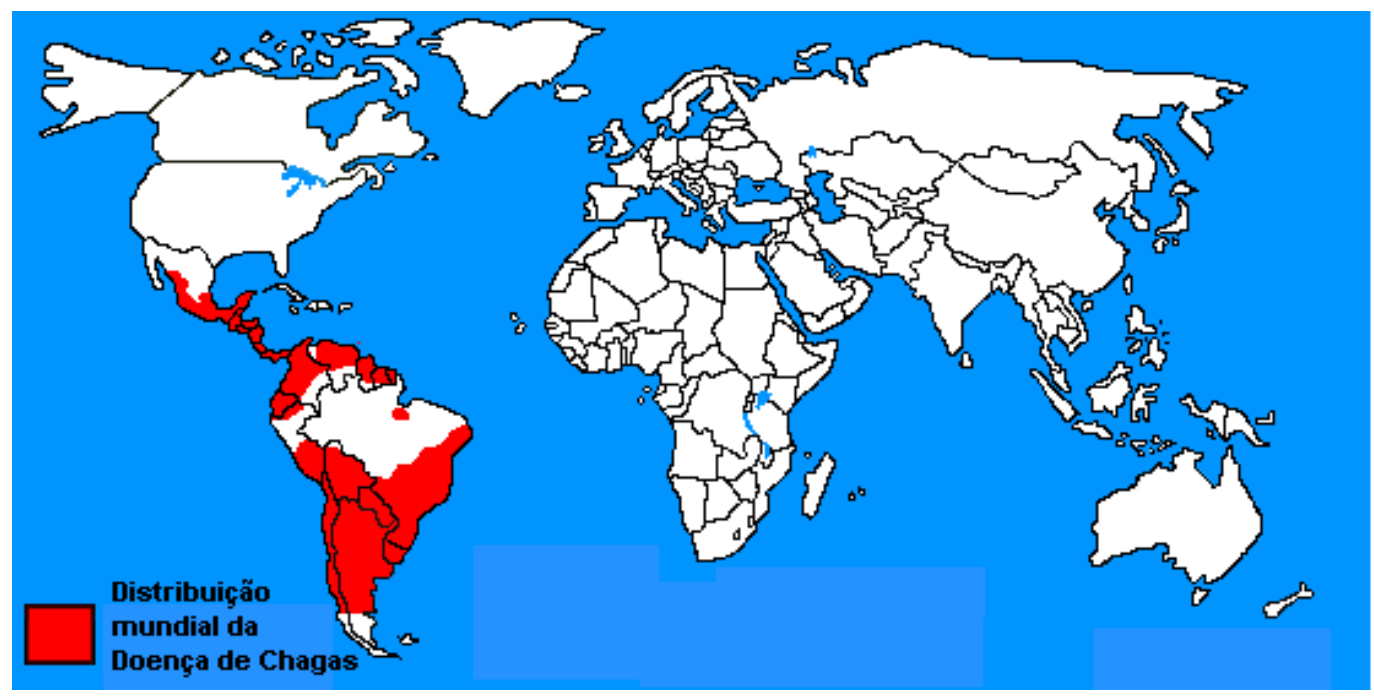

Figura 2 - Distribuição geográfica da doença de Chagas.

Fonte: COURA, DIAS, 2009 (adaptado) 
Com o desenvolvimento industrial a partir da década de 1950, a doença passou a ser fortemente urbazinada pela migração contínua de pessoas infectadas para os grandes centros. Com isto, o perfil epidemiológico da doença de Chagas foi se alterando devido aos movimentos migratórios rural-urbanos, transformando a infecção por T.cruzi também de caráter urbano. Neste sentido, trata-se de problema de saúde pública relacionado, principalmente, com as cidades grandes, pois é para elas que se dirigem as pessoas infectadas na busca de trabalho. Ademais, nessas metrópoles encontram-se os doentes à procura de tratamento (ARAÚJO \& SABROZA, 2009).

No Brasil, a doença de Chagas é a quarta causa de morte entre as doenças infecto-parasitárias, sendo que a maior incidência ocorre em indivíduos acima de 45 anos de idade e principalmente na região Sudeste (ARAÚJO \& SABROZA, 2009).

O objetivo da terapêutica antichagásica consiste em suprimir a infecção ou mesmo impedir o desenvolvimento da doença e promover a eliminação dos parasitas da corrente sanguínea e dos tecidos, entretanto o arsenal terapêutico hoje utilizado na quimioterapia contra a doença de Chagas, além de apresentar eficácia questionável, é composto por fármacos que apresentam graves efeitos adversos ao paciente.

A doença desafia as tentativas de uma quimioterapia eficiente e segura, pois existem apenas dois fármacos (benznidazol e nifurtimox), que não satisfazem totalmente estes objetivos. Além de sua toxicidade por serem inespecíficos, não apresentam eficácia na forma crônica da doença, Figura 3 (ARAYA et al., 2003, CASTRO et al., 2006; DOCAMPO, 1985; URBINA, 2002 e 2003; CANÇADO, 1999; KATZUNG, 2001).

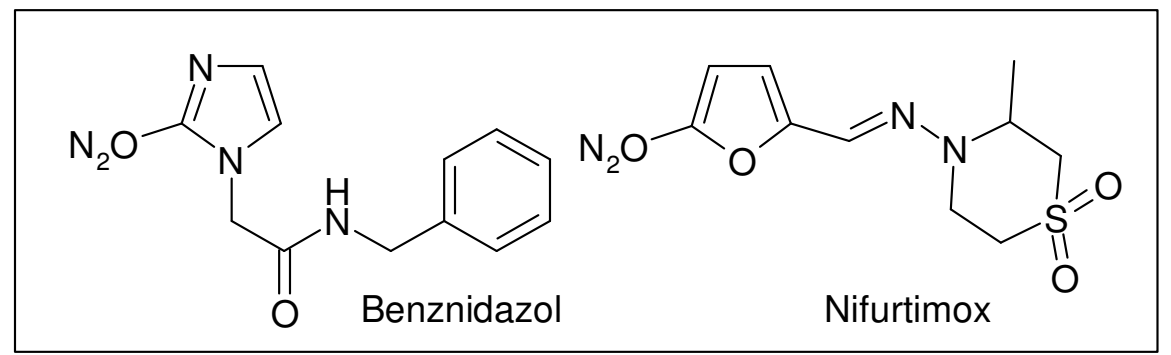

Figura 3 - Estrutura química dos fármacos atualmente empregados no tratamento da doença de Chagas. 
Para o desenvolvimento de fármacos mais seletivos, eficazes e com menor toxicidade é cada vez mais importante a seleção do alvo terapêutico, o que permite uma busca racional por agentes que provoquem a resposta desejada específica para o controle da doença. O maior foco para a descoberta de novos fármacos antichagásicos durante os últimos anos tem sido a identificação e caracterização bioquímica e molecular de alvos (ZINGALES \& COLLI, 1985; COURA \& DE CASTRO, 2002; URBINA \& DO CAMPO, 2003; DIAS et al., 2009).

A pesquisa de novas alternativas medicamentosas tem como base 0 conhecimento da estrutura e dos processos metabólicos do Trypanosoma cruzi. Estudos comparativos entre o metabolismo dos tripanossomas e os seus hospedeiros mamíferos têm demonstrado a existência de alvos biológicos e enzimáticos específicos para a ação de novos compostos com atividade antichagásica (KRAUTH-SIEGEL, BAUER, SCHIRMER, 2005; COURA \& CASTRO, 2002).

Vários processos bioquímicos têm sido apontados como alvos terapêuticos potenciais, entre eles: a enzima tripanotiona redutase (TR). A TR foi descoberta em 1985 e é uma flavoenzima responsável pela proteção contra radicais livres de tripanossomas, a enzima ocorre exclusivamente em tripanomatides e catalisa a redução da tripanotiona dissulfeto $\left[\mathrm{T}(\mathrm{S})_{2}\right]$ em tripanotiona ditiol $\left[\mathrm{T}(\mathrm{SH})_{2}\right]$, Figura 4 (KRAUTH-SIEGEL, BAUER, SCHIRMER, 2005).

Considera-se que o processo de redução dos nitrocompostos resulta em inibição da TR, sendo que este mecanismo resulta em formação de produto eletrofílico que promove a oxidação da ligação dissulfeto do substrato tripanotiona reduzido, $\left(\mathrm{TS}_{2}\right)$, e a subsequente formação de substrato oxidado $\left(\mathrm{TSH}_{2}\right)$ (KrauthSiegel et al., 2005; Blumenstiel et al., 1999). Este processo inibe a formação do substrato biologicamente ativo da TR, a partir da biomolécula $\left(\mathrm{TSH}_{2}\right)$ o que torna o parasita deficiente em suas defesas enzimáticas contra espécies reativas de oxigênio (Chauviére et al., 2003; Viodé et al., 1999; Hardman et al.,1996; Henderson et al.,1988). 


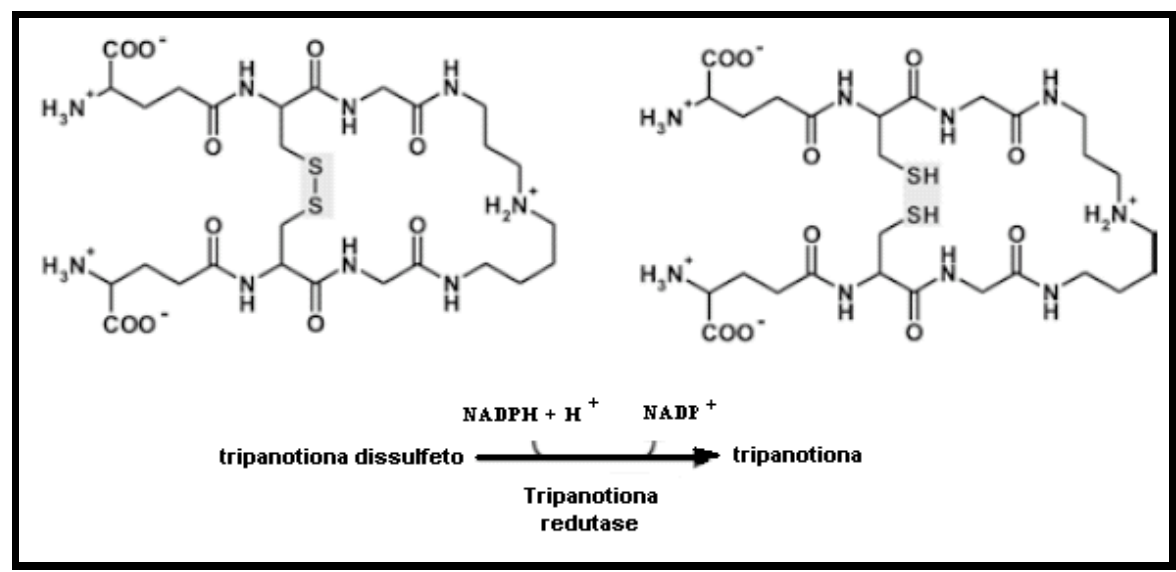

Figura 4 - Redução de tripanotiona dissulfeto para tripanotiona ditiol pela enzima tripanotiona redutase (KRAUTH-SIEGEL e INHOFT, 2003).

Além de exercer uma função fundamental para o parasita, outra característica que faz com que a TR seja alvo interessante para o planejamento de fármacos antiparasitários é sua significativa diferença estrutural em relação a glutationa redutase (GR), enzima com função correspondente no homem (Figura 5). As principais diferenças entre a TR e a GR estão relacionadas ao tamanho, carga e distribuição dos bolsos hidrofílicos/hidrofóbicos. Estas diferenças fazem com que o sítio ativo da TR, em comparação ao da GR, seja capaz de acomodar facilmente substratos apresentando grupos mais volumosos (GIRAULT et al., 2001; MARTYN et al., 2007; HOLLOWAY et al., 2007). Além disso, a TR apresenta resíduos carregados negativamente e regiões hidrofóbicas em seu sítio ativo que são capazes de interagir, via interações eletrostáticas e de Van de Waals, respectivamente, com seu substrato. Ao contrário, a GR apresenta resíduos de arginina, carregados positivamente, que interagem por ligação eletrostática com seu substrato (BOND et al., 1999). Estas diferenças podem ser aproveitadas no planejamento de inibidores seletivos da TR.

Dados da literatura indicam que derivados nitrofurânicos atuam como substratos da TR e são também efetivos inibidores enzimáticos da redução da tripanotiona dissulfeto- substrato fisiológico da enzima (AGUIRRE, et al., 2005). Ademais, nota-se que estes produtos ou demais intermediários formados a partir da reação de redução destes fármacos também podem causar danos às enzimas e ao DNA do T. cruzi (TOCHER, 1997). Ainda assim, considera-se o processo de redução 
dos nitrocompostos e a formação do radical nitro aniônico como etapa fundamental para atividade biológica (VIODÉ et al., 1999; HARDMAN et al., 1996). Desta forma, por esta via, os compostos 5- nitro-heterocíclicos são responsáveis pela inativação da tripanotiona redutase e se apresentam como compostos promissores para o estudo e desenvolvimento de futuros candidatos à fármacos antichagásicos (CHIBALE \& MUSONDA, 2003; AGUIRRE et al., 2004).

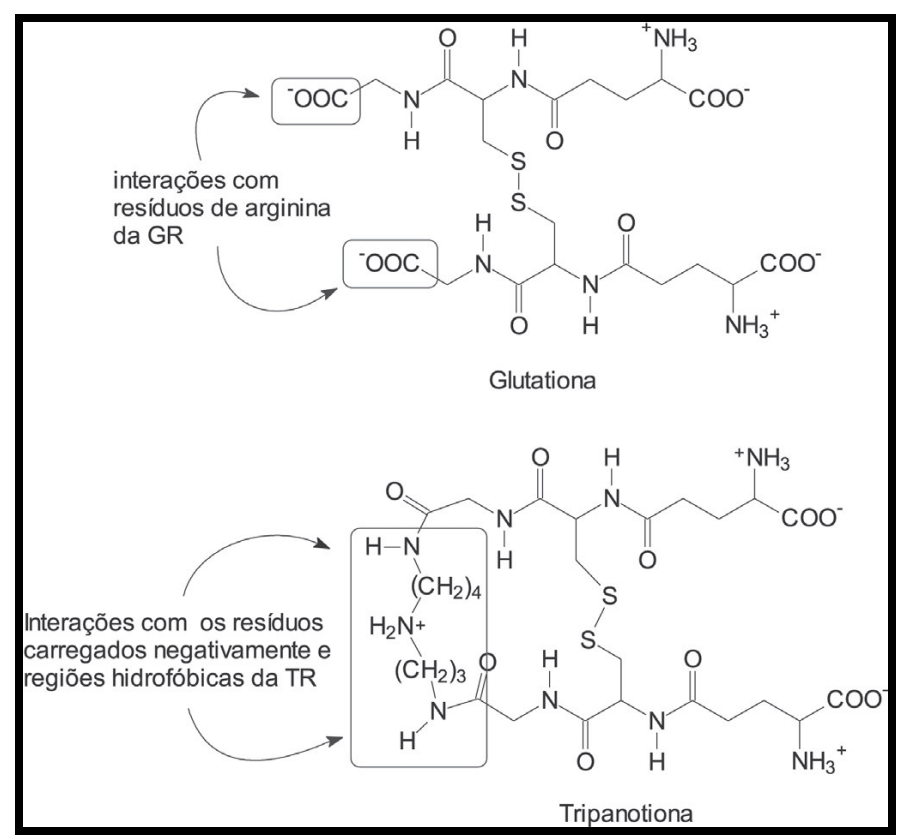

Figura 5 - Comparação entre as estruturas da glutationa e tripanotiona, substratos da GR e TR, respectivamente (OLIVEIRA et al., 2008).

\subsubsection{Nitrocompostos}

Os nitrocompostos são empregados em várias classes terapêuticas e possuem diversas aplicações clínicas, entre as quais se citam usos como antianginosos (dinitrato de isossorbida, nitroglicerina), anti-hipertensivos (nifedipina, anticoagulante (acenocumarol), antibacterianos (clorafenicol, metronidazol, nitrofural), entre outras (DODD \& STILMAN, 1944; VIODÉ et al., 1999; TAVARES et al.,1999; KATZUNG, 2001; HORROCKS et al., 2007; RAETHER \& HÄNEL, 2003; KOROLKOVAS 2007; TOCHER, 1997).

Entre os nitrocompostos identificam-se diversos compostos nitroheterocíclicos com atividade antichagásica que podem ser utilizados em estudos 
visando o aperfeiçoamento do seu perfil antiparasitário (AGUIRRE et al., 2005, CERECETTO et al., 2000). Entre estes compostos, o nitrofural (NF), 5-nitro-2furaldeído-semicarbazona (Figura 6), foi o primeiro fármaco 5-nitrofurânico introduzido na terapêutica e que foi amplamente utilizado durante a Segunda Guerra Mundial como agente antimicrobiano de amplo espectro (CRENSHAW et al., 1976).

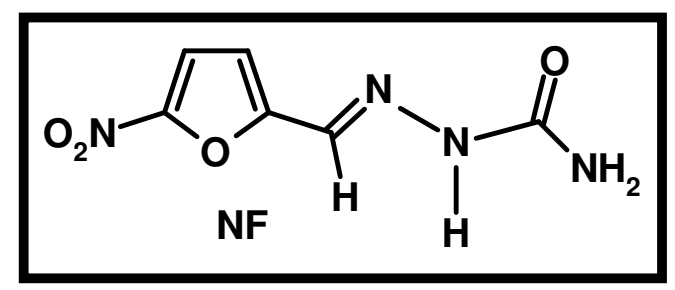

Figura 6 - Estrutura química do nitrofural

Em 1969, ANDRADE E BRENER observaram que o nitrofural provocava destruição do T. cruzi. Mais tarde, HENDERSON e colaboradores (1988) constataram a inibição da tripanotiona redutase por nitrofuranos, incluindo o nitrofural.

O processo de biorredução enzimática do grupo nitro apresenta-se como prérequisito para a ação antiparasitária dos nitrocompostos, constituindo assim em exemplo típico de bioprecursor, pois a sua atividade terapêutica é devido à formação de metabólitos intermediários, como a hidroxilamina e o nitro radical, que interagem com biomacromoléculas comprometendo assim, algumas funções vitais à manutenção da espécie invasora.

É importante destacar que o melhor desempenho da atividade biológica pode ocorrer com a introdução de novos nitrocompostos, baseados em estruturas já conhecidas e com bioatividade comprovada, resultantes de modificações moleculares planejadas com base na influência de propriedades físico-químicas que influenciam a atividade desta classe de compostos. 


\subsubsection{Mecanismo de ação dos nitrocompostos com atividade antichagásica}

Estudos com derivados nitro-heterocíclicos demonstraram que o grupo nitro na posição 5 do anel é essencial para o estabelecimento da atividade antichagásica. O mecanismo de ação antichagásica da maioria dos nitrocompostos está ligado ao processo de biorredução do grupo nitro e a subsequente interação dos produtos, formados na redução, com biomacromoléculas vitais do parasita (VIODÉ et al., 1999, DECLERCK \& DE RANTER, 1986, SQUELLA et al., 2005

Neste contexto, podem ser observados estudos sobre o mecanismo de biorredução do grupo nitro e a determinação do potencial de redução por meio de técnicas eletroquímicas, sendo possível, deste modo, conhecer os intermediários formados e estimar, para cada um destes, a possibilidade de atividade biológica (BOLLO et al., 2010, 2003; LA-SCALEA et al., 2009 e 2005; NUÑEZ-VERGARA et al., 1997; JULIÃO et al., 2006, 2005; YAÑEZ et al., 2005; SQUELLA et al., 2005 e 2007; MANDAL, 2004).

A redução dos nitro-heterocíclicos é um processo complexo e pode ser produzido via dois mecanismos diferentes de acordo com as condições do meio em ser anaeróbico ou aeróbico, mas, em ambas as condições, a primeira etapa é a redução de um elétron para formação do nitro radical (BOLLO et al., 2010; DECLERCK \& DE RANTER, 1987; EDWARDS, 1993; ZUMAN et al., 1992; LA SCALEA , 1998):

$$
\mathrm{R}-\mathrm{NO}_{2}+\mathrm{e}^{-}=\mathrm{R}-\mathrm{NO}_{2}{ }^{--}
$$

Em condições anaeróbicas, o nitro radical pode sofrer reações subseqüentes e produzir os derivados nitroso (RNO) e hidroxilamínico (R-NHOH), de acordo com:

$$
\begin{aligned}
& \text { R- }-\mathrm{NO}_{2}{ }^{-}+\mathrm{e}^{-}+2 \mathrm{H}^{+} \longrightarrow \mathrm{R}-\mathrm{NO}+\mathrm{H}_{2} \mathrm{O} \\
& \mathrm{R}-\mathrm{NO}+2 \mathrm{e}^{-}+2 \mathrm{H}^{+} \longrightarrow \mathrm{R}-\mathrm{NHOH}
\end{aligned}
$$

A adição de mais dois elétrons pode formar a amina correspondente:

$$
\mathrm{R}-\mathrm{NHOH}+2 \mathrm{e}^{-}+2 \mathrm{H}^{+} \longrightarrow \mathrm{R}-\mathrm{NH}_{2}+\mathrm{H}_{2} \mathrm{O}
$$


Nesta via metabólica, o nitro radical e a hidroxilamina formados são os principais intermediários ou metabólitos do processo de redução enzimática do grupo nitro até amina. $\mathrm{O}$ radical $\left(\mathrm{R}^{-\mathrm{NO}_{2}}{ }^{-}\right)$e o derivado hidroxilamínico $(\mathrm{R}-\mathrm{NHOH})$ podem interagir com o DNA celular, o que pode resultar em lesões tais como a destruição da dupla hélice e em também, desestabilizar as ligações entre as bases pirimidínicas com as suas correspondentes bases purínicas (EDWARDS, 1993; TOCHER \& EDWARDS, 1994).

Assim há evidências que a formação do nitro radical, em reação envolvendo um elétron e representado pelo par $\mathrm{R}-\mathrm{NO}_{2} / \mathrm{R}-\mathrm{NO}_{2}{ }^{-}-$, é intermediário chave no processo de redução e está diretamente envolvido na ação antichagásica dos derivados 5-nitro-heterocíclicos (VIODÉ et al.,1999; BOLLO et al., 2003, 2010). Neste caso, constatada a ocorrência de redução do nitrocomposto e formação deste radical é possível avaliar o processo de transferência eletrônica. Desse modo, a determinação do potencial redox correspondente à redução do grupo nitro permitiria, supostamente, avaliar a influência deste parâmetro sobre a atividade antichagásica destes compostos.

Entretanto, existem outros intermediários que podem apresentar atividade biológica, como por exemplo, o derivado nitroso (Ar-NO), que se apresenta como eficiente ligante de grupos tióis biomoleculares essenciais a enzimas e células (JULIÃO et al.,2005 e 2006).

Por outro lado, em condições aeróbicas, o nitro radical formado pode se reoxidar regenerando o composto nitro inicial e produzir o superóxido $\left(\mathrm{O}_{2}^{\bullet}{ }^{-}\right)$, como segue:

$$
\mathrm{R}-\mathrm{NO}_{2}^{\bullet-}+\mathrm{O}_{2}=\mathrm{R}-\mathrm{NO}_{2}+\mathrm{O}_{2}^{\bullet-}
$$

Neste presente meio, o nitro radical gerado no processo de redução enzimática interage com o oxigênio presente no meio, em uma etapa metabólica denominada de ciclo fútil, formando o radical $\mathrm{O}_{2}{ }^{\bullet}-$, onde posteriormente, sofre ação de enzimas como a superóxido redutase, S.O.D., formando peróxido de hidrogênio $\left(\mathrm{H}_{2} \mathrm{O}_{2}\right)$ que pode desestruturar membranas biológicas e também interagir com enzimas ferrodoxinas, liberando outras espécies reativas de oxigênio, como $\mathrm{OH}^{\bullet}$, 
que são tóxicas as células parasitárias (MAYA et al., 2007; VIODÉ et al., 1999; TOCHER et al., 1997).

A ativação biológica através do processo de biorredução de nitrocompostos apresenta-se como ponto importante para a pesquisa e o planejamento de novos compostos nitro-heterocíclicos mais eficazes ao tratamento da doença de Chagas.

Estudos polarográficos e voltamétricos foram empregados com o intuito de elucidar o mecanismo de redução e investigar sua semelhança com o caminho metabólico desenvolvido pelos nitrocompostos no ambiente biológico (JULIÃO et al., 2005; BOLLO et al., 2003; KARAKUS \& ZUMAN, 1995). Desse modo, as técnicas eletroquímicas são usadas em várias aplicações biológicas visto que as mesmas são ferramentas poderosas na construção de modelos biomiméticos. Segundo Brajter Toth et al., 1981, este processo se deve à constatação experimental de que as reações de transferência de carga, promovidas em uma interface eletrizada (eletrodo/solução), conduzem a intermediários, os quais são os mesmos produzidos por sistemas biológicos como por exemplo, os sistemas enzimáticos ( SERRANO et al., 2006, SERRANO \& GIL, 2005, ABREU et al., 2002, BRAJTER-TOTH et al., 1981). Desta forma, as técnicas eletroquímicas podem ser usadas não meramente para fins analíticos, mas também para a elucidação dos mecanismos de ação de fármacos.

De forma similar, diversos trabalhos registram estudos sobre 0 comportamento eletroquímico de compostos nitro-heterocíclicos, principalmente derivados nitrofurânicos e nitrotiofênicos, avaliando a possibilidade destes compostos em atuarem como inibidores de ligação da enzima tripanotiona redutase do T.cruzi com o seu substrato. Assim, sugere-se que algum dos intermediários advindos do processo de biorredução in vivo atue como inibidor da tripanotiona redutase, enzima fundamental para sobrevivência do parasita.

Ademais, Aguirre e colaboradores (2004), em trabalho realizado com análogos do NF contendo semicarbazona e tiossemicarbazona em suas estruturas, têm estudado um segundo mecanismo de ação para este tipo de compostos relacionando à ligação covalente com a cruzaína. Este mecanismo de ação foi proposto por Du e colaboradores, em 2002, na qual compreende a interação da tiocarbonila das tiossemicarbazonas com a Cys25 da cruzaína. Desta forma, podese esperar mecanismo de ação duplo para esses análogos. É válido destacar que a 
cruzaína é uma enzima encontrada no organismo do $T$. cruzi e que corresponde a cisteína-protease mais abudante do tripanossoma e está relacionado no desenvolvimento do parasita e na invasão ao hospedeiro.

\subsubsection{Técnicas eletroquímicas}

Como pode ser notado através da literatura apontada neste trabalho, constata-se que os compostos nitro-heterocíclicos sofrem processo de biorredução, formando uma série de intermediários que serão então ativos contra o parasita. Neste sentido, as técnicas eletroquímicas apresentam-se como excelente alternativa para o estudo de fármacos eletroativos e que possuam como características da ação biológica processos de transferência de carga.

Inserido neste contexto, as técnicas voltamétricas se apresentam como ferramenta útil para simular processos farmacológicos, bioquímicos e/ou toxicológicos envolvendo mecanismos de transferência eletrônica e de estresse oxidativo (BOLLO et al., 2003; ABREU et al., 2002).

Neste sentido e através de registros da literatura sobre o comportamento eletroquímico de compostos nitro-heterocíclicos (principalmente em meio não aquoso), tendo como foco principal a geração e estabilização do nitro radical, as técnicas voltamétricas têm sido propostas como método de escolha para medida do potencial de redução e monitoramento de novos nitrocompostos a serem empregados como potenciais agentes antichagásicos (SQUELLA et al., 1996; LASCALEA et al., 2005).

Através da voltametria obtêm-se dados qualitativos e quantitativos de uma espécie química, através do registro de curvas corrente-potencial feitas em uma cela eletroquímica na presença de eletrólito de suporte constituída de pelo menos dois eletrodos, sendo um deles, o de menor área, o eletrodo de trabalho e o outro um eletrodo de superfície relativamente grande, usualmente um eletrodo de referência (WANG, 2000; BRETT \& BRETT, 1996; BARD \& FAULKNER, 2001).

O potencial é aplicado entre dois eletrodos em forma de varredura, isto é, variando-o a uma velocidade constante em função do tempo. O potencial e corrente são registrados simultaneamente. A curva corrente vs. potencial obtida é chamada de voltamograma. O eletrodo de gota de mercúrio foi um dos eletrodos de trabalho dos mais utilizados para estudos eletroanalíticos de nitro-heterocíclicos (SQUELLA 
et al., 2005; WANG, 2000; LA-SCALEA et al., 1998; ROZENSKI, et al., 1995; MORALES et al., 1987). Entretanto, por conseqüências ambientais do emprego do mercúrio, este está sendo substituído por outros eletrodos metálicos sólidos, como ouro e platina, além de carbono, sendo estes últimos, de maneira geral, os mais utilizados para determinação de espécies com potenciais redox positivos ou metais insolúveis em mercúrio (SERRANO et al., 2006; SERRANO \& GIL, 2005; WANG, 2000).

O eletrodo de carbono vítreo possui ampla faixa de potencial $(+1,5 \mathrm{~V}$ a $-1,3 \mathrm{~V}$ vs eletrodo de calomelano saturado- ECS, dependendo do meio da reação), é quimicamente inerte, apresenta resultados reprodutíveis e é relativamente menos oneroso (WANG, 2000). Exemplo importante é o uso de carbono vítreo que vem ganhando popularidade em eletroanálise devido às suas propriedades mecânicas e eletroquímicas, além de proporcionar melhor compreensão dos fenômenos ocorridos na interfase eletrodo-solução (KALCHER et al., 1995). Nos últimos anos inúmeros relatos do processo da redução de nitrocompostos envolvendo técnicas voltamétricas têm sido descritos na literatura ressaltando o emprego da Voltametria Cíclica (VC) (LA-SCALEA et al., 1998; 2005; 2009; JULIÃO et al.,2006; YAÑEZ et al.,2005; SQUELLA et al., 2007; NUÑEZ-VERGARA et al., 1997; BOLLO et al., 2010; LEMKE \& WILLIANS, 2008).

A voltametria cíclica (VC) é provavelmente a técnica eletroquímica mais amplamente utilizada para o estudo de processos de eletrodo a partir de curvas corrente-potencial. Ademais, VC possibilita a obtenção de informações sobre o potencial redox de espécies eletroativas, elucidação da cinética das reações de eletrodo e a avaliação da influência do meio de reação sobre o processo redox a partir das medidas de corrente em função do potencial sob condições de completa polarização do eletrodo de trabalho (SERRANO \& GIL, 2005; HARRIS, 2001; WANG, 2000; BRETT \& BRETT, 1993). A eficiência de VC resulta de sua habilidade de rapidamente fornecer informações sobre a cinética de reações, múltiplas reações de transferência de carga, reações químicas acopladas e efeitos adsortivos, pois podem ser facilmente identificadas (BROW \& SANDIFER, 1986). Este processo resulta, assim, no registro das reações eletroquímicas existentes.

$\mathrm{Na}$ instrumentação faz-se uso de um potenciostato com gerador de programa de potencial, computador para registrar os gráficos de corrente em função do 
potencial, célula convencional de três eletrodos e uma solução contendo o analito e eletrólito suporte (BRETT \& BRETT, 1996).

A Figura 7A mostra o padrão típico da excitação do sinal em VC, que é decorrente da aplicação de uma rampa triangular de potencial ao eletrodo de trabalho. Mantendo-se o eletrodo em estado estacionário, inicia-se a aplicação do potencial (ciclo 1- $\mathrm{E}_{\mathrm{i}}$ ) em valor no qual nenhuma reação ocorra (BRETT \& BRETT, 1996, BARD \& FAULKANER, 2001; WANG, 2000).

A faixa de variação do potencial aplicado deve ser aquele onde a espécie em análise é eletroativo e o solvente é estável. Dependendo do analito pode-se fazer apenas um ciclo ou múltiplos ciclos. O aumento do potencial para regiões mais negativas provoca a redução do composto em solução, gerando um pico de corrente (catódica) proporcional à sua concentração. Quando o potencial já atingir um valor no qual nenhuma reação de redução ocorre, o potencial é varrido no sentido inverso (b) até o valor inicial (d). Posteriormente, novos ciclos podem ser produzidos (ciclo 2 , por exemplo), com a manutenção dos mesmos parâmetros do ciclo 1. O tipo de voltamograma gerado depende do tipo de mecanismo redox que o composto em questão sofre no eletrodo, o que faz da voltametria cíclica uma ferramenta valiosa para estudos mecanismos de reação. Se o potencial aplicado for ao sentido positivo, as reações possíveis serão de oxidação, sendo a corrente (anódica) também proporcional à concentração (BRETT \& BRETT, 1996, BARD \& FAULKANER, 2001; WANG, 2000). Através da Figura 7B pode-se observar o perfil típico de um voltamograma cíclico.

A voltametria cíclica é aplicada a sistemas em repouso para garantir que a espécie de interesse chegue à superfície do eletrodo por meio de processo exclusivamente difusional (BRETT \& BRETT, 1996). A partir de parâmetros obtidos por esta técnica é possível estimar a velocidade da reação de transferência de carga, além de caracterizar a existência de reações químicas acopladas ao processo eletroquímico. Também é utilizada para estudar a reversibilidade do processo eletródico, ou seja, se o processo é reversível, quase-reversível ou irreversível e avaliar a influência do meio reacional sobre estes parâmetros, bem como sobre a existência e estabilidade de radicais e intermediários formados pela redução de espécies eletroativas como os nitrocompostos (SQUELLA et al., 1996; BRETT \& BRETT, 1996; MORALES et al., 1987). A voltametria cíclica, portanto, tem mais 
importância do ponto vista da elucidação de processos de eletrodos e mecanismos de reação do que do ponto vista analítico (BRETT \& BRETT, 1996; OLMSTEAD et al., 1969).
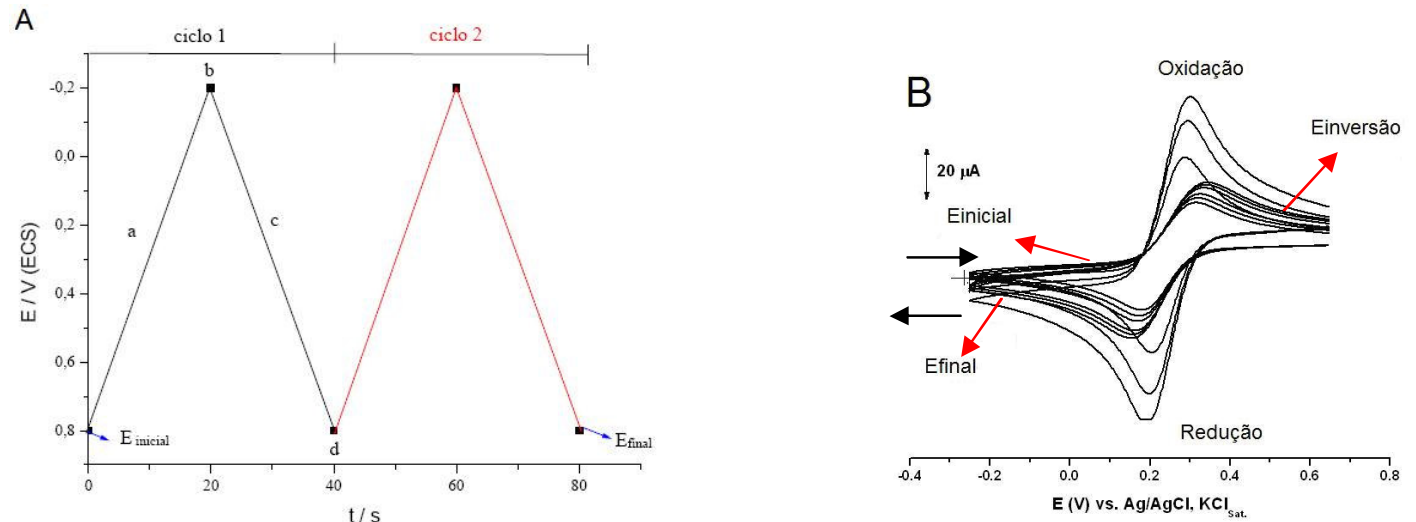

Figura 7- (A) Excitação típica do sinal para voltametria cíclica, potencial na forma de onda triangular, (B) gráfico da corrente vs potencial característica de VC obtido de dez ciclos com variação de velocidade de varredura.

Também é válido destacar, o emprego das técnicas eletroquímicas com aplicação de pulsos de potencial como a Voltametria de Pulso Diferencial (VPD) e a Cronoamperometria (CRO) que auxiliam na estimativa do número de elétrons envolvidos em nos processos redox. Na VPD são aplicados ao eletrodo de trabalho, pulsos de amplitude fixos sobrepostos a uma rampa de potencial crescente e a corrente é medida duas vezes, uma antes da aplicação do pulso e outra logo no final do pulso. O objetivo de se fazer duas leituras da corrente é de se trabalhar com a diferença entre elas, com o interesse de se empregar correção da corrente capacitiva - corrente que não é proveniente da reação química envolvida na superfície do eletrodo. À medida que se aplica o pulso, ocorre um acréscimo da contribuição da corrente capacitiva e da corrente faradaica, mas a corrente capacitiva diminui exponencialmente, enquanto que a corrente faradaica diminui linearmente, assim, escolhendo um tempo apropriado para se fazer a segunda leitura, faz-se a leitura da corrente total a um valor de corrente onde a contribuição da corrente capacitiva (não-faradaica) pode ser desconsiderada. Assim, desvinculando o valor da primeira leitura de corrente da segunda, obtém-se uma 
minimização da contribuição da corrente de fundo. Esta correção de correntes possibilitada pelo modo de pulso diferencial permite obter limites de detecção menores do que em VC (BRETT \& BRETT, 1996; BARD \& FAULKANER, 2001; WANG, 2000).

A CRO, como o próprio nome sugere, determina a corrente que flui através do eletrodo de trabalho como função do tempo em um potencial constante. Esse fluxo é correlacionado com a gradiente de concentração das espécies oxidadas ou reduzidas na superfície do eletrodo de trabalho. $\mathrm{Na}$ CRO são aplicados dois potenciais, sendo que o primeiro potencial aplicado em uma região ode não ocorre reação com as espécies eletroativas e tem como função carregar a dupla camada elétrica na superfície do eletrodo de trabalho. Já o segundo potencial é o potencial onde ocorre a redução ou oxidação das espécies eletroativas.

\subsubsection{Gênese de fármacos (KOROLKOVAS, 1988; WERMUTH, 2008a)}

O homem, desde as priscas épocas, vem à procura de descobrir novos agentes terapêuticos na tentativa de buscar o completo bem - estar físico, mental e social, por isso a dedicação na descoberta de fármacos mais eficazes e menos tóxicos é um processo contínuo.

Os fármacos são introduzidos na terapêutica principalmente por um dos seguintes métodos:

- Acaso: Foram descobertos em laboratórios químicos ou clínicos por mero acidente;

- $\quad$ Triagem empírica: Todas as substâncias químicas disponíveis são submetidas a uma variedade de ensaios biológicos na esperança que algumas manifestem atividade útil;

- Extração de princípios ativos de fontes naturais: Durante muito tempo a humanidade usou extratos de partes vegetais ou de órgãos animais para o tratamento de muitas doenças;

- Modificação molecular: Também é conhecido por método da variação ou processo seletivo. É o mais recompensador, pois constitui em tomar uma substância química bem determinada e de ação biológica bem definida. A partir da mesma toma-se como modelo, ou protótipo sintetiza-se novos compostos que sejam 
congêneres, homólogos ou análogos. Este método apresenta as seguintes vantagens:

$\checkmark \quad$ Probabilidade de apresentar propriedades farmacológicas semelhantes as do protótipo;

$\checkmark$ Possibilidade de se obter produtos mais eficazes e com menor toxicidade;

$\checkmark$ Probabilidade de a produção de novos fármacos ser mais econômico;

$\checkmark \quad$ Possibilidade de elucidar a relação estrutura-atividade e também 0 mecanismo de reação de fármacos;

$\checkmark$ Emprego dos mesmos métodos de ensaios biológicos, químicos e físicos utilizados para o protótipo.

A modificação molecular é considerada, portanto a técnica mais promissora para a introdução de novos fármacos na terapêutica. Tal processo permite a alteração de elementos ou grupos químicos, a fim de anular efeitos indesejáveis dos fármacos utilizados, ou introduzir outros que potencializem ou intensifiquem a atividade biológica, uma vez conhecido o mecanismo de ação do fármaco. Podem, também, aumentar a afinidade com um receptor, ou alterar a lipofilicidade, efeitos estéricos e eletrônicos da molécula, interferindo, assim, com a farmacocinética do fármaco ou composto com atividade terapêutica. Diversos processos de modificação molecular podem ser utilizados, entre eles, o bioisosterismo.

Neste contexto, ressalta-se que a maioria dos trabalhos envolvendo a modificação molecular de nitro-heterocíclicos à procura de novos candidatos antichagásicos faz-se uso da ferramenta de bioisosterismo, que é amplamente empregada no planejamento e desenvolvimento de outras diversas classes terapêuticas (LEMKE \& WILLIANS, 2008).

\subsubsection{Bioisosterismo}

O termo isosterismo é oriundo do grego, na qual isos significa igual e steros significa volume. Compostos bioisósteros são aqueles resultantes da troca isostérica de simples átomos ou subunidades estruturais, por outros átomos ou subunidades estruturais, similares em distribuições eletrônicas, volumes moleculares ou 
propriedades físico- químicas, capazes de apresentar propriedades similares ao composto original. Ademais, as propriedades biológicas similares referem-se ao reconhecimento pelo mesmo biorreceptor (BURGER, 1991).

Por conseguinte, o bioisosterismo é uma estratégia largamente empregada em Química Farmacêutica para o desenvolvimento de novos fármacos, onde é aplicado em um composto dito como líder, para o qual se conhece completamente a estrutura química, mecanismo de ação e se possível a interação topográfica com o receptor (LIMA \& BARREIRO, 2005).

Existem dois tipos de bioisosterismo, que são: o clássico e não-clássico. $\mathrm{O}$ primeiro atende as características definidas por Grimm \& Erlenmeyer, onde os bioisósteros seriam átomos ou grupos que possuíam camadas de valência semelhantes (BURGER, 1991). Já no bioisosterismo não-clássico não há necessidade de seguir a estas regras em termos de estrutura eletrônica ou de átomos, a substituição busca principalmente uma atividade biológica similar (PATANI \& LAVOIE, 1996; LIMA \& BARREIRO, 2005; CIAPETTI \& GIETHLEN, 2008).

Neste sentido, existem inúmeras razões para o emprego do bioisosterismo no desenvolvimento de novos fármacos, incluindo a necessidade de melhorias da atividade farmacológica, obtenção de seletividade para determinado receptor ou enzima, com simultaneidade de redução da toxicidade e otimização das propriedades farmacocinéticas do composto líder. A título de aplicação do bioisosterismo pode-se citar a substituição do cloro, presente no anel aromático do itraconazol por flúor, no posaconazol, o que permite melhor interação entre o fármaco com o sítio da enzima CYP51 em Mycobacterium tuberculosis (ZHAO et al., 2003).

Desta forma, o bioisosterismo é uma ferramenta importante na obtenção de fármacos mais ativos e com menores efeitos adversos e é o método mais empregado de modificação estrutural dos nitro-heterocíclicos no planejamento e desenvolvimento de diversas classes terapêuticas, principalmente como candidato antichagásico (LEMKE \& WILLIANS, 2008).

Aguirre e colaboradores (2005), em trabalho realizado com análogos de NF contendo semicarbazona e tiossemicarbazona em suas estruturas, têm estudado um segundo mecanismo de ação para esse tipo de compostos relacionado a ligação covalente com a cruzaína, enzima que está implicada no desenvolvimento do $T$. 
cruzi e na diferenciação dos vários estágios do ciclo biológico do parasita (DU et al., 2002). Assim, em trabalho anterior de nosso grupo de pesquisa, desenvolvido por TROSSINI (2008), planejou e propôs a síntese de bioisósteros de NF (Figura 8) com a presença de grupos (tio) semicarbazona combinados com a variação entre o $\mathrm{O}$ e $\mathrm{S}$ no anel heterocíclico com o intuito de se estudar um segundo mecanismo de ação entre estes análogos com a cruzaína, protease específica encontrada no $T$. cruzi, promovendo inibição desta enzima que é de fundamental importância para a vida do parasito.

NFS

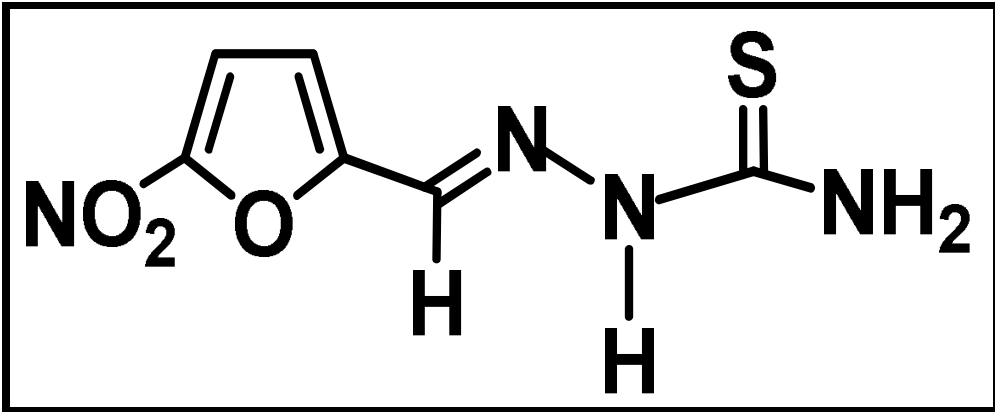

NTS

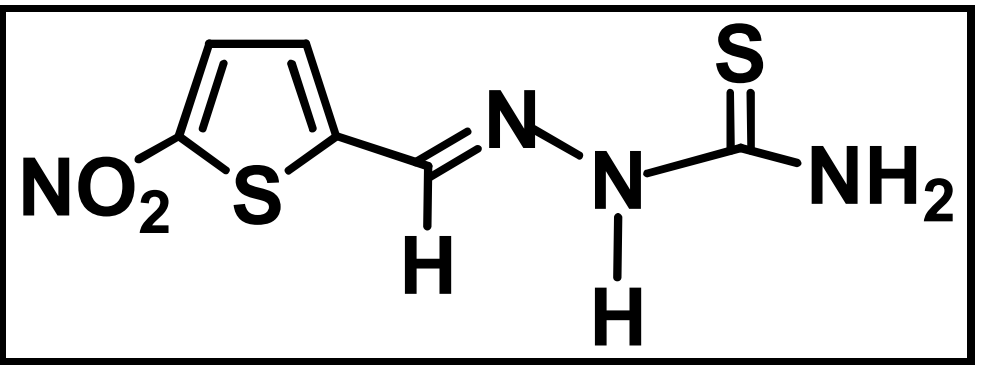

NT

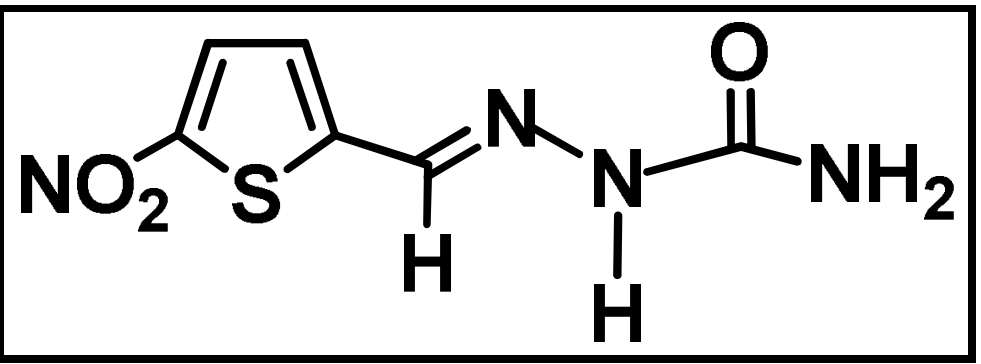

Figura 8- Análogos de NF. 


\subsection{OBJETIVOS}

Como pôde ser observado os compostos nitro-heterocíclicos apresentam atividade biológica a partir da redução do grupo nitro, formando o nitro radical como principal responsável pela ação antichagásica. Com isto, o estudo eletroquímico de compostos bioativos apresenta-se como área de interface importante com a química farmacêutica, pois a elucidação de reação envolvendo processos de transferência de elétrons pode ser útil para a melhor compreensão do mecanismo de ação biológica dessas moléculas. Estes estudos podem trazer importantes subsídios para o planejamento de novas moléculas potencialmente bioativas, podendo contribuir para a busca de alternativas para terapêutica da doença de Chagas, além de outras moléstias.

A proposta deste trabalho levando em conta o que se já se conhece sobre os metabólitos de NF e seu comportamento eletroquímico, comparar o comportamento voltamétrico do NF com seus bioisósteros sintetizados por TROSSINI (2008). Com isto, poder-se-á estabelecer paralelo com outros derivados da mesma classe, que sofram processos de óxido-redução em sua biotransformação, possibilitando a obtenção de novos conhecimentos que levem à proposição e elucidação de mecanismos de reação e/ou ação biológica, além de novos métodos de detecção.

Neste sentido, empregou-se a técnica da voltametria cíclica (VC) para estudar o mecanismo de redução dos nitro-heterocíclicos deste trabalho, pois a mesma é uma excelente ferramenta no estudo de metabólitos oriundos do processo de transferência de carga (BARD \& FAULKANER, 2001; WANG, 2000). De forma auxiliar, a voltametria de pulso diferencial e cronoamperometria também foram aplicadas. Ademais, a possibilidade de produzir eletroquimicamente o radical R-NO ${ }_{2}{ }^{-}$- tem sido também alvo de estudo para outros compostos de interesse farmacológico (CARBAJO et al., 2002; MANDAL, 2004; YAÑEZ et al., 2005; SQUELLA et al., 2007; BOLLO et al., 2010). Todavia, a geração e detecção do nitro radical em meio aquoso usando a VC é um fator importante principalmente por apresentar maior proximidade ao meio intracelular onde ocorre a atividade antichagásica (JULIÃO et al., 2005).

Diante do exposto, o foco do trabalho está direcionado em estudar o comportamento voltamétrico de NF e compará-lo com os seus bioisósteros. De 
forma complementar, avaliar o comportamento redox do nitro radical, gerado dos compostos em estudo, com o intuito de compreender melhor o efeito estrutural e do substituinte sobre a atividade redox. Portanto, as informações obtidas poderão ser úteis para a compreensão do mecanismo desses compostos e para aplicação ao estudo da relação entre estrutura química e atividade biológica com vistas ao desenvolvimento de novos fármacos. 


\section{Capítulo 2}

\section{Parte Experimental}

\subsection{MATERIAIS}

\subsubsection{Reagentes e solventes}

A seguir estão relacionados os reagentes de grau analítico utilizados neste trabalho, sem nenhum tratamento prévio :

- $\quad$ Ácido orto-fosfórico p.a. (Merck);

- $\quad$ Ácido bórico p.a. (Merck);

- $\quad$ Ácido acético p.a. (Merck);

- Hidróxido de sódio p.a. (Merck);

- $\quad$ Etanol p.a. (Merck);

- $\quad N-N$ - Dimetilformamida p.a. (Merck);

- $\quad$ Soluções tampão MercK (4,0-7,0-9,0);

- $\quad$ Tiosemicarbazida (Sigma-Aldrich);

- $\quad$ Cloridrato de semicarbazida (Sigma-Aldrich);

- 5-nitro-2-tiofenocarboxaldeído (Sigma-Aldrich);

- 5-nitro-2-furfuraldeído (Sigma-Aldrich);

- $\quad$ Nitrofural (Companhia Avocado);

- $\quad$ Ferricianeto de potássio (Merck).

O gás argônio (Ar) grau reagente utilizado nos experimentos foi adquirido da Air Liquide, São Paulo, Brasil.

\subsubsection{Equipamentos}

$\checkmark$ Agitadores magnéticos;

$\checkmark$ Aparelho capilar Büchi e de fusão automática, modelo M-565, para determinação de faixa de fusão;

$\checkmark$ Bomba de alto vácuo, modelo E2M5 EDWARDS; 
$\checkmark$ Espectrômetro de Ressonância Magnética Nuclear 300 MHz BRUKER, modelo Advance DPX-300;

$\checkmark$ Espectrômetro de absorção UV/Vis de feixe duplo, Hitachi, modelo H 900.

$\checkmark$ Purificador de água por meio do sistema Gehaka Master System;

$\checkmark$ Potenciostato/galvanostato Autolab PGSTAT 30 Eco-Chimie;

$\checkmark$ Eletrodos: trabalho (carbono vítreo- ECV), auxiliar (platina- Pt) e de referência (prata/cloreto de prata- $\mathrm{Ag} / \mathrm{AgCl}, \mathrm{KCl}$ sat.);

$\checkmark$ pHmetro-Methrom 54;

Tais equipamentos encontram-se disponíveis no LAPEN - Laboratório de Planejamento e Síntese de Quimioterápicos Potencialmente Ativos em Endemias Tropicais, na Química Farmacêutica, e, também, no Departamento de Farmácia, da FCF/USP.

\subsection{MÉTODOS}

\subsubsection{Síntese dos bioisósteros de NF (TROSSINI, 2008)}

Os análogos do NF foram obtidos utilizando metodologia descrita em TROSSINI (2008), utilizando os nitroaldeídos, aldeído do 5-nitrotiofilideno, ou o aldeído do 5-nitrofurano, e a semicarbazona ou tiosemicarbazona correspondente.

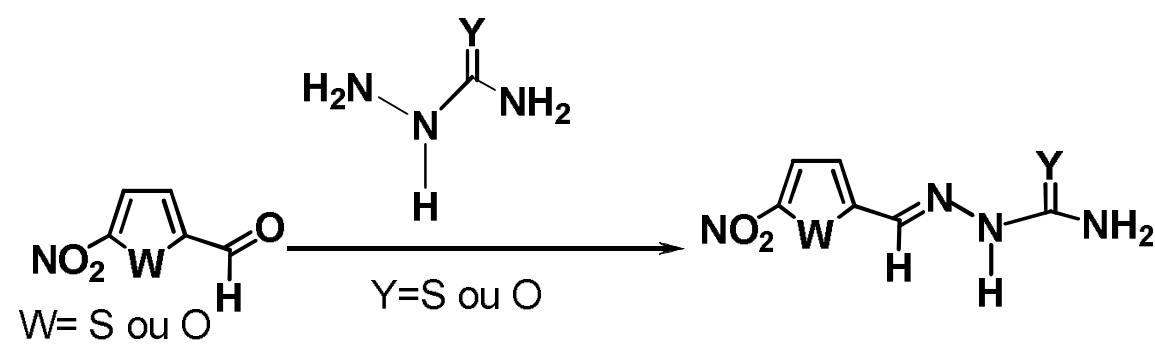

Esquema 1 - Síntese de análogos do NF. Reação geral da síntese dos bioisósteros de NF. NF $(W=O, Y=O) ; \boldsymbol{N F S}(W=O, Y=S) ; \boldsymbol{N T S}(W=S, Y=S) ; \boldsymbol{N T}$ $(W=S, Y=O)$. 


\subsubsection{Experimento dos análogos de NF}

Para a síntese dos compostos utilizou-se o aldeído do 5-nitrotiofilideno ou 5nitrofurano e a tiossemicarbazona ou semicarbazona na proporção de 1:1, por 2 horas. Em balão de $100 \mathrm{~mL}$, adicionou-se $1 \mathrm{mmol}$ do respectivo aldeído, solubilizando em etanol/água (1:1), mantendo-se sob agitação magnética. Após solubilização, adicionou-se, lentamente, a respectiva carbazona, sob aquecimento brando até à formação de um precipitado. Posteriormente, a reação permaneceu sob agitação por 2 horas. Ao final, o produto foi filtrado sob pressão reduzida e lavado com água. O produto obtido foi armazenado em dessecador de sílica-gel e pentóxido de fósforo.

\subsubsection{Soluções}

Todas as soluções foram preparadas utilizando-se água ultrapura, através do equipamento Gehaka Master System pelo sistema Millipore Milli-Q.

\subsubsection{Soluções estoques de tampão universal pH 2,03 -12,01}

As soluções tampão que compreendem o intervalo de $2,03 \leq \mathrm{pH} \leq 12,01$ foram preparadas, a partir da neutralização de uma solução constituída de $\mathrm{H}_{3} \mathrm{PO}_{4}$, $\mathrm{H}_{3} \mathrm{CCOOH}$ e de $\mathrm{H}_{3} \mathrm{BO}_{3}$ (todos $0,4 \mathrm{~mol} / \mathrm{L}$ ) com volume apropriado de solução de $\mathrm{NaOH}$ 2,0 mol/L (LURIE, 1978). O pH final de cada solução tampão foi medido com eletrodo de vidro combinado conectado a aparelho medidor de $\mathrm{pH}$ Metrohm, modelo 744, em temperatura ambiente.

\subsubsection{Soluções estoques de 5,0 mmol/L de NF e bioisósteros}

As soluções estoque de $5,0 \mathrm{mmol} / \mathrm{L}$ de $\mathrm{NF}$ e bioisósteros foram preparadas por dissolução direta de quantidade apropriada do reagente 5-nitro-2furfurilidenossemicarbazida (NF), 5-nitro-2- furfurillidenotiossemicarbazida (NFS), 5-

nitro-2-tiofurfurillidenossemicarbazida (NT) e de 5-nitro-2-tio furfurillidenotiossemicarbazida (NTS), numa mistura (1:1 em volume) de $\mathrm{N}-\mathrm{N}-$ dimetilformamida e água ultrapura com auxílio de ultrassom. As soluções obtidas 
foram estocadas em frasco âmbar, para evitar degradação fotoquímica e posteriormente conservada em geladeira, por no máximo 1 mês.

2.2.2.3 Solução estoque de 1,0 mmol/L de ferricianeto de potássio $\left(\mathrm{K}_{3} \mathrm{Fe}(\mathrm{CN})_{6} .3 \mathrm{H}_{2} \mathrm{O}\right)$

A solução de ferricianeto de potássio foi preparada a partir de dissolução direta de quantidade apropriada em $100 \mathrm{~mL}$ de água ultrapura, contendo solução $\mathrm{KCl} 0,5$ $\mathrm{mmol} / \mathrm{L}$ como eletrólito suporte. A solução, sempre recém-preparada, obtida foi utilizada para o registro dos voltamogramas cíclicos necessários à determinação voltamétrica da área efetiva do eletrodo de carbono vítreo (ECV). Estes ensaios foram feitos em triplicata variando a velocidade de varredura em intervalos de $0,1 \mathrm{~V} / \mathrm{s}$ a 1 $\mathrm{V} / \mathrm{s}$.

\subsubsection{Ensaios espectrofotométricos}

Os espectros de absorção por espectrofotometria UV/Vis foram realizados num espectrofotômetro de feixe duplo, da Hitachi modelo H 900. A aquisição e tratamento dos dados foram efetuados com auxílio do software UV Solutions 2.2 e as medidas foram realizadas em cubetas de quartzo, com caminho óptico $=1,0 \mathrm{~cm}$.

\subsubsection{Ensaios eletroquímicos}

Os voltamogramas cíclicos de pulso diferencial $e$ os ensaios cronoamperométricos foram registrados utilizando-se o potenciostato/galvanostato Autolab PGSTAT 30, acoplado a uma célula eletroquímica com três eletrodos: eletrodo de carbono vítreo (ECV) como eletrodo de trabalho, $\mathrm{Ag} / \mathrm{AgCl}, \mathrm{KCl}$ Sat, como referência e Pt como eletrodo auxiliar. Para a aquisição e o tratamento de dados foi empregado o programa GPES 4.3 (Eco-Chimie). Borbulhou-se gás argônio (Ar) nas soluções por aproximadamente 10 minutos para remover o oxigênio presente no meio. Controlou-se o pH das soluções estudadas utilizando-se medidor de $\mathrm{pH}$ Metrohm 744 e eletrodo de vidro combinado a temperatura ambiente. 


\subsubsection{Pré-tratamento do eletrodo de carbono vítreo}

O ECV foi manualmente polido com suspensão de diamante $1 \mu \mathrm{m}$ em spray em tecido de veludo metalográfico Supra (Arotec S/A, com granulometria 1/4 de $\mu \mathrm{m})$. Para efeito de comparação, o ECV também foi manualmente polido com suspensão de alumina (Arotec) de granulometria de $1 \mu \mathrm{m}$ sobre pano para polimento e lavado com água desionizada.

\subsubsection{Cálculo de $\alpha$ n}

Os valores de an foram obtidos através de equação voltamétrica para reações eletroquímicas irrerversíveis (Equação I):

$$
\mathrm{E}_{\mathrm{c}, \mathrm{p}}-\mathrm{E}_{\mathrm{p} / 2}=48 /(\alpha \mathrm{n})
$$

(Equação l)

sendo: $E_{c, p}$ corresponde ao potencial do primeiro pico de redução; $E_{p / 2}$ corresponde ao pico a meia altura da corrente de pico de $\mathrm{i}_{\mathrm{pc}, 1}$ e $\alpha$ é o produto do coeficiente de transferência de carga pelo número de elétrons envolvidos no processo eletródico.

\subsubsection{Cálculo do coeficiente de difusão (D) de NF e de seus análogos}

Os coeficientes de difusão em meio aquoso ( $D_{a q .}$. foram estimados por método desenvolvido por Wilke-Chang (Equação II) onde se emprega análise conformacional por método semi-empírico AM1 através do programa Molinspiration (LA SCALEA et al., 2005; LA SCALEA et al., 2009; MOLINSPIRATION, 2009).

$$
D=\frac{7.4 \times 10^{-8}(x \mathrm{M})^{0.5} \mathrm{~T}}{\eta \mathrm{V}^{0.6}}
$$

(Equação II)

sendo: $D=$ coeficiente de difusão do analito em água $\left(\mathrm{cm}^{2} / \mathrm{s}\right) ; \eta=$ viscosidade do solvente $(\mathrm{cP})$ em determinada temperatura de ensaio, $\mathrm{M}=$ massa molar do solvente (18,0 $\mathrm{g} / \mathrm{mol}), T=$ temperatura absoluta $(\mathrm{K}), x=$ parâmetro de solvente, no caso da água $2,6, T=298 \mathrm{~K}\left(25^{\circ} \mathrm{C}\right)$ e $\eta=0,8937 \mathrm{em}\left(25^{\circ} \mathrm{C}\right)$. 
O valor de $D$ foi posteriormente empregado para cálculo do número de elétrons do processo de redução dos analitos em estudo.

2.2.4.4 Procedimento para estimar a área efetiva do eletrodo ECV usando voltametria cíclica a partir de solução de $1,0 \mathrm{mmol} / \mathrm{L}$ de ferricianeto de potássio

Utilizando a voltametria cíclica e diversas velocidades de varredura, mantendo-se constante a concentração da espécie eletroativa, construiu-se o gráfico de ip (corrente de pico) em função de $v^{1 / 2}$ (raiz quadrada da velocidade de varredura), e através do coeficiente angular, utilizando-se a equação de RandlesSevick (Equação III) para sistema reversível, calculou-se a área do eletrodo (WANG, 2000; BARD \& FAULKANER, 1980).

$$
I_{c, p}=-2,69 \times 10^{5} n^{3 / 2} A D^{1 / 2} v^{1 / 2} C
$$

(Equação III)

sendo: $\mathbf{I}_{\mathbf{c}, p}$ a corrente de pico catódica dos compostos em estudo, $\mathbf{n}$ o número de elétrons envolvidos, A a área do eletrodo $\left(\mathrm{cm}^{2}\right)$, D o coeficiente de difusão $\left(\mathrm{cm}^{2} \mathrm{~s}^{-1}\right), \boldsymbol{v}$ é a velocidade de varredura $\left(V^{-1}\right)$, e $\mathbf{C}$ a concentração da espécie química $\left(\mathrm{mol} \mathrm{cm}^{-3}\right)$.

Optou-se pela solução de ferricianeto de potássio $\left(\mathrm{K}_{3} \mathrm{Fe}(\mathrm{CN})_{6} \cdot 3 \mathrm{H}_{2} \mathrm{O}\right)$, em solução de $\mathrm{KCl}$ 0,5 mol/L, como eletrólito de suporte, pelo fato do processo ser reversível e, na concentração de $1,0 \mathrm{mM}$, conhece-se o valor do coeficiente de difusão, que corresponde a $6,50 \times 10^{-6} \mathrm{~cm}^{2} \mathrm{~s}^{-1}$ (ROFFEL \& VAN DE GRAFF, 1977; LEON \& SAWYER, 1981). Para este exemplo em específico, o número de elétrons, $n$, envolvidos no processo reversível $\mathrm{Fe}(\mathrm{CN})_{6}{ }^{3-} / \mathrm{Fe}(\mathrm{CN})_{6}{ }^{4-}$ é igual a 1 e a área efetiva, $A$, do ECV foi estimada a partir da média de cinco leituras independentes e, com polimento entre as mesmas, onde se obteve o valor médio de 0,037 $\pm 0,004$ $\mathrm{cm}^{2}$. Utilizaram-se os seguintes parâmetros experimentais: $E_{\text {inicial }}=+0,6 \mathrm{~V}, \mathrm{E}_{\lambda 1}=-$ $0,25, E_{\lambda 2}=+0,6 V ; E_{\text {final }}=+0,6 V$. 


\subsubsection{Estimativa do número de elétrons correspondente ao pico de redução principal}

Neste trabalho, calculou-se o número de elétrons $(n)$ por comparação do comportamento voltamétrico dos análogos em estudo ao NF. Utilizaram-se para este fim, diferentes equações, dependendo do método empregado para esta comparação. Empregou-se a equação de função de corrente para VC, equação IV, a equação da largura do pico à meia-altura para VPD, equação $V$ (BROWN \& SANDIFER, 1986, BRETT \& BRETT, 1993; LA-SCALEA et al., 2009).

Como a função de corrente para VC depende de $n^{3 / 2}$ e $D_{a q}^{1 / 2}$ (BARD \& FAULKNER, 2001) estimou-se o número de elétrons envolvidos por comparação das funções de corrente do NF aos bioisósteros. A comparação entre os análogos é uma estratégia viável, pois os compostos apresentam valores de coeficientes de difusão (D) similares, os quais foram calculados a partir dos respectivos volumes moleculares (V) seguindo procedimento 2.2.4.3 (LA-SCALEA, MENEZES, FERREIRA, 2005).

$$
\mathrm{I}=\mathrm{I}_{\mathrm{c}, \mathrm{p}} / \mathrm{v}^{1 / 2} \mathrm{C}
$$

\section{(Equação IV)}

onde: I é a função de corrente, $\mathbf{I}_{c, p}$ é a corrente de pico catódica principal dos compostos em estudo, $v$ é a velocidade de varredura $\left(V s^{-1}\right)$ e $C$ é a concentração da espécie química $\left(\mathrm{mol} \mathrm{cm}{ }^{-3}\right)$.

$$
W_{1 / 2}=0,090 n
$$

(Equação V)

onde: $\mathbf{W}_{1 / 2}$ é a largura à meia altura do pico observado no voltamograma de pulso diferencial e $\mathbf{n}$ é o número de elétrons. Condições experimentais: amplitude de pulso $=0,05 \mathrm{~V}$, intervalo de pulso $=0,5 \mathrm{~s}$, tempo de equilíbrio $=5 \mathrm{~s}, \mathrm{E}_{\text {inicial }}=0,0 \mathrm{~V}, \mathrm{E}_{\text {final }}=$ $-0,7 \mathrm{~V}$.

Empregou-se também as equações de Radles-Sevcik para sistemas reversíveis (Equação III, página 29) e para sistemas irreversíveis (equação VI).

$$
I_{c, p}=-2,99 \times 10^{5}(\alpha n)^{1 / 2} A D^{1 / 2} v^{1 / 2} C
$$


sendo: $I_{c, p}$ a corrente de pico catódica dos compostos em estudo, $\alpha$ é o coeficiente de irreversibilidade, $\mathbf{n}$ o número de elétrons envolvidos, $\mathbf{A}$ a área do eletrodo $\left(\mathrm{cm}^{2}\right)$, D o coeficiente de difusão $\left(\mathrm{cm}^{2} \mathrm{~s}^{-1}\right), \mathbf{v}$ é a velocidade de varredura $\left(V \mathrm{~s}^{-1}\right)$, e $\mathbf{C}$ a concentração da espécie química $\left(\mathrm{mol} \mathrm{cm}^{-3}\right)$ Também, utilizou-se a técnica cronoamperométrica, que determina a corrente que flui através do eletrodo de trabalho como função do tempo em um potencial constante, por meio da equação de Cottrell, equação VII (BARD \& FAULKANER, 2001).

$$
l_{\mathrm{d}}=\mathrm{nFACD}{ }^{1 / 2} \pi^{-1 / 2} \mathrm{t}^{-1 / 2}
$$

(Equação VII)

onde: $\mathbf{I}_{\mathbf{d}}$ é a corrente difusional a um tempo $\mathrm{t}$, $\mathbf{n}$ é o número de elétrons, $\mathbf{F}$ é a constante de Faraday, A é a área do eletrodo, C é a concentração das espécies reduzidas e D é o coeficiente de difusão das espécies reduzidas. Condições experimentais: Número de pulsos de potencial (3): nível (1) potencial $0 \mathrm{~V}$, duração: $0.2 \mathrm{~s}$, tempo de amostragem: 0,05, nível (2) potencial $-0,7 \mathrm{~V}$, duração: $15 \mathrm{~s}$, tempo de amostragem: 0,05, nível (3) potencial 0V, duração: 0.2s, tempo de amostragem: $0,05 s$.

É válido destacar que para construção do gráfico ld como função de $\mathrm{t}^{-1 / 2}$ é necessário que se evite a grande influência da corrente capacitiva. Para isto se desconsidera os valores obtidos de corrente entre 0 a 0,25 $\mathrm{s}$, da curva cronoamperométrica, pois é a faixa em que se tem a maior contribuição da corrente capacitiva, que corresponde ao carregamento da dupla camada elétrica.

\subsubsection{Geração do nitro radical}

\subsection{Estimativa do número de elétrons}

O número de elétrons envolvidos na redução dos nitro-heterocíclicos na formação do nitro radical foi estimado empregando-se a equação de Randles-Sevick para um sistema reversível (Equação III) (BROWN \& SANDIFER, 1986; BRETT \& BRETT, 1996). 


\subsection{Cálculo da razão de corrente}

Neste trabalho, calculou-se a razão de corrente para o nitro radical aplicandose a Equação VIII (BROWN \& SANDIFER, 1986; BRETT \& BRETT, 1996).

$$
\left|\frac{I_{\mathrm{a}, \mathrm{p}}}{I_{\mathrm{c}, \mathrm{p}}}\right|=\frac{\left(I_{\mathrm{a}, \mathrm{p}}\right)_{0}}{I_{\mathrm{c}, \mathrm{p}}}+\frac{0,485\left(I_{\lambda}\right)_{0}}{I_{\mathrm{c}, \mathrm{p}}}+0,086
$$

(Equação VIII)

sendo: $I_{\mathrm{a}, \mathrm{p}}$ e $\left(I_{\mathrm{a}, \mathrm{p}}\right)_{()}=$correspondem a corrente de pico anódica dos compostos em estudo $(\mu \mathrm{A}), I_{c, p}=$ a corrente de pico catódica $(\mu \mathrm{A})$ e $\left(\mathbf{I}_{\lambda}\right)_{0}$ a corrente medida no potencial de inversão.

2.2.4.6.3 Cálculo da constante de velocidade $\left(k_{2}\right)$ e do tempo de meia-vida ( $\left.t_{1 / 2}\right)$ do nitro radical aniônico de NF e de seus bioisósteros

Os valores experimentais das razões de corrente para o nitro radical, medidos a cada velocidade de varredura, foram inseridos numa curva de trabalho construída a partir do modelo teórico proposto por OLMESTEAD et al.(1969) e determinou-se o parâmetro cinético $\boldsymbol{\Phi}$, que incorpora os parâmetros de constante de velocidade, concentração dos compostos envolvidos e velocidade de varredura como mostra a Equação IX. No entanto, através do modelo teórico proposto por OLMESTEAD et al.(1969) é necessário primeiramente estabelecer uma curva de trabalho relacionando as razões de corrente com o parâmetro $\Phi$, levando em conta o grau de esfericidade do eletrodo de trabalho. Desta forma, como foi empregado neste trabalho um eletrodo plano, cuja esfericidade é nula, escolheu-se a partir do modelo supracitado os valores das razões de corrente correspondentes a zero de esfericidade do eletrodo. Assim, traçou-se a curva de trabalho entre $\boldsymbol{\sigma}$ e as razões de corrente e, verificou-se que a mesma obedeceu ao modelo matemático da equação de derivada exponencial de segunda-ordem. Aplicando-se os dados obtidos de razões de corrente (Equação VIII) calcularam-se os valores de $\bar{\Phi}$, para 
cada velocidade de varredura, de acordo esta equação citada. Posteriormente foi possível estabelecer a curva entre $\boldsymbol{\Phi}$ e $\tau$.

$$
\bar{\sigma}=k_{2} \mathrm{C} \tau
$$

(Equação IX)

sendo: $\boldsymbol{k}_{\mathbf{2}}$ a constante de velocidade da reação de decomposição do nitro-radical aniônico $\left(\mathrm{L}^{\mathrm{mol}}{ }^{-1} \mathrm{~s}^{-1}\right), \quad \mathbf{C}$ a concentração da espécie química $\left(\mathrm{mol} \mathrm{L}^{-1}\right)$, $\tau=\left(E_{1 / 2}-E_{\lambda}\right) / v$, na qual $E_{1 / 2}=E_{p / 2}+0,0285 / n, E_{\lambda} 0$ potencial de inversão em voltametria cíclica e $v$ a velocidade de varredura. $O$ potencial de inversão foi estabelecido considerando-se a menor influência do segundo pico catódico. Os valores de $\boldsymbol{k}_{2}$ foram estimados a partir da relação linear estabelecida entre $\boldsymbol{\boldsymbol { \sigma }}$ em função de $\tau$.

De posse desses resultados, a estabilidade do radical nitro pôde ser estimada pelo cálculo de meia-vida, equação $X$.

$$
t_{1 / 2}=1 /\left[\mathrm{R}^{-N_{2}}{ }^{\bullet-}\right] k_{2}
$$

(Equação X)

sendo: $\mathbf{t}_{1 / 2} \circ$ tempo de meia-vida do nitro radical (s), $\left[\mathrm{R}-\mathrm{NO}_{2}{ }^{-}{ }^{-}\right]$a concentração do nitrocomposto em $\mathrm{mol} \mathrm{L}^{-1}$. 


\section{Capítulo 3}

Resultados e Discussão 


\subsection{ESTUDO DA ESTABILIDADE DO NF E DE SEUS BIOISÓSTEROS}

\subsubsection{Espectrofotometria de UV/Vis}

A escolha dos solventes baseou-se no critério de solubilidade dos compostos estudados. Sabe-se que os compostos nitro-heterocíclicos são pouco solúveis em água. Assim sendo, NF e seus análogos foram dissolvidos na mistura (1:1) $N$-N-dimetilformamida e água ultrapura com auxílio de ultrassom, por 6 minutos, com objetivo de diminuir o tempo de preparo das soluções. Na Figura 9 constam os espectros UV/Vis de NF e seus bioisósteros na mistura de DMF/água na proporção supracitada com e sem assistência de ultrassom, com a finalidade de verificar a estabilidade das soluções frente ao tratamento com ultassom.

De acordo com a Figura 9, os compostos apresentaram perfil espectrofotométrico semelhante ao NF, com duas bandas de absorção ( 382nm e 270nm). Também é observado que não há indicativos de degradação dos compostos com a assistência do ultrassom, pois os mesmos apresentaram perfil espectrofotométrico similar para os dois procedimentos.

É válido destacar que todas as soluções manteram-se estáveis durante o período de 3 meses. 

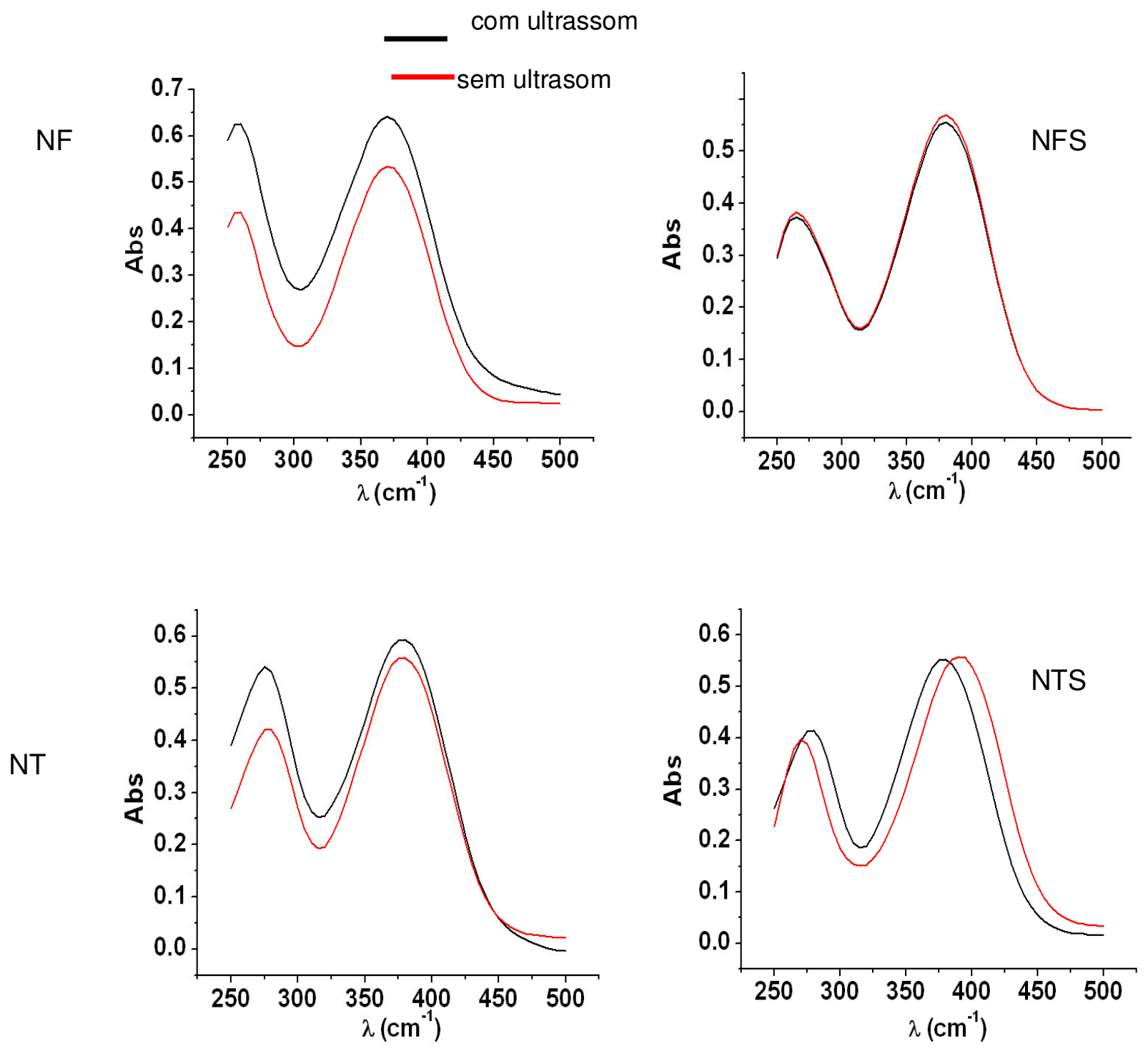

Figura 9- Espectros de UV/Vis de NF e bioisósteros. [Composto]= $0,1 \mathrm{mmol} / \mathrm{L}$, em meio (1:1) DMF e água ultrapura, scan de 200-500 nm, velocidade de scan $2400 \mathrm{~nm} \mathrm{~min}^{-1}$. 


\subsection{Comportamento Voltamétrico do NF e seus bioisósteros}

A discussão feita a seguir apresenta de forma detalhada os resultados obtidos para o comportamento voltamétrico dos derivados estudados com o objetivo de elucidar melhor o mecanismo de redução voltamétrica desses derivados.

Os voltamogramas cíclicos obtidos em solução $5,0 \times 10^{-4} \mathrm{~mol} \mathrm{~L}^{-1}$ de NF e de seus bioisósteros no intervalo de $2,10 \leq \mathrm{pH} \leq 6,04$ apresentaram comportamento voltamétrico semelhantes, com registro de única onda de redução $\left(\mathrm{Ec}_{, \mathrm{p} 1}\right)$ irreversível e registrou-se também, na região positiva de potencial um pico de oxidação $\left(\mathrm{Ea}_{\mathrm{p} p 1}\right)$ sem o respectivo componente catódico (Tabelas 1 e 2). Nestas condições experimentais nota-se que o análogo NT apresentou ligeira facilidade de redução em relação ao outros derivados. Consequentemente, a ocorrência do processo de oxidação em sequência, acompanha essa mesma ordem de reatividade dos compostos. Apesar disso, as variações nos valores de potencial de pico registrados não são significativas o suficiente para afirmar que as modificações moleculares efetuadas introduziram alterações determinantes no comportamento voltamétrico dos análogos quando comparados ao NF. De forma complementar, esse comportamento pode ser verificado pelos voltamogramas apresentados na Figura 10. 
Tabela 1. Parâmetros voltamétricos obtidos na redução de $0,5 \mathrm{mmol} / \mathrm{L}$ de NF e NFS em $\mathrm{pH} 4,0$ usando ECV em $0,01 \leq v \leq 1,0$.

\begin{tabular}{c|c|c|c|c}
\hline \multicolumn{3}{c|}{ NF } & \multicolumn{2}{c}{ NFS } \\
\hline $\mathbf{v ~ ( V / s )}$ & $\begin{array}{c}\text { Ec,p1 } \\
(\mathbf{V})\end{array}$ & $\alpha \mathbf{n}$ & $\begin{array}{c}\mathbf{E c}_{, \mathbf{p} 1} \\
(\mathbf{V})\end{array}$ & $\alpha \mathbf{n}$ \\
& & & & \\
\hline 0,01 & $-0,359$ & 1,12 & $-0,364$ & 0,87 \\
0,05 & $-0,376$ & 1,09 & $-0,391$ & 0,81 \\
0,08 & $-0,425$ & 0,92 & $-0,410$ & 0,80 \\
0,1 & $-0,442$ & 0,91 & $-0,430$ & 0,79 \\
0,3 & $-0,457$ & 0,87 & $-0,439$ & 0,76 \\
0,5 & $-0,459$ & 0,85 & $-0,457$ & 0,75 \\
0,7 & $-0,462$ & 0,84 & $-0,460$ & 0,73 \\
1,0 & $-0,464$ & 0,82 & $-0,462$ & 0,71 \\
\hline
\end{tabular}

Tabela 2. Parâmetros voltamétricos obtidos na redução de $0,5 \mathrm{mmol} / \mathrm{L}$ de NT e NTS em $\mathrm{pH} 4,0$ usando ECV em $0,01 \leq v \leq 1,0$.

\begin{tabular}{c|c|c|c|c}
\hline \multicolumn{3}{c}{ NT } & \multicolumn{2}{c}{ NTS } \\
\hline$v($ V/s) & Ec,p1 $_{\text {, }}$ & $\alpha$ n & Ec,p1 $_{\text {, }}$ & $\alpha$ n \\
& $(\mathbf{V})$ & & (V) & \\
\hline 0,01 & $-0,360$ & 0,98 & $-0,369$ & 1,2 \\
0,05 & $-0,354$ & 0,98 & $-0,366$ & 1,1 \\
0,08 & $-0,383$ & 0,96 & $-0,386$ & 1,0 \\
0,1 & $-0,410$ & 0,89 & $-0,427$ & 0,98 \\
0,3 & $-0,415$ & 0,87 & $-0,430$ & 0,97 \\
0,5 & $-0,415$ & 0,85 & $-0,432$ & 0,96 \\
0,7 & $-0,417$ & 0,84 & $-0,434$ & 0,95 \\
1,0 & $-0,419$ & 0,83 & $-0,435$ & 0,93 \\
\hline
\end{tabular}



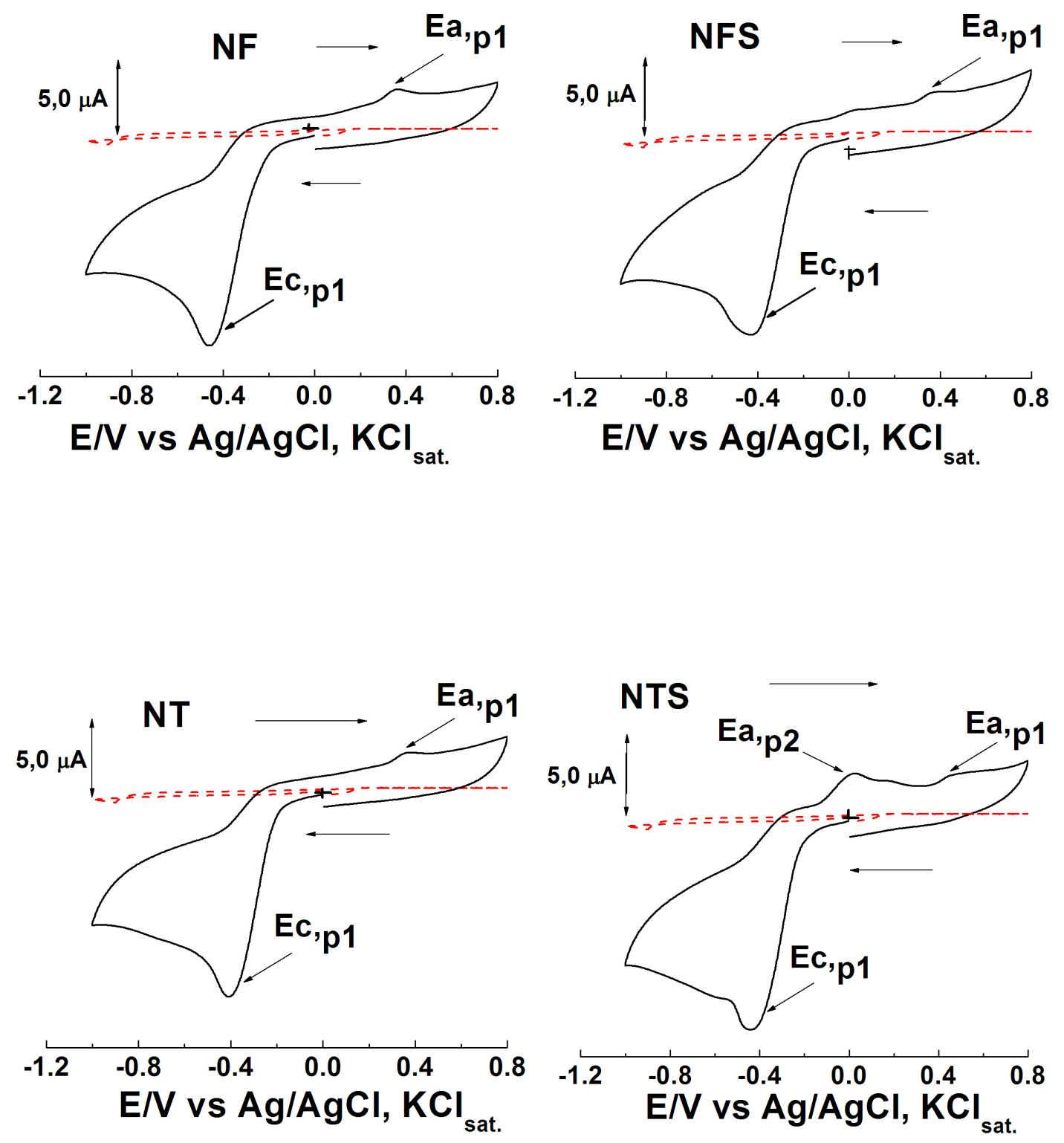

Figura 10- Voltamogramas cíclicos obtidos em pH 4,02, (-----) branco. [Composto]= $0,5 \mathrm{mmol} / \mathrm{L}, v=0,1 \mathrm{~V} / \mathrm{s}$. Condições experimentais: $E_{\text {inicial }}=0,0 \mathrm{~V}, \mathrm{E}_{\lambda}=-$ $1,0 \mathrm{~V}, \mathrm{E}_{\lambda 2}=+0,80 \mathrm{~V}, \mathrm{E}_{\text {final }}=0,0 \mathrm{~V}$. 
Todos os compostos apresentaram perfil voltamétrico semelhante em $\mathrm{pH}$ 4,02. Como anteriormente mencionado, os voltamogramas cíclicos obtidos neste meio apresentaram um único pico de redução, seguido da oxidação dos produtos formados, exceção do NTS que apresentou dois picos de oxidação $\left(E a_{, p 1}\right.$ e Ea,p2). De acordo com a literatura (MORALES et al., 1984, MORALES et al., 1987, LASCALEA et al., 2005 e 2009), os processos eletroquímicos envolvidos em $E_{c_{p, 1}}$ e $\mathrm{Ea}_{\mathrm{p}, 1}$ correspondem à redução do grupo nitro a hidroxilamina (reação 6) e oxidação da hidroxilamina ao respectivo derivado nitroso (reação 7), de acordo com as equações a seguir:

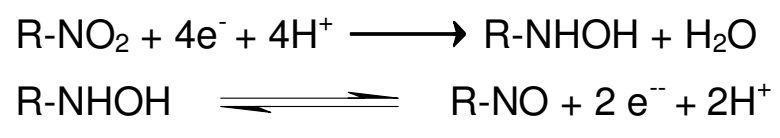

As Tabelas 1 e 2 também mostram os valores de $\mathrm{Ec}_{\mathrm{p} p 1}$ em função da velocidade de varredura na faixa de 0,01 a 0,5 V para todos os análogos estudados. Pode-se observar que o pico de redução é deslocado no sentido negativo de potencial com o aumento da velocidade de varredura, confirmando o processo de reação irreversível para a formação do intermediário hidroxilamínico (R-NHOH).

Os valores de $\alpha$ foram obtidos a partir da relação entre $\mathrm{Ec}_{, \mathrm{p} 1}$ e o potencial na metade da altura do pico para processo irreversível (Equação I) (BROWN \& SANDIFER, 1986; BRETT \& BRETT, 1996). Estes resultados também estão apresentados nas Tabelas 1 e 2 . Os valores de $\alpha$ ao redor de 1 sugerem a participação de dois elétrons na etapa determinante da reação de eletrodo, indicando que a etapa lenta do processo principal de redução dos análogos estudados deve-se à provável formação do respectivo derivado nitroso. Adicionalmente, este parâmetro como critério de irreversibilidade de reações de eletrodo pode ser considerado procedimento válido, na qual a queda significativa dos valores de on indica que a irreversibilidade do sistema é aumentada a valores crescentes da velocidade de varredura, pois a aplicação de potencial torna-se mais rápida do que o processo de transferência de carga envolvida nessa etapa lenta do processo. Esse comportamento acompanha resultados anteriores obtidos para o comportamento voltamétrico do NF (LA-SCALEA et al., 2005 e 2009). 
Também observou experimentalmente que as correntes de pico obtidas em $\mathrm{I}_{\mathrm{p}, 1}$ variaram linearmente $\operatorname{com} \mathrm{v}^{1 / 2}$, como indicado pela Figura 11. Este comportamento indica que o processo de transferência de carga envolvido na etapa principal de redução é controlado por difusão para todos os análogos. Vale destacar que foi necessário o polimento do eletrodo a cada mudança de velocidade de varredura. Até este ponto, com o processo de redução sendo estudado em meio ácido, não se observou qualquer alteração do comportamento voltamétrico dos análogos estudados em consequência do procedimento de polimento da superfície do ECV, seja com suspensão de alumina, seja com spray de diamante.

A confirmação de que o registro de $\mathrm{Ea}_{\mathrm{p} p 1}$ é dependente dos produtos formados pela etapa de redução foi efetuada pela restrição da faixa de potencial entre $E_{i}=0,0 \vee, E_{\lambda 1}=-0,35 V, E_{\lambda 2}=0,80 V$. Nota-se pela Figura 12 que nestas condições não há registro do pico anódico correspondente a $\mathrm{Ea}_{\text {,p1 }}$, demonstrando que o mesmo é dependente do produto formado indicado pelo pico $\mathrm{Ec}_{, \mathrm{p} 1}$ de acordo com a redução de nitrocompostos em meio aquoso, sugerindo que $E_{\mathrm{p}, 1}$ é decorrente de re-oxidação da hidroxilamina ( $\mathrm{R}-\mathrm{NHOH}$ ) ao intermediário nitroso ( $\mathrm{R}$ NO), como descrito pela reação 7 (JULIÃO et al, 2005; SQUELLA et al, 2005; MANDAL, 2004; BOLLO et al., 2003; LA-SCALEA et al., 1999; SQUELLA et al., 1996; KARAKUS \& ZUMAN, 1995; MONTEAGUDO et al.,1992; MORALES et al.,1987). Ademais, estudos complementares foram realizados nas páginas 56 e 57 , para avaliação deste intermediário.

Adicionalmente, comportamento incomum foi registrado para o análogo NTS, com o qual um segundo pico de oxidação, Ea,p2, foi observado. Vale destacar que registro semelhante não é encontrado na literatura para os derivados de nitrocompostos. Nota-se que Ea,p2 não depende do pico de redução, levando à suposição da existência de processo de adsorção da molécula sobre a superfície do ECV. A presença dos dois átomos de enxofre neste análogo, grupo tionila juntamente com o núcleo tiofênico, podem ser os responsáveis por esse fenômeno, pois nos compostos contendo apenas um átomo de enxofre pico semelhante não foi encontrado, como também não foi registrado para o NF. 

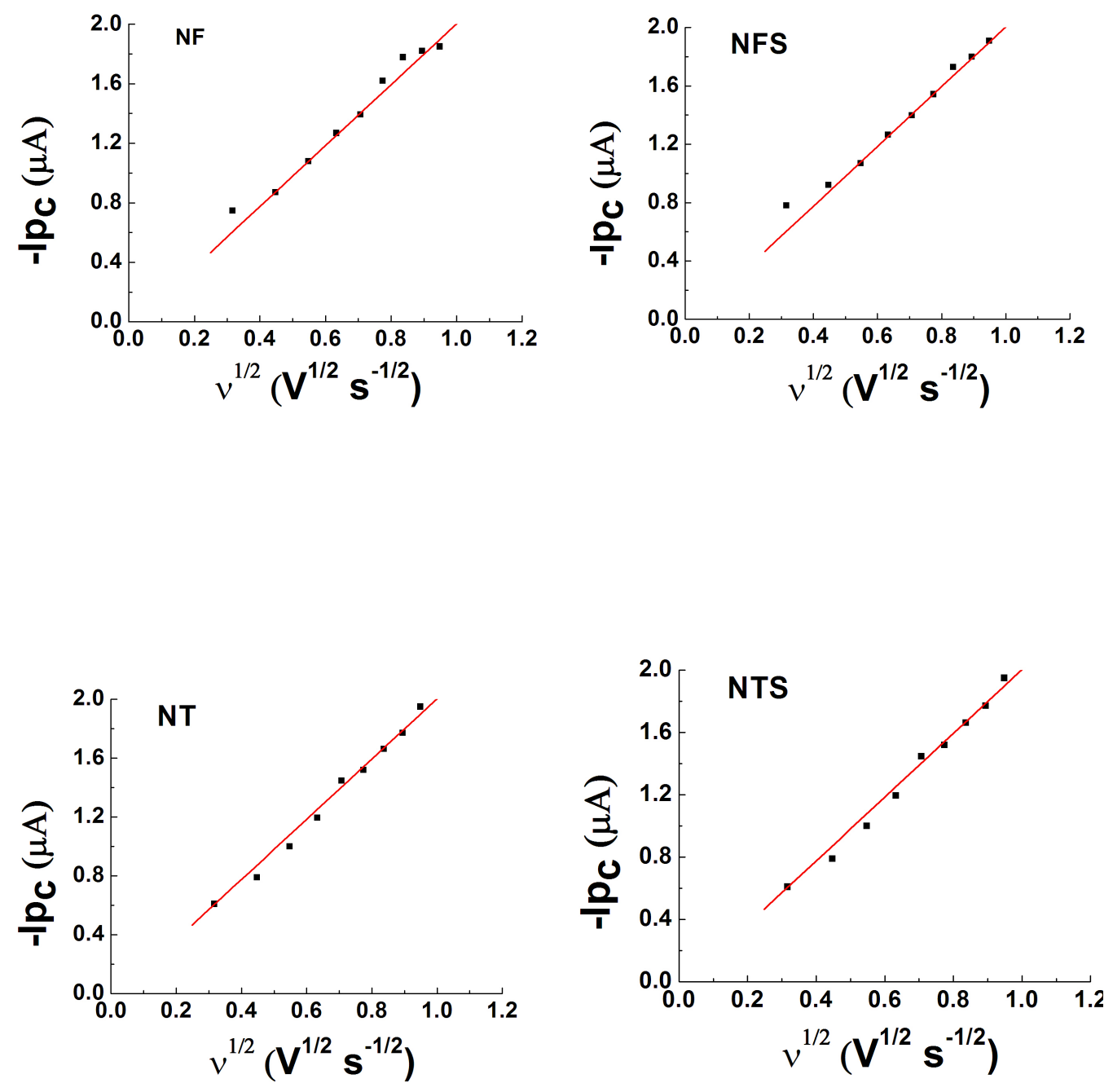

Figura 11- Variação de $-\mathrm{Ic}_{\mathrm{p}, 1}$ vs $v^{1 / 2} \mathrm{em} \mathrm{pH}$ 4,02. Dados obtidos usando ECV em [Composto] $=0,5 \mathrm{mmol} / \mathrm{L}$.

Equações da reta:
(NF) $-I p_{c, 1}=0,059 \mu \mathrm{A}+2,01 \mu \mathrm{A} v^{1 / 2}$
$R^{2}=0,997$
(NFS) $-I p_{c, 1}=0,096 \mu \mathrm{A}+1,92 \mu \mathrm{A} v^{1 / 2}$
$R^{2}=0,991$
(NT) $-\mid p_{c, 1}=0,096 \mu \mathrm{A}+2,01 \mu \mathrm{A} v^{1 / 2}$
$R^{2}=0,991$
(NTS) $-\mid p_{c, 1}=0,096 \mu \mathrm{A}+2,01 \mu \mathrm{A} v^{1 / 2}$
$R^{2}=0,991$ 

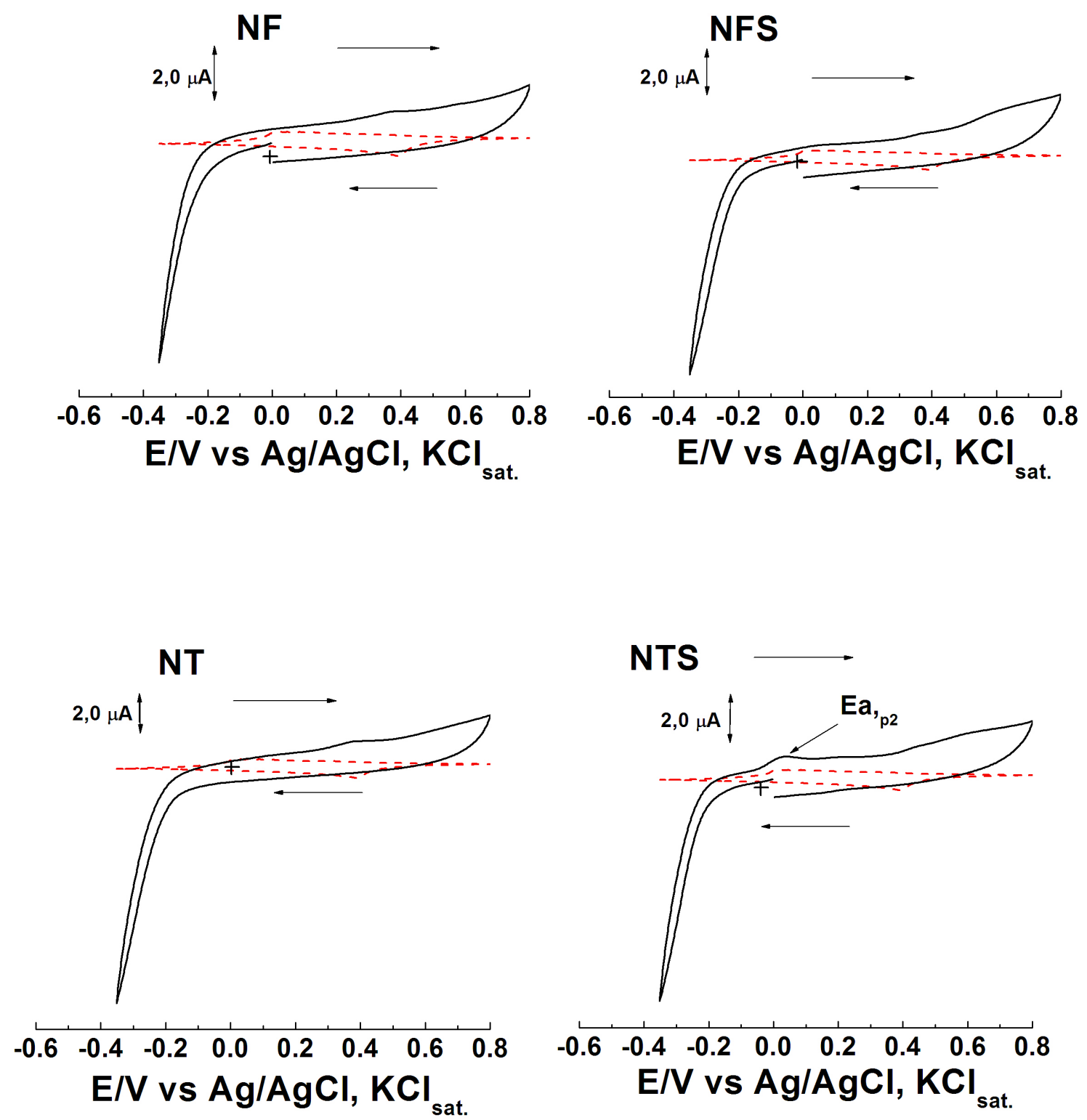

Figura 12- Voltamogramas cíclicos registrados em pH 4,02 com janela de potencial restrita em relação a Figura 10, (-----) branco. [Composto]= 0,5mmol/L, $v=0,1 \mathrm{~V} / \mathrm{s}$. Condições experimentais: $\mathrm{E}_{\text {inicial }}=0,0 \mathrm{~V}, \mathrm{E}_{\lambda_{1}}=-0,35 \mathrm{~V}, \mathrm{E}_{\lambda_{2}}=$ $+0,8 \mathrm{~V} ; \mathrm{E}_{\text {final }}=0,0 \mathrm{~V}$. 


\subsubsection{Estimativa do número de elétrons envolvidos na redução voltamétrica de NF e seus análogos}

A redução voltamétrica de NF pode envolver quatro ou seis elétrons, conforme o meio reacional, formando os respectivos derivados hidroxilamina ou amina. Trabalhos da literatura (JULIÃO et al, 2005; LA-SCALEA et al., 2005; LASCALEA et al., 2009) mostram que em meio aquoso-ácido, e com emprego de tampão Britton-Robinson, o mecanismo de redução do grupo nitro no NF envolve quatro elétrons com a formação do derivado hidroxilamínico (R-NHOH).

Diante do exposto, estimou-se o número de elétrons ( $\mathrm{n}$ ) envolvidos em $\mathrm{pH}$ 4,02 e 7,41, correspondendo ao pico principal de redução $\left(\mathrm{Ec}_{\mathrm{p}, 1}\right)$, pela comparação do comportamento voltamétrico dos análogos sintetizados ao NF, utilizando-se VC e VPD. A Tabela 3 mostra os respectivos resultados voltamétricos obtidos com ECV.

Trabalhos anteriores (LA-SCALEA et al.,2005; LA-SCALEA et al., 2009) apresentam estimativas para o número de elétrons envolvidos na redução voltamétrica de NF aplicando estratégia semelhante, a partir da comparação com os valores de corrente limite registradas por voltametria de varredura linear para metronidazol e cloranfenicol. Essa comparação baseou-se em resultados registrados na literatura obtidos por coulometria, que indicam que a redução em meio ácido do grupo nitro desses compostos ocorre com o envolvimento total de quatro elétrons (DECLERCK \& RANTER, 1987).

Desta forma, comparando-se os resultados voltamétricos obtidos para a redução dos bioisósteros do NF em pH 4,02 e pH 7,41 ( Tabela 3), pode-se concluir que os análogos estudados apresentam mecanismos de redução voltamétrica semelhantes com envolvimento de igual número de elétrons. De forma complementar, a proximidade entre os valores de corrente de pico e da largura do pico à meia-altura $\left(W_{1 / 2}\right)$ (Equação III) obtidos por VPD, confirma que os análogos estudados possuem processos de redução semelhantes. Nas Figuras 13 e 14 constam os voltamogramas de pulso diferencial com solução $0,1 \mathrm{mmolL}^{-1}$ de NF e de seus bioisósteros em pH 4,02 e pH 7,41, respectivamente.

Portanto, baseando-se na discussão acima se pode inferir que quatro elétrons estão envolvidos no processo principal de redução dos compostos analisados, levando à formação de hidroxilamina. Resultados similares têm sido reportados para outros derivados de nitro-heterocíclicos usando técnicas voltamétricas (TOCHER, 
1997; SQUELLA et al., 1994). Merece ser mencionado que em pH 7,41 foi possível detectar único pico de redução devido às baixas velocidades de aplicação do potencial em ambas as técnicas VC $(v=0,01 \mathrm{~V} / \mathrm{s})$ e VPD $(v=0,05 \mathrm{~V} / \mathrm{s})$, pois ao contrário este sinal de redução pode ser desmembrado em dois picos, como será descrito na próxima seção deste trabalho.

De maneira a corroborar com os resultados obtidos, foi feito uso das equações de Radles-Sevcik para sistemas reversíveis e para sistemas irreversíveis, e em pH 4,02, uma vez que o processo registrado em $\mathrm{Ec}_{\mathrm{p}, 1}$ é controlado por difusão. Neste sentido foi possível substituir o declive ("slope") obtido a partir do gráfico linear de $p_{c, 1} v s v^{1 / 2}$ (Figura 11) e calculou-se o número de elétrons, $n$, Tabela 4. Ademais, para o cálculo do número de elétrons para sistema irreversível usou-se o valor de an médio, Tabelas 1 e 2 da página 38, para cada um dos análogos. Como pode ser observado a partir dos dados da Tabela 4 , o número de elétrons, $n$, calculado para o pico de redução, $\mathrm{Ec}_{\mathrm{p}, 1}$, foi igual a aproxidamente 4 , e está de acordo com os resultados obtidos em VC e em VPD.

Estudos cronoamperométricos foram executados com o objetivo de corroborar os resultados obtidos por VC e VPD. As Figuras 15 e 16 mostram as variações de $l_{d}$ em função de $\mathrm{t}^{-1 / 2}$ registrados em pH 4,02 e 7,41 com $0,5 \mathrm{mmolL}^{-1}$ para todos os análogos. Adicionalmente, a Tabela 5 (página 51) apresenta o número de elétrons calculados de acordo com a Equação de Cottrell (Equação VII) para NF e de seus bioisósteros, considerando o processo correspondente ao pico principal de redução. Os resultados obtidos indicam que praticamente quatro elétrons estão envolvidos nesse mecanismo, estando de acordo com todos os dados reportados na literatura para outros nitro-heterocíclicos (DECLERCK \& RANTER, 1987; SQUELLA et al, 2005; BOLLO et al., 2003; SQUELLA et al., 1996). 

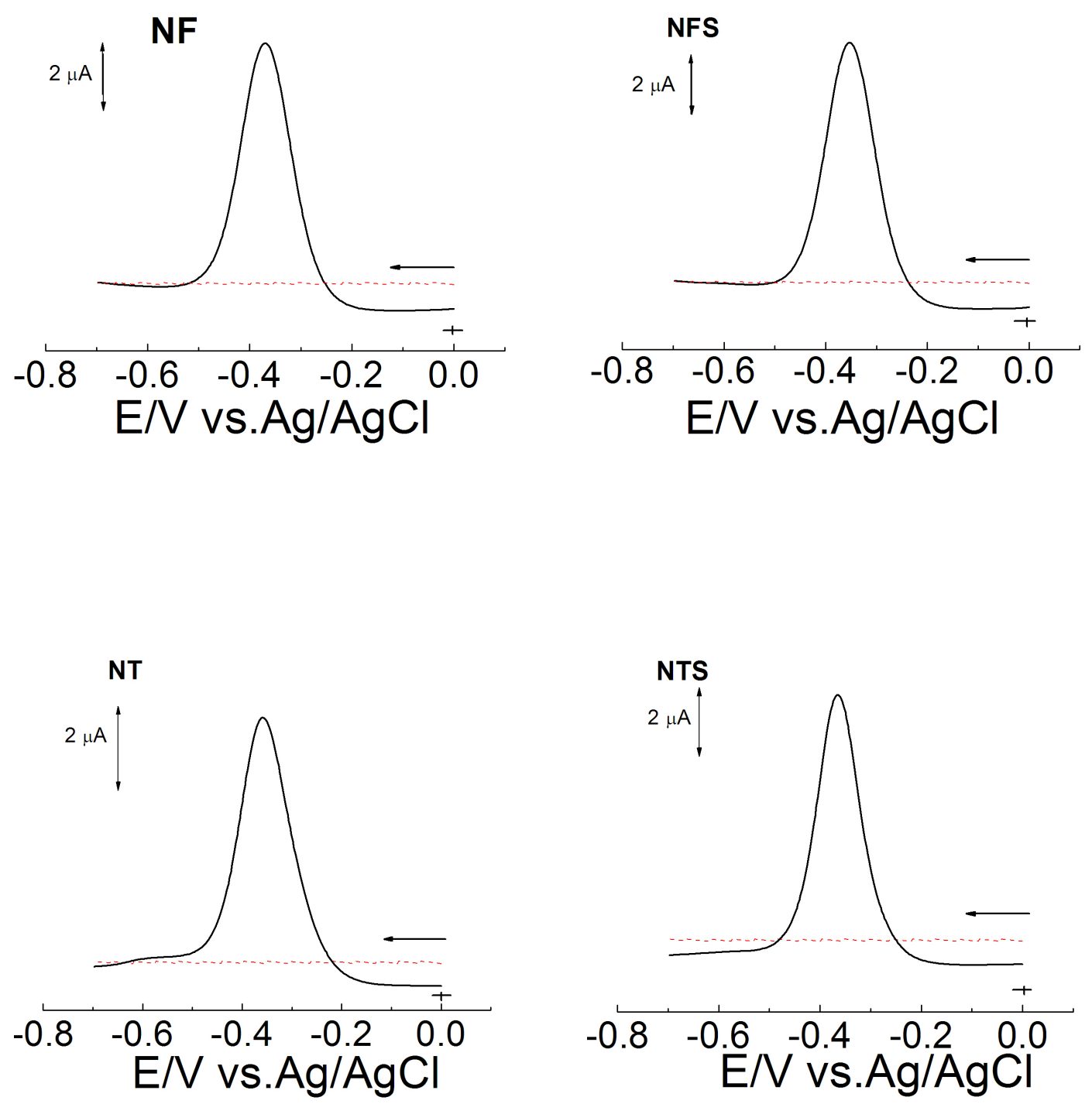

Figura 13- Voltamogramas de pulso diferencial obtidos em pH 4,02 usando eletrodo de carbono vítreo. (-----) branco [Composto] $=0,1 \mathrm{mmol} / \mathrm{L}, v=0,05 \mathrm{~V} / \mathrm{s}$. Condições experimentais: amplitude de pulso $=0,05 \mathrm{~V}$, intervalo de pulso $=0,5 \mathrm{~s}$, duração do pulso $=0,05 \mathrm{~s}$, tempo de equilíbrio $=5 \mathrm{~s}, \mathrm{E}_{\text {inicial }}=0,0 \mathrm{~V}$, $E_{\text {final }}=-0,7 \mathrm{~V}$. 

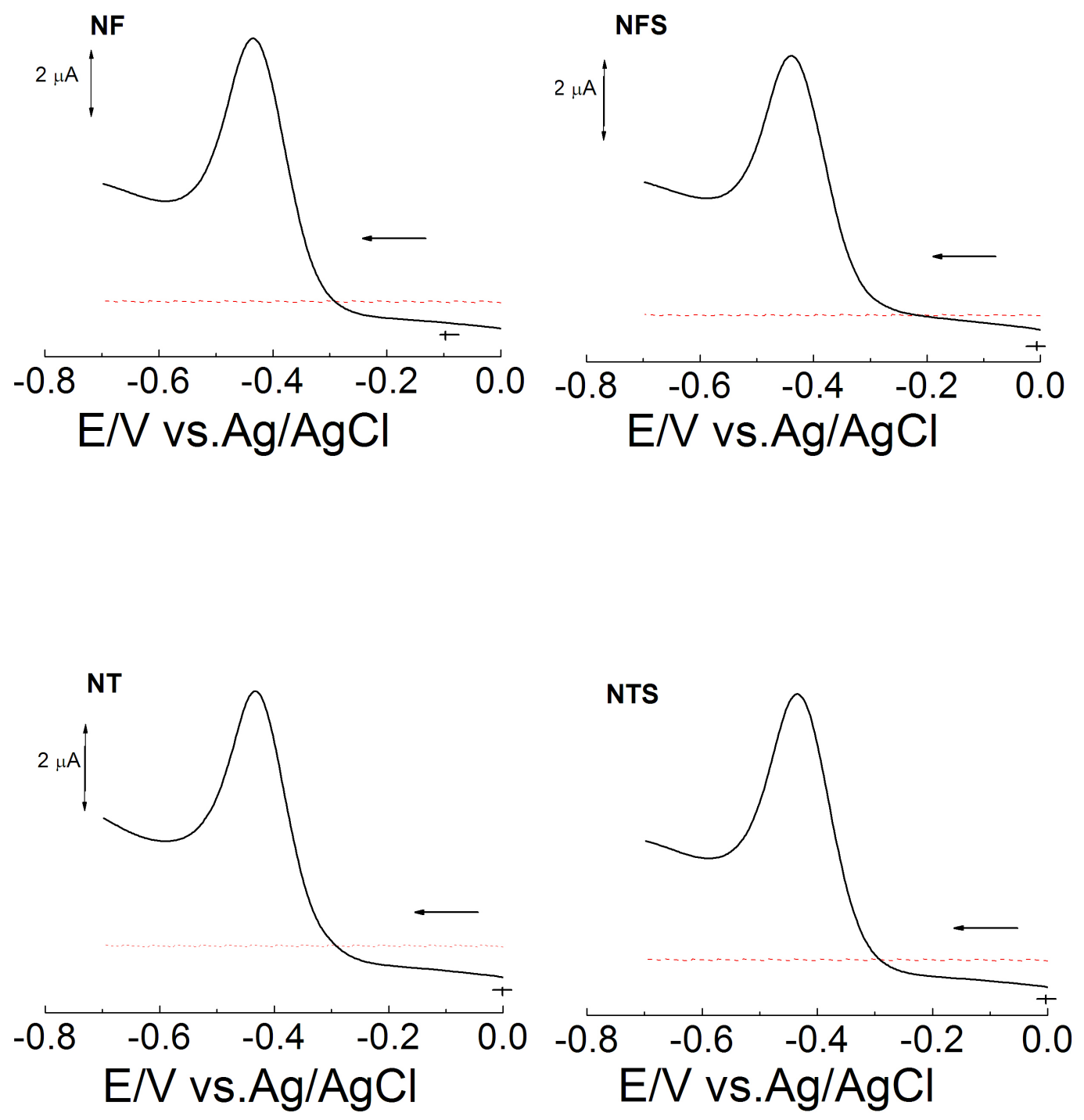

Figura 14- Voltamogramas de pulso diferencial obtidos em $\mathrm{pH} 7,41$ usando eletrodo de carbono vítreo. (-----) branco [Composto] $=0,1 \mathrm{mmol} / \mathrm{L}, v=0,05 \mathrm{~V} / \mathrm{s}$. Condições experimentais: amplitude de pulso $=0,05 \mathrm{~V}$, intervalo de pulso $=0,5 \mathrm{~s}$, duração do pulso $=0,05 \mathrm{~s}$, tempo de equilíbrio $=5 \mathrm{~s}, \mathrm{E}_{\text {inicial }}=0,0 \mathrm{~V}$, $E_{\text {final }}=-0,7 \mathrm{~V}$. 
Tabela 3. Valores de coeficiente de difusão e do volume molar dos compostos estudados em pH 4,02 e 7,41, usando ECV.

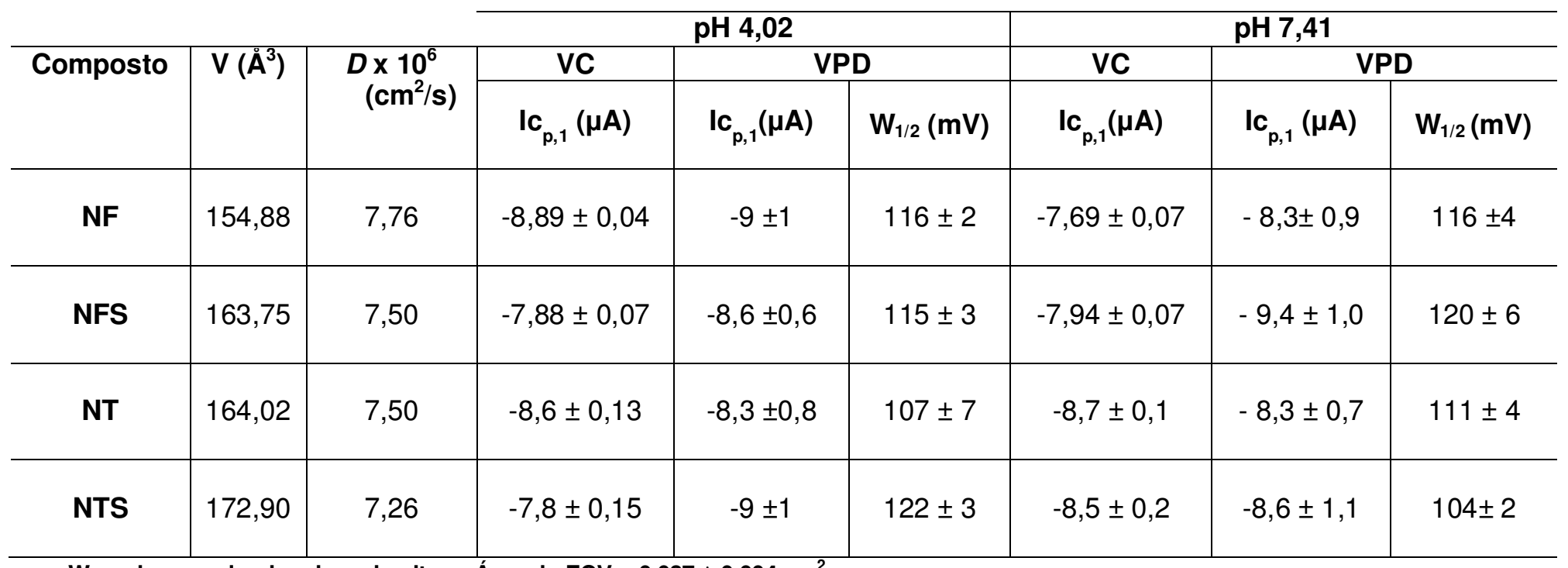

$\mathrm{W}_{1 / 2}=$ largura do pico de meia-altura. Área do $\mathrm{ECV}=0,037 \pm 0,004 \mathrm{~cm}^{2} .$. 

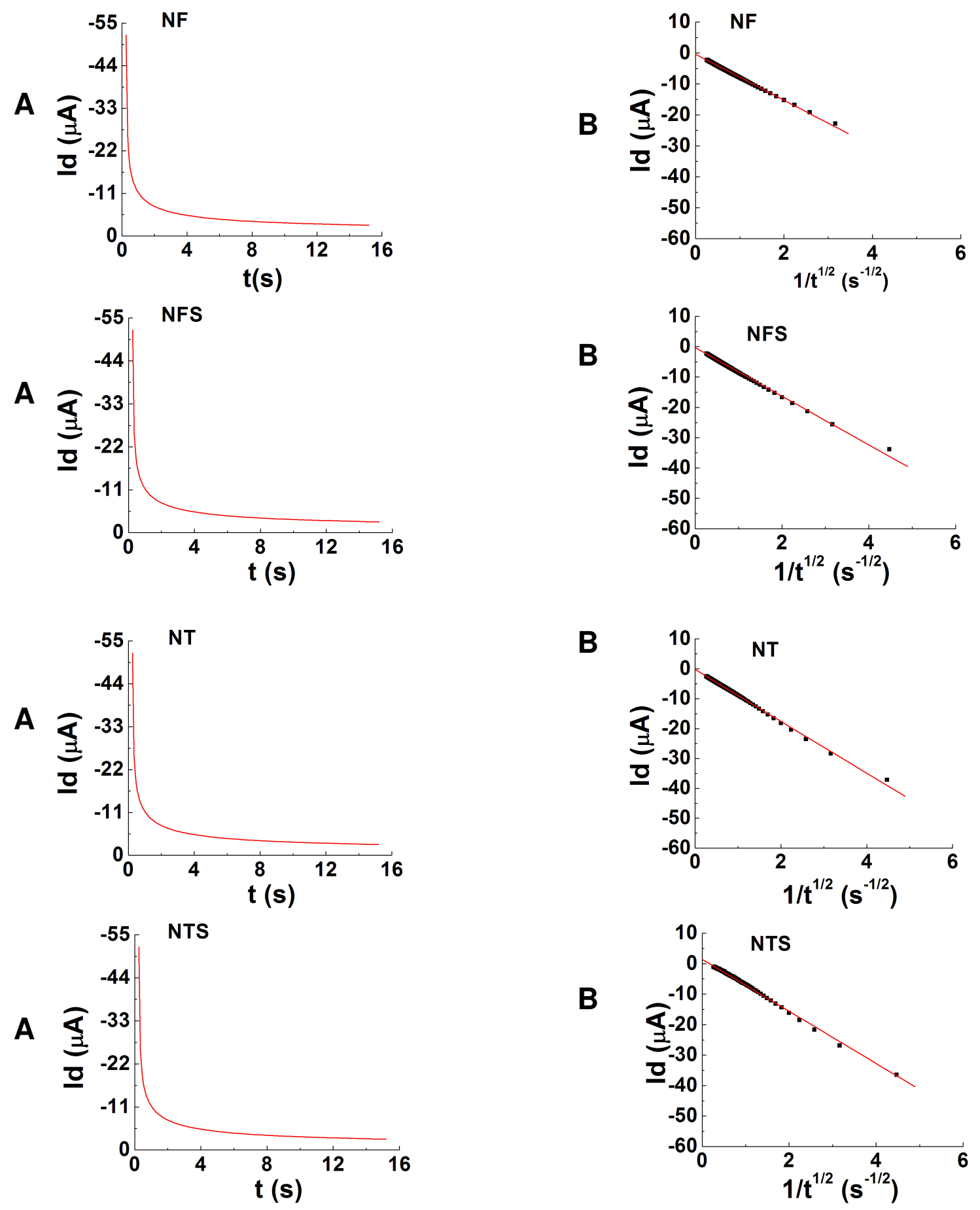

Figura 15- (A) Variação de Id em função de $\mathrm{t}^{-1 / 2}$ (B) Variação entre Id em função de t. Dados obtidos em ECV, em pH 4,02, [Composto]= 0,5mmol/L. Número de pulsos de potencial (3): nível (1) potencial $0 \mathrm{~V}$, duração: 0.2s, tempo de amostragem: 0,05s, nível (2) potencial $-0,7 \mathrm{~V}$, duração: $15 \mathrm{~s}$, tempo de amostragem: $0,05 \mathrm{~s}$, nível (3) potencial $0 \mathrm{~V}$, duração: $0.2 \mathrm{~s}$, tempo de amostragem: $0,05 \mathrm{~s}$. 

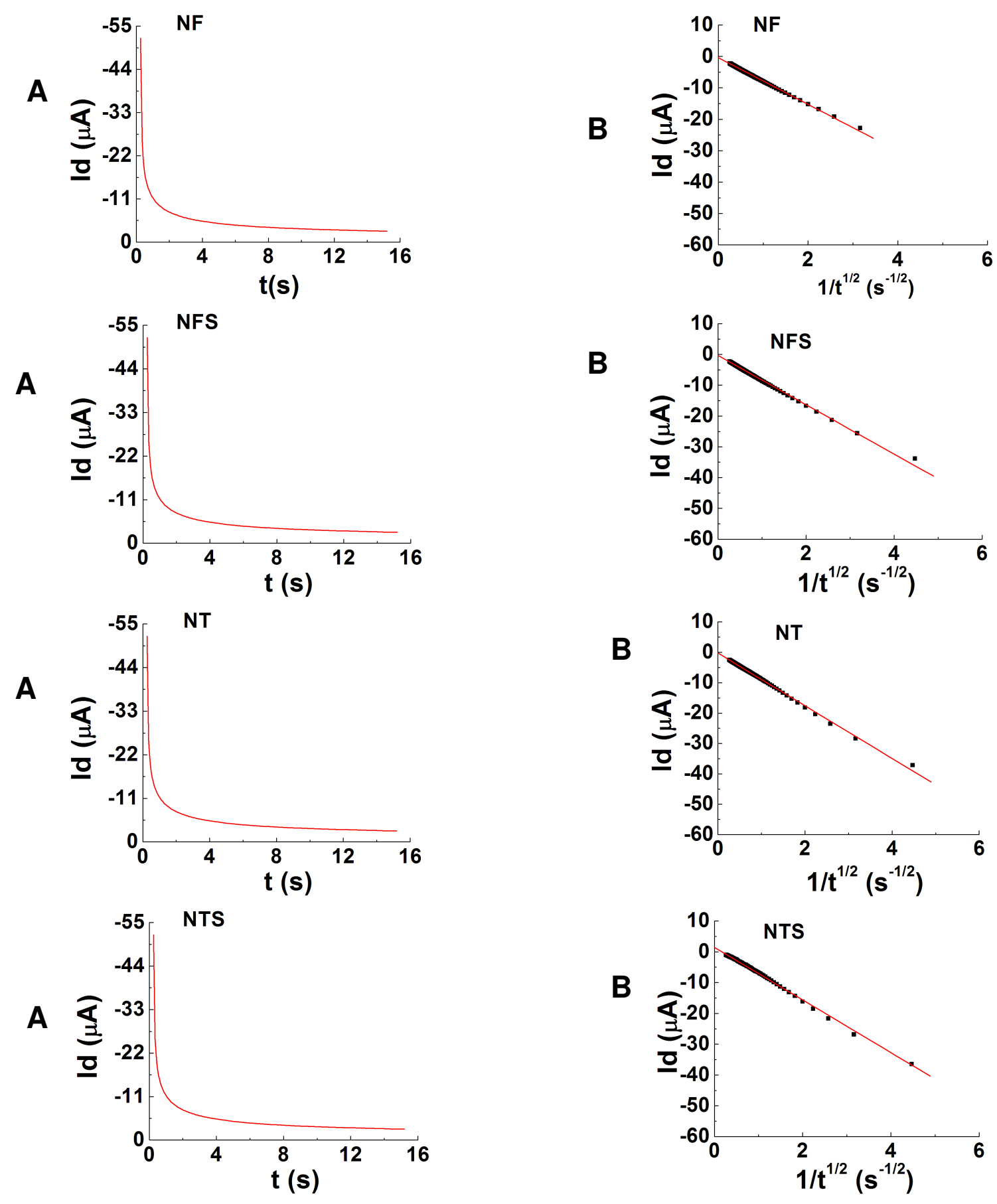

Figura 16- Variação de Id em função de $\mathrm{t}^{-1 / 2}$ (B) Variação entre Id em função de $t$. Dados obtidos em ECV, em pH 7,41, [Composto]= 0,5mmol/L. Número de pulsos de potencial (3): nível (1) potencial $0 \mathrm{~V}$, duração: $0.2 \mathrm{~s}$, tempo de amostragem: $0,05 \mathrm{~s}$, nível (2) potencial $-0,7 \mathrm{~V}$, duração: $15 \mathrm{~s}$, tempo de amostragem: 0,05s, nível (3) potencial 0V, duração: 0.2s, tempo de amostragem: $0,05 \mathrm{~s}$. 
Tabela 4. Número de elétrons (n) para a redução de $0,5 \mathrm{mmol} / \mathrm{L}$ de $\mathrm{NF}$ e de seus análogos de NF e seus análogos em pH 4,02 usando ECV e a Equação de Randles-Sevick

\begin{tabular}{c|c|c}
\hline \multirow{2}{*}{ Composto } & Sistema reversível(*) $^{*}$ & Sistema irreversível(*) $^{*}$ \\
\cline { 2 - 3 } & $\mathbf{p H} \mathbf{4 , 0 2}$ & $\mathbf{p H} \mathbf{4 , 0 2}$ \\
\cline { 2 - 3 } NF & $3,3 \pm 0,1$ & $3,3 \pm 0,2 / \alpha n_{\text {médio }}=0,96^{b}$ \\
NFS & $3,3 \pm 0,2$ & $3,3 \pm 0,2 / \alpha n_{\text {médio }}=0,80^{b}$ \\
NT & $3,3 \pm 0,2$ & $3,3 \pm 0,2 / \alpha n_{\text {médio }}=0,80^{b}$ \\
NTS & $3,2 \pm 0,2$ & $3,2 \pm 0,2 / \alpha n_{\text {médio }}=0,80^{b}$ \\
\hline \hline
\end{tabular}

(*)-Equações de reta obtidas da Figura 12, página 43, a - valores médios a partir de 3 medidas; b - valores médios entre as velocidades de varredura de $0,01 \mathrm{~V} / \mathrm{s} \leq \mathrm{v} \leq 1,0 \mathrm{~V} / \mathrm{s}$

Tabela 5. Número de elétrons (n) para a redução de $0,5 \mathrm{mmol} / \mathrm{L}$ de $\mathrm{NF}$ e de seus análogos de NF e seus análogos em pH 4,02 e 7,41 usando ECV e a Equação de Cottrell.

\begin{tabular}{|c|c|c|c|c|}
\hline \multirow[b]{2}{*}{ Composto } & \multicolumn{2}{|c|}{ pH 4,02 } & \multicolumn{2}{|c|}{ pH 7,41 } \\
\hline & n (no. elétrons) ${ }^{a}$ & Eq. Cotrell ${ }^{b}$ & $\begin{array}{l}\text { n (no. } \\
\text { elétrons) }\end{array}$ & Eq. Cotrell ${ }^{c}$ \\
\hline NF & $3,4 \pm 0,2$ & $\begin{array}{c}\mathrm{Id}=-0,68 \mu \mathrm{A}-6,9 \\
\times\left(10^{-6}\right) \mathrm{t}^{1 / 2}\end{array}$ & $3,6 \pm 0,2$ & $\begin{aligned} \mathrm{Id}= & -0,14 \mu \mathrm{A}-7,9 \\
& \times\left(10^{-6}\right) \mathrm{t}^{1 / 2}\end{aligned}$ \\
\hline NFS & $3,6 \pm 0,1$ & $\begin{array}{c}\text { Id }=-0,27 \mu \mathrm{A}-8,4 \\
\times\left(10^{-6}\right) \mathrm{t}^{1 / 2}\end{array}$ & $3,5 \pm 0,2$ & $\begin{aligned} \mathrm{Id}= & -0,15 \mu \mathrm{A}-7,8 \\
& \times\left(10^{-6}\right) \mathrm{t}^{1 / 2}\end{aligned}$ \\
\hline NT & $3,4 \pm 0,2$ & $\begin{array}{l}\mathrm{Id}=-0,24 \mu \mathrm{A}- \\
\quad 8,7 \times\left(10^{-6}\right) \mathrm{t}^{1 / 2}\end{array}$ & $3,9 \pm 0,1$ & $\begin{aligned} \mathrm{Id}= & -0,14 \mu \mathrm{A}-7,9 \\
& x\left(10^{-6}\right) \mathrm{t}^{1 / 2}\end{aligned}$ \\
\hline NTS & $3,8 \pm 0,2$ & $\begin{aligned} I d= & -0,15 \mu A-8,2 \\
& x\left(10^{-6}\right) t^{1 / 2}\end{aligned}$ & $4,0 \pm 0,2$ & $\begin{aligned} \mathrm{Id}= & -0,15 \mu \mathrm{A}-8,3 \\
& x\left(10^{-6}\right) \mathrm{t}^{1 / 2}\end{aligned}$ \\
\hline
\end{tabular}

a - valores médios a partir de 5 medidas; $b$ - eqs. de reta correspondentes às curvas da Fig. 15; $R^{2}=0,987$ e relacionado a uma determinada medida; $c$ - eqs. de reta correspondentes às curvas da Fig. $16 ; R^{2}=0,991$ e relacionado a uma determinada medida 


\subsubsection{Efeito do polimento no ECV}

Os ECV usados em eletroquímica são geralmente submetidos a tratamento prévio com a finalidade de produzir uma resposta interfacial de forma reprodutível. Existe uma variedade de procedimentos de pré-tratamento tais como polimento mecânico, tratamentos térmico e eletroquímico, ativação a laser, radiofreqüência de plasma, aplicação de ultrassom (VETTORAZZI et al., 1998). Entretanto, não existe um padrão de procedimento de pré-tratamento e a escolha dá-se através de observações empíricas ou baseadas na prática em uso (VETTORAZZI et al., 1998; ZHANG \& COURY, 1993).

Baseado em estudos anteriores (LA-SCALEA et al., 2005; 2009) aplicou-se estudo comparativo do efeito do polimento mecânico utilizando-se suspensões de diamante e alumina com granulometria de $1 \mu \mathrm{m}$. É importante mencionar que nos estudos iniciais deste trabalho, o procedimento de pré-tratamento do ECV incluía o emprego do ultrassom após polimento da superfície com alumina. O uso do ultrassom tinha como intuito aumentar a eficiência na retirada de resíduos de alumina que poderiam permanecer adsorvidos na superfície do ECV, evitando eventuais interferências no processo de redução dos compostos (LA-SCALEA et al., 2005). Todavia, o uso continuado do ultrassom provocou deterioração física do ECV promovendo variações nos resultados voltamétricos encontrados. Com isto, o emprego do ultrassom foi abandonado e estudo comparativo foi realizado entre polimento com diamante e alumina na busca do melhor procedimento para o prétratamento da superfície do ECV.

\subsubsection{Estudo do efeito do $\mathrm{pH}$ no comportamento voltamétrico de NF e de seus bioisósteros}

Os resultados destes efeitos sobre os potenciais de redução em função do $\mathrm{pH}$, no intervalo de $2,10 \leq \mathrm{pH} \leq 12,02$, são apresentados na Figura 17. Utilizando-se polimento com suspensão de diamante observou-se comportamento semelhante para todos os compostos, no qual único pico catódico irreversível foi registrado em meio ácido. Além disso, o potencial de pico correspondente $\left(E_{, p p 1}\right)$ foi deslocado linearmente para valores mais negativos com aumento do $\mathrm{pH}$. Este comportamento é claro indicativo da existência de equilíbrio ácido-base no mecanismo de redução, 
indicando a participação de íons $\mathrm{H}^{+}$em etapa anterior ao processo de transferência de carga. Como já mencionado em discussão anterior, estes picos referem-se à formação do derivado hidroxilamínico em meio ácido (equação 6), precedido pelo equilíbrio descrito a seguir:

$$
\mathrm{R}-\mathrm{NO}_{2}+\mathrm{H}^{+}=\mathrm{R}-\mathrm{NO}_{2} \mathrm{H}^{+}
$$

A partir de $\mathrm{pH} 7,41$ processo distinto pode ser observado, no qual surge um pico a potencial mais positivo $(\sim-0,50 \mathrm{~V})$, além dos valores de $\mathrm{Ec}_{\mathrm{p} \text {, } 1}$ manterem-se constantes em meio alcalino. $O$ desdobramento deste pico em meio alcalino é atribuído à geração do nitro radical. Pode-se afirmar, portanto, que nestas condições todos os análogos apresentaram mecanismos de protonação semelhantes, no qual o aumento do $\mathrm{pH}$ provocou maior distanciamento entre os valores de Ec, ${ }_{\mathrm{p} 1}$ e Ec, $\mathrm{p}_{\mathrm{p} 2 \mathrm{R}}$, correspondente ao novo pico registrado. Desta forma, pode-se concluir que a ausência de prótons em solução dificultou a formação do derivado hidroxilamínico e simultaneamente, favoreceu a estabilização do nitro radical. Vale destacar que os valores de $\mathrm{Ec}_{\mathrm{p} 2 \mathrm{R}}$ não sofreram variação com o aumento do $\mathrm{pH}$.

Utilizando-se polimento com alumina os compostos apresentaram comportamento similar aquele observado em meio ácido. Entretanto, em estudo com NF aplicando-se alumina, a variação de $\mathrm{Ec}_{, \mathrm{p} 1}$ em função do $\mathrm{pH}$ apresentou duas faixas lineares, sendo a segunda faixa linear apenas registrada a partir de pH 8,0. Em oposição, os análogos com átomos de enxofre não apresentaram diferenças significativas no comportamento voltamétrico associadas aos processos de polimento aplicados. 

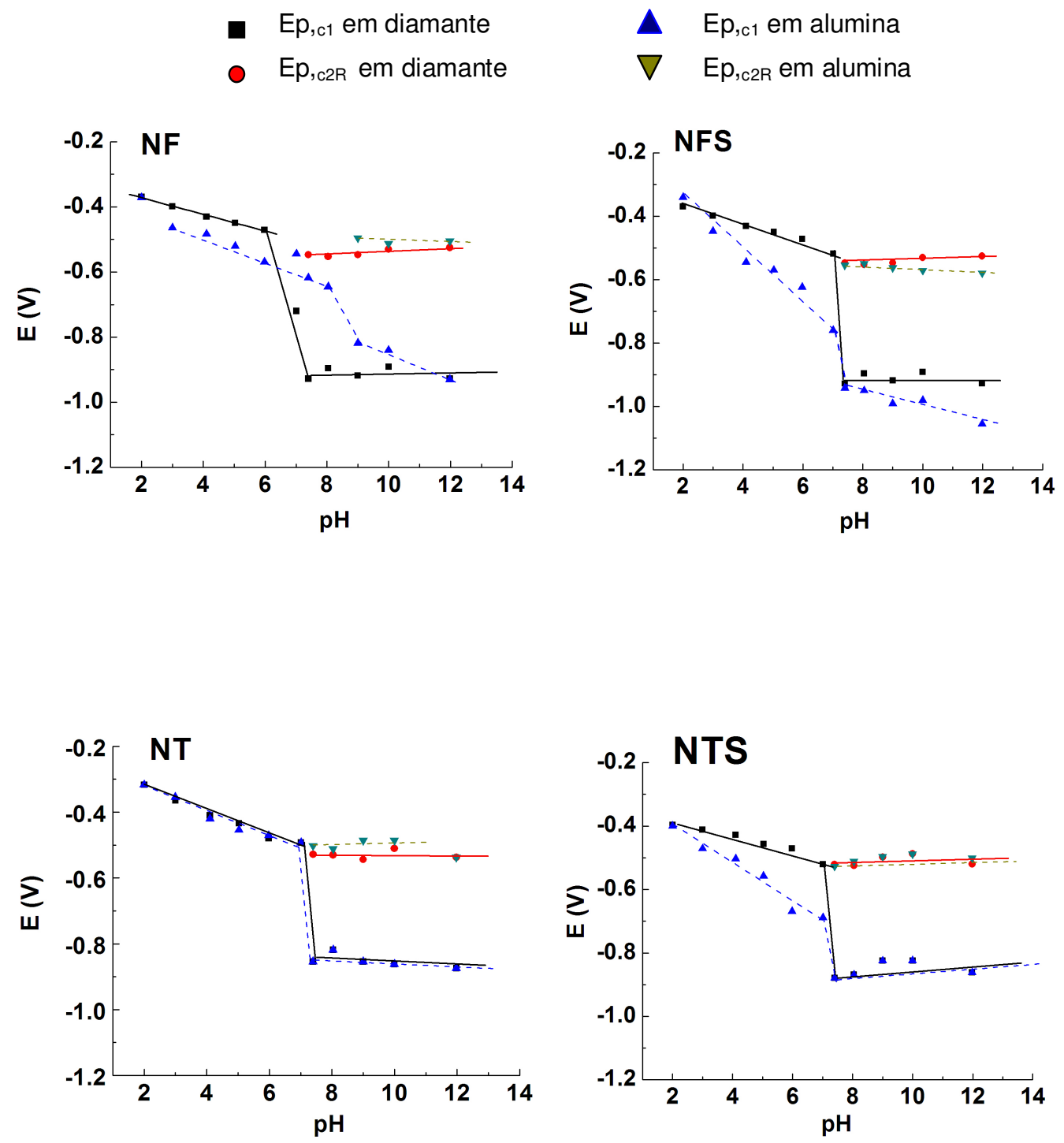

Figura 17- Variação dos potenciais de pico catódico $\left(\mathrm{Ec}_{, \mathrm{p} 1}\right.$ e $\left.\mathrm{Ec}_{, \mathrm{p} 2}\right)$ vs $\mathrm{pH}$ usando eletrodo de carbono vítreo como eletrodo de trabalho, variando-se o procedimento de polimento [Composto] $=0,5 \mathrm{mmol} / \mathrm{L}, \mathrm{v}=0,10 \mathrm{~V} / \mathrm{s}$. 
A Tabela 6 apresenta os resultados de regressão linear para as faixas lineares de $\mathrm{pH}$ obtidas para NF e análogos. Comparando-se os resultados obtidos para cada procedimento de polimento, pode-se constatar que o mecanismo de protonação foi semelhante para todos os análogos. Já a comparação entre os procedimentos de polimento mostrou ligeira diferença entre os valores de inclinação de reta, nos quais com aplicação de alumina maiores valores foram registrados.

Tabela 6. Equações das retas obtidas a partir das regiões lineares do gráfico Ec,p1 vs. $\mathrm{pH}$. [Composto] $=0,5 \mathrm{mmol} / \mathrm{L}, \mathrm{v}=0,1 \mathrm{~V} / \mathrm{s}$.

\begin{tabular}{|c|c|c|}
\hline & Spray de Diamante & Alumina \\
\hline Composto & Equação da reta & Equação da reta \\
\hline NF & $\begin{array}{c}E c_{, p 1}=-0,293-0,033 p H \\
R=0,990\left({ }^{a}\right)\end{array}$ & $\begin{array}{c}E c_{, p 1}=-0,390-0,039 p H \\
R=0,970\left({ }^{c}\right)\end{array}$ \\
\hline NFS & $\begin{array}{c}E c, p 1=-0,293-0,033 p H \\
R=0,993\left({ }^{b}\right)\end{array}$ & $\begin{array}{c}E c, p 1=-0,202-0,076 p H \\
R=0,983\left({ }^{b}\right)\end{array}$ \\
\hline NT & $\begin{array}{c}\mathrm{Ec}_{\mathrm{p} p 1}=-0,254-0,036 \mathrm{pH} \\
\mathrm{R}=0,991\left(^{\mathrm{b}}\right)\end{array}$ & $\begin{array}{c}E c, p 1=-0,254-0,036 p H \\
R=0,980\left({ }^{b}\right)\end{array}$ \\
\hline NTS & $\begin{array}{c}E c, p 1=-0,278-0,040 p H \\
R=0,986\left({ }^{b}\right)\end{array}$ & $\begin{array}{c}E c, p 1=-0,278-0,060 p H \\
R=0,982\left({ }^{b}\right)\end{array}$ \\
\hline
\end{tabular}

a - faixa de pH de 2,0 a 6,0; b - faixa de $\mathrm{pH}$ de 2,0 a 7,0; c - faixa de $\mathrm{pH}$ de 2,0 a 8,0

Hipótese provável para estas diferenças pode ser atribuída à possível permanência de alumina na superfície do ECV, pois devido às suas propriedades ácido-base o processo de protonação pode ter sido facilitado. Exemplo mais nítido pode ser notado com NF que apresentou respectiva faixa linear mais ampla. Além disso, o polimento com suspensão de diamante pode ter contribuído de forma um pouco mais eficiente para a formação de uma interface eletrodo-solução mais hidrofóbica, favorecendo a geração do nitro-anion radical em solução aquosa. De qualquer forma, estes resultados mostram que os dois procedimentos são eficientes para o tratamento da superfície do ECV.

Além disso, essas diferenças observadas não permitem afirmar que as 
modificações moleculares efetuadas a partir do NF introduziram alterações no comportamento voltamétrico de seus bioisósteros.

Quanto ao primeiro pico anódico, Ea,p1, este foi observado em toda faixa de $\mathrm{pH}$ estudada. Seu potencial variou para valores menos positivos com o aumento do $\mathrm{pH}$, facilitando o processo de oxidação, Figura 18. Entretanto, nenhuma alteração de comportamento foi registrada envolvendo os dois procedimentos de polimento. A Tabela 7 apresenta as respectivas equações de reta correspondentes ao $(E a, p 1)$ de NF e de seus derivados.
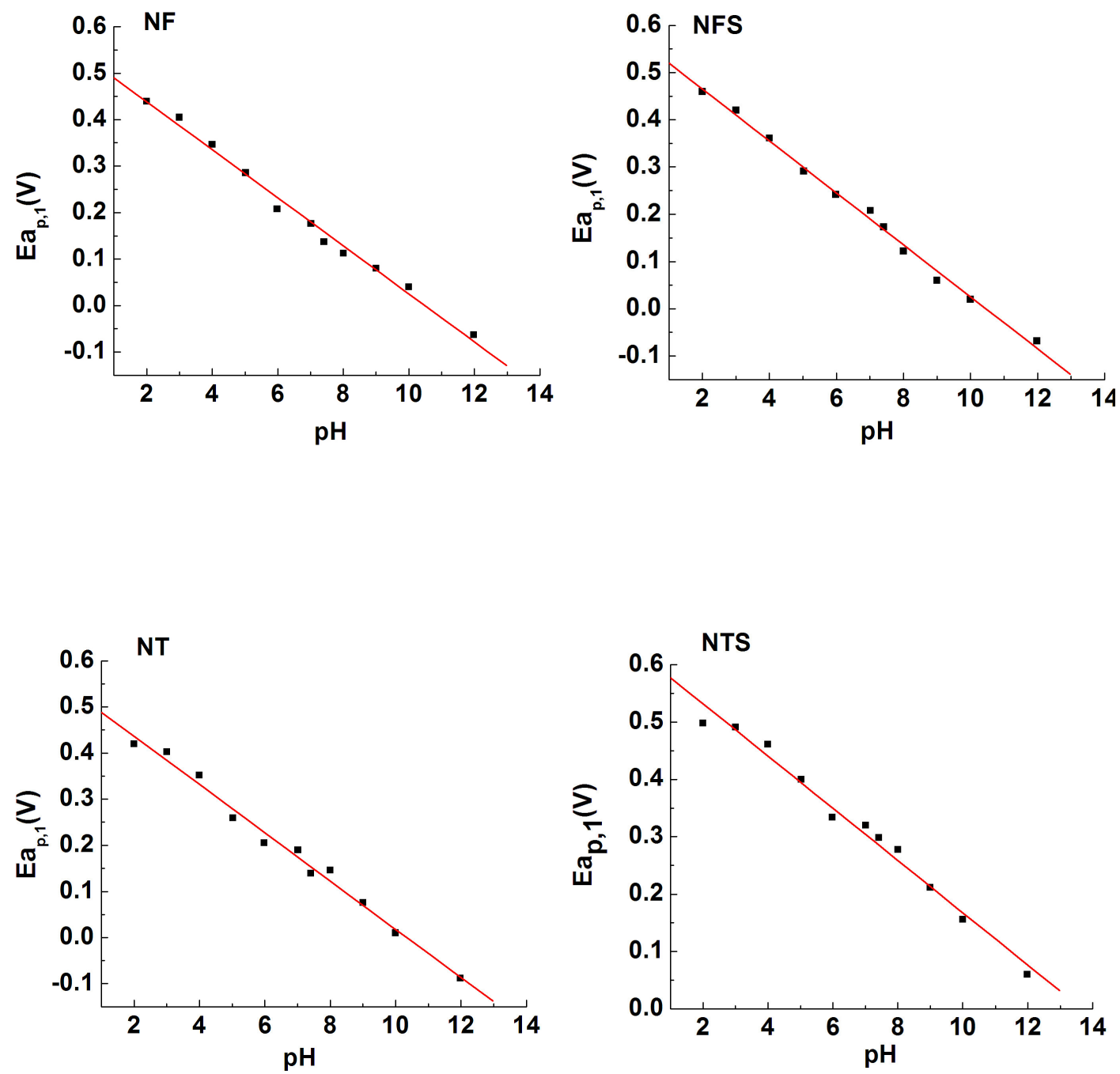

Figura 18- Variação dos potenciais do primeiro pico anódico $\left(\mathrm{Ea}_{\mathrm{p} 1}\right)$ vs $\mathrm{pH}$. Dados obtidos usando ECV a $v=0,10 \mathrm{~V} / \mathrm{s}$, [Composto] $=0,5 \mathrm{mmol} / \mathrm{L}$. 
Tabela 7. Equações das retas obtidas a partir do gráfico $E a_{p, 1}$ vs. pH . Dados obtidos em ECV e concentração de $0,5 \mathrm{mmol} / \mathrm{L}$.

\begin{tabular}{c|c|c|c}
\hline Composto & Faixa de pH & Equação da reta & $\mathbf{R}^{\mathbf{2}}$ \\
\hline NF & 2,0 a 12,0 & $\mathrm{Ea}_{\mathrm{p}, 1}(\mathrm{mV})=0,548-0,053 \mathrm{pH}$ & 0,994 \\
NFS & 2,0 a 12,0 & $\mathrm{Ea}_{\mathrm{p}, 1}(\mathrm{mV})=0,575-0,055 \mathrm{pH}$ & 0,997 \\
NT & 2,0 a 12,0 & $\mathrm{Ea}_{\mathrm{p}, 1}(\mathrm{mV})=0,541-0,052 \mathrm{pH}$ & 0,994 \\
NTS & 2,0 a 12,0 & $\mathrm{Ea}_{\mathrm{p}, 1}(\mathrm{mV})=0,623-0,046 \mathrm{pH}$ & 0,992 \\
\hline
\end{tabular}

A partir dos valores de inclinação da reta, nota-se que a variação de $\Delta \mathrm{Ea}_{, \mathrm{p} 1} / \Delta \mathrm{pH}$ indica que praticamente o número de prótons envolvidos no processo é igual ao número de elétrons. Estas observações corroboram a hipótese que o pico registrado em Ea,p1 é atribuído à oxidação da hidroxilamina (equação do respectivo derivado nitroso reação 8), na qual se tem o envolvimento de 2 prótons e 2 elétrons.

\subsection{Geração do nitro radical ânion $\left(\mathrm{R}-\mathrm{NO}_{2} / \mathrm{R}-\mathrm{NO}_{2}{ }^{-}\right)$em meio aquoso}

De forma complementar à discussão anterior e como já descrito inicialmente, os voltamogramas cíclicos registrados para NFS, NT e NTS em pH 7,01 apresentaram comportamento voltamétrico semelhante aos obtidos no intervalo de $2,10 \leq \mathrm{pH} \leq 6,04$, com registro de única onda de redução $\left(E c_{p, 1}\right)$ irreversível e um pico de oxidação $(E a, p 1)$, aplicando-se polimento com suspensão de diamante. No entanto, com este mesmo tratamento e em $\mathrm{pH}=7,01$, NF foi único que apresentou um outro pico de redução (Ec,p2R) com respectivo componente anódico (Ea,p3R). Na Figura 19 são apresentados os voltamogramas de NF e seus análogos em pH 7,01.

Como já observado, em meio alcalino registrou-se o aparecimento de um segundo pico de redução $\left(\mathrm{Ec}_{\mathrm{p}, \mathrm{p} 2 \mathrm{R}}\right)$ para os bioisósteros do NF em torno da mesma 
faixa de potencial $(\sim-0,50 \mathrm{~V})$ com respectivo componente anódico $\left(\mathrm{Ea}_{\mathrm{a}, \mathrm{p} \mathrm{R}}=\sim-0,41 \mathrm{~V}\right)$, conforme pode ser observado na Figura 20. Destaca-se que os picos atribuídos a $\mathrm{Ea}_{, \mathrm{p} 1}, \mathrm{Ec}_{, \mathrm{p} 1}$ e Ea,p2 referem-se aos mesmos picos já observados e descritos em meio ácido. Segundo dados da literatura, o par $\mathrm{Ec}_{, \mathrm{p} 2 \mathrm{R}}$ e $\mathrm{Ea}_{\mathrm{p}, \mathrm{R} R}$ pode ser atribuído ao equilíbrio do par redox $\mathrm{R}-\mathrm{NO}_{2} / \mathrm{R}-\mathrm{NO}_{2}{ }^{\bullet-}$, conforme já foi mostrado pela reação 1 (LASCALEA et al., 2009):

$$
\mathrm{R}-\mathrm{NO}_{2}+\mathrm{e}^{-} \rightleftharpoons \mathrm{R}-\mathrm{NO}_{2}^{\bullet-}
$$



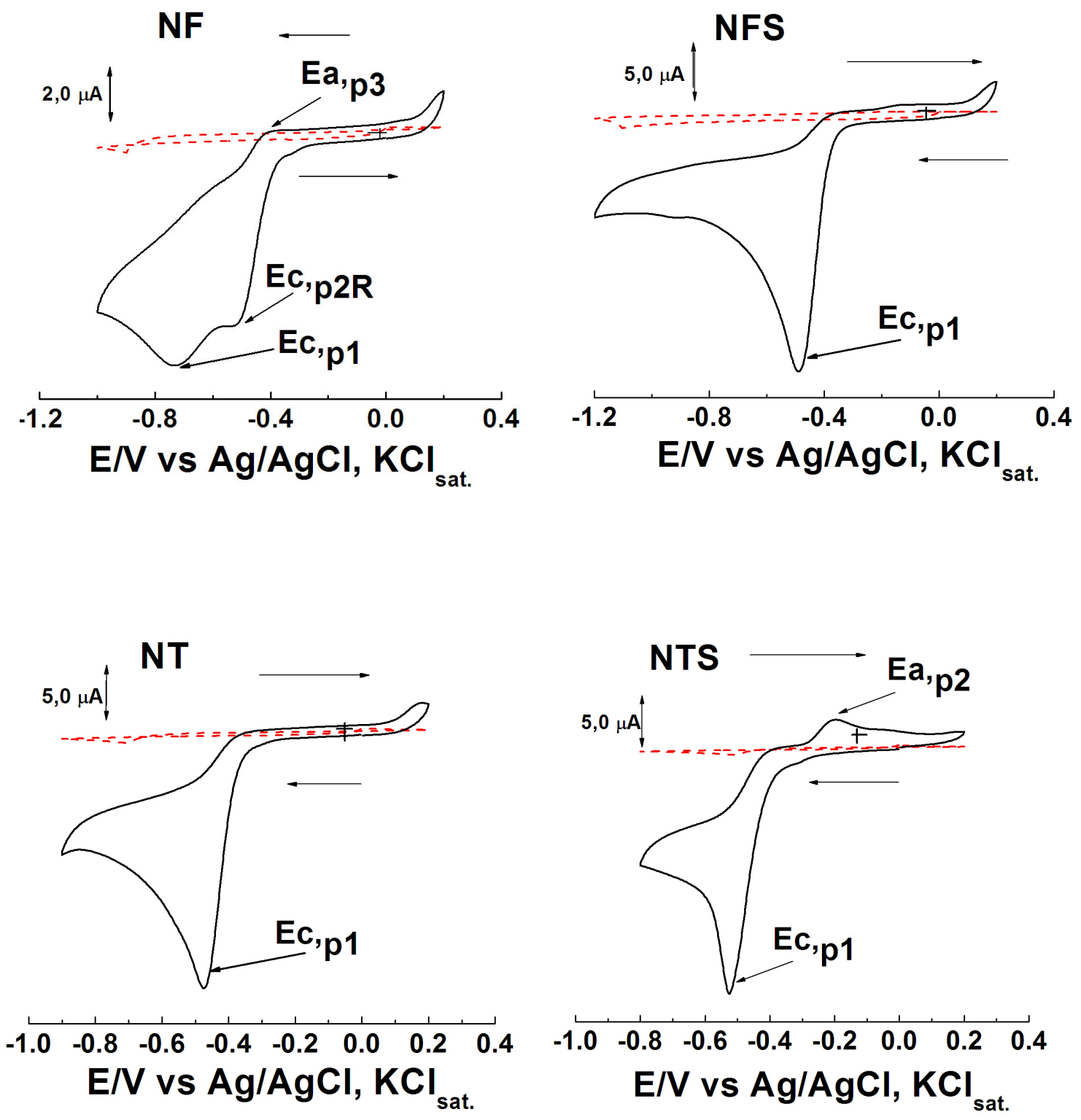

Figura 19- Voltamogramas cíclicos obtidos em pH 7,01 usando eletrodo de carbono vítreo. [Composto] $=0,5 \mathrm{mmol} / \mathrm{L}, v=0,1 \mathrm{~V} / \mathrm{s}$. Condições experimentais:
$E_{\text {inicial }}=0,0 \mathrm{~V}$,
$E_{\lambda 1}=$
$-1,2 \mathrm{~V}<\mathrm{E}_{\lambda}<-0,80 \mathrm{~V}$
$\mathrm{E}_{\lambda 2}=$
$+0,2 \mathrm{~V}$;
$\mathrm{E}_{\text {final }}=0,0 \mathrm{~V}$. 

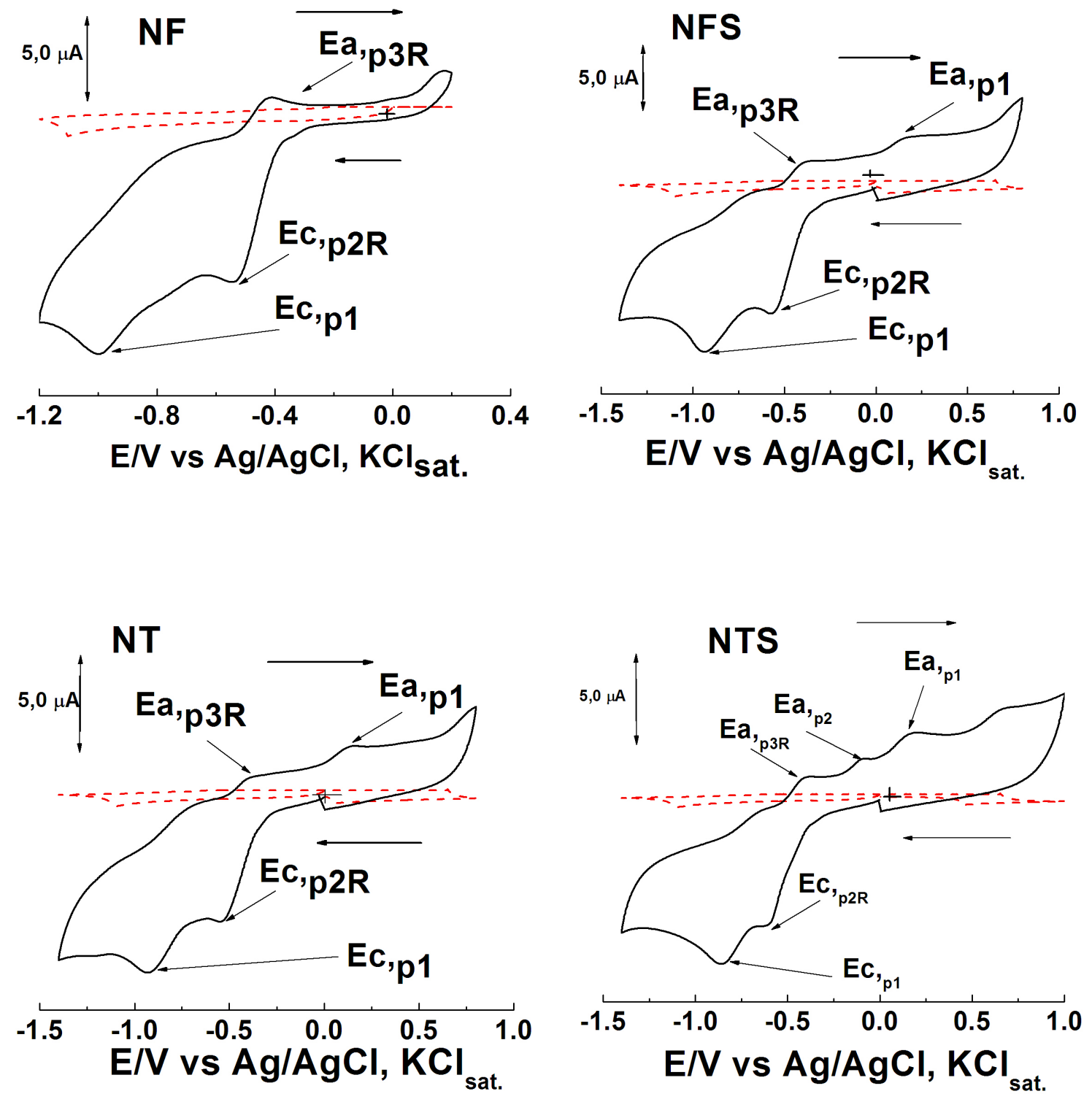

Figura 20- Voltamogramas cíclicos obtidos em $\mathrm{pH} 7,41$ usando eletrodo de carbono vítreo. [Composto] $=0,5 \mathrm{mmol} / \mathrm{L}, v=0,1 \mathrm{~V} / \mathrm{s}$. Condições experimentais:

$$
\begin{aligned}
& \mathrm{E}_{\text {inicial }}=0,0 \mathrm{~V}, \quad \mathrm{E}_{\lambda 1}=\quad-1,2 \mathrm{~V}<\mathrm{E}_{\lambda}<-1,5 \mathrm{~V} \quad, \quad \mathrm{E}_{\lambda 2}=\quad+1,0 \mathrm{~V} ; \\
& \mathrm{E}_{\text {final }}=0,0 \mathrm{~V} .
\end{aligned}
$$




\subsubsection{Aplicação dos critérios de reversibilidade}

Como já observado no decorrer deste trabalho, registrou-se em meio alcalino o aparecimento do pico de redução $\left(\mathrm{Ec}_{\mathrm{c}, \mathrm{p} 2 \mathrm{R}}\right)$ para NF e seus bioisósteros em torno da mesma faixa de potencial $(\sim-0,50 \mathrm{~V})$ com respectivo componente anódico $(E a, p 3 R=\sim-0,42 V)$. Nesta condição experimental e, segundo dados relatados da literatura, o pico de redução $\mathrm{Ec}, \mathrm{p} 2 \mathrm{R}$ refere-se à redução reversível do grupo nitro ao nitro radical, com envolvimento de um elétron (CARBAJO et al., 2002; LA-SCALEA et al., 2005).

Portanto, complementando os dados já obtidos para a caracterização do comportamento voltamétrico de NF e de seus análogos e na tentativa de dirimir qualquer dúvida quanto à geração e estabilização do nitro radical em meio aquoso. Para tanto, no estudo isolado desse par redox, registraram-se voltamogramas cíclicos ajustados numa janela de potencial apropriada $\left(-0,2 \mathrm{~V} \leq \mathrm{E} \mathrm{c}_{\mathrm{p}, 2 \mathrm{R}} \leq-0,7 \mathrm{~V}\right)$ em meio suficientemente alcalino e concentração de $0,5 \mathrm{mmol} \mathrm{L}^{-1}$ para $\mathrm{NF}$ e seus análogos.

Com a intenção de se avaliar a reversibilidade do par redox $\mathrm{R}-\mathrm{NO}_{2} / \mathrm{R}-\mathrm{NO}_{2}{ }^{\bullet-}$ empregou-se dois critérios eletroquímicos que foram a variação dos potenciais de pico de redução $(\mathrm{Ec}$, p2R $)$ e de oxidação $(\mathrm{Ea}, \mathrm{p3R})$ em função da velocidade de varredura $\left(100 \leq v \leq 1000 \mathrm{mV} \mathrm{s}^{-1}\right)$ bem como as diferenças entre os seus respectivos potenciais. A Figura 21 mostra os voltamogramas cíclicos registrados em pH 10,01 nestas condições. É válido destacar que os voltamogramas apresentam-se bem resolvidos e foram obtidos depois de duas varreduras consecutivas.

Nota-se que o pico de redução e o correspondente de oxidação não se deslocaram significativamente com aumento da velocidade de varredura indicando que o processo apresenta caráter reversível. De acordo com a literatura (BROWN \& SANDIFER, 1986) para sistemas semi-reversíveis o valor da diferença de potencial $\left(\Delta E_{p}\right)$ pode variar de $120 / n$ a $60 / n$ mV então, segundo este parâmetro, como esta diferença encontra-se em aproximadamente $90 \mathrm{mV}$, sugerem-se processo monoeletrônico para o referido par redox, Figura 22. 

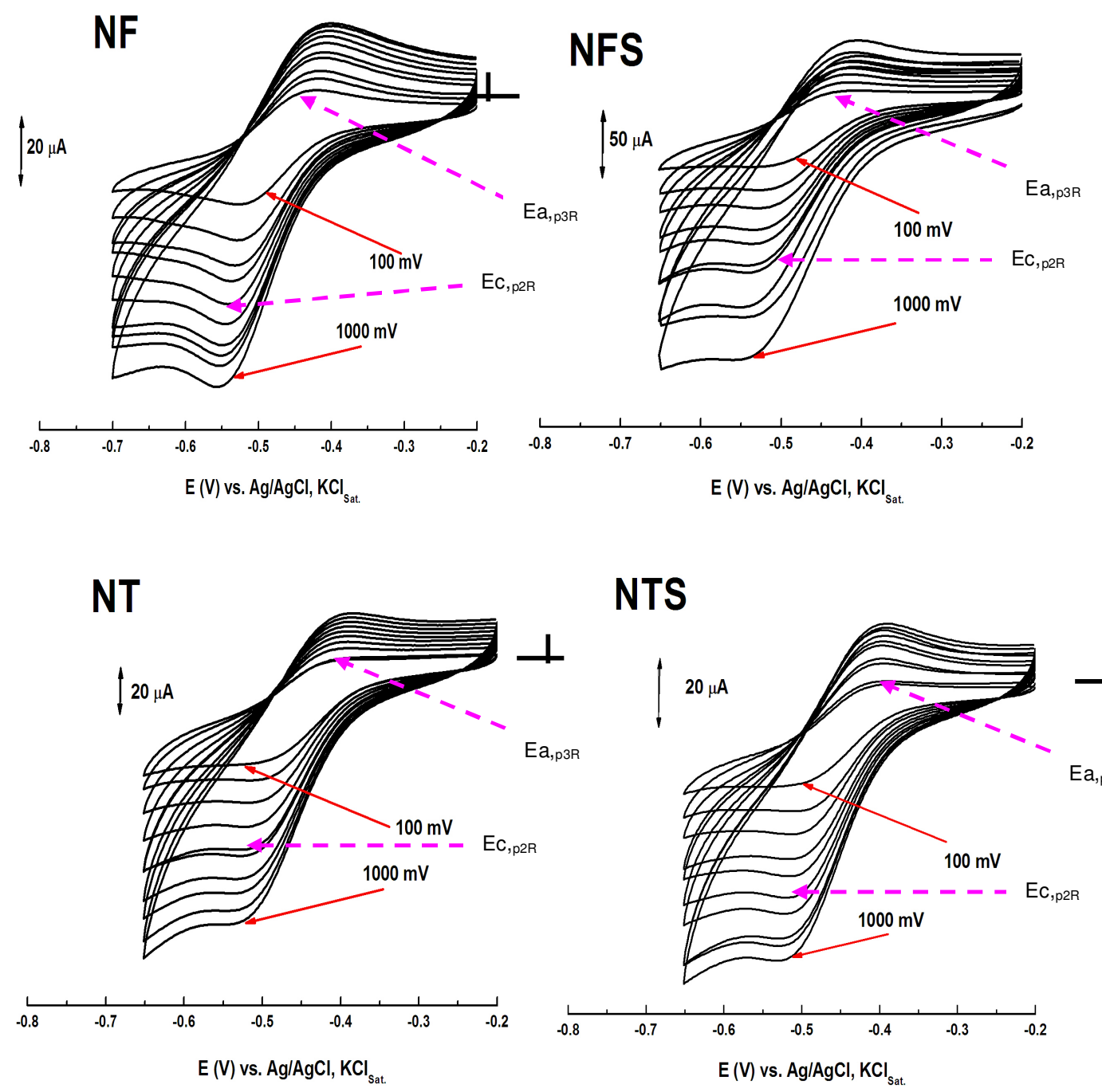

\section{NTS}

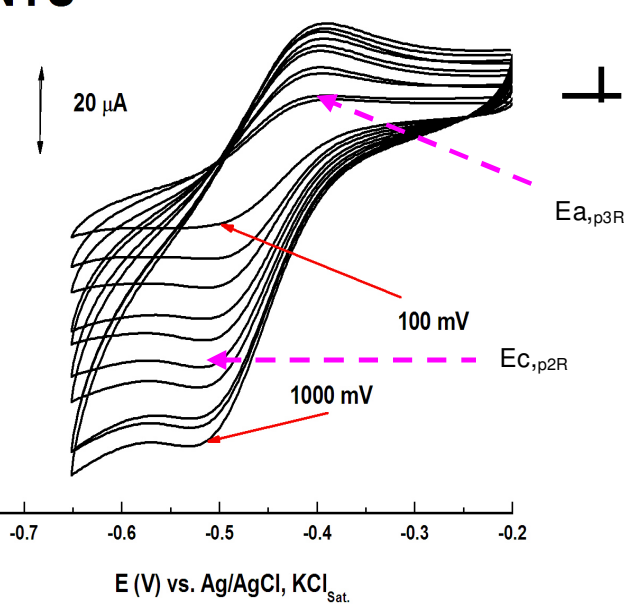

Figura 21- Voltamogramas cíclicos obtidos em pH 10,01 usando eletrodo de carbono vítreo, spray de diamante para polimento. [Composto] $=0,5$ $\mathrm{mmol} / \mathrm{L}$. Condições experimentais: $E_{\text {inicial }}=-0,2 \mathrm{~V},-0,60 \mathrm{~V}<\mathrm{E}_{\lambda}<-0,70 \mathrm{~V}$, $E_{\text {final }}=-0,2$ V. Intervalo de $100 \leq v \leq 1000 \mathrm{mV} \mathrm{s}^{-1}$. Área do $\mathrm{ECV}=0,035 \pm 0,004 \mathrm{~cm}^{2}$. 

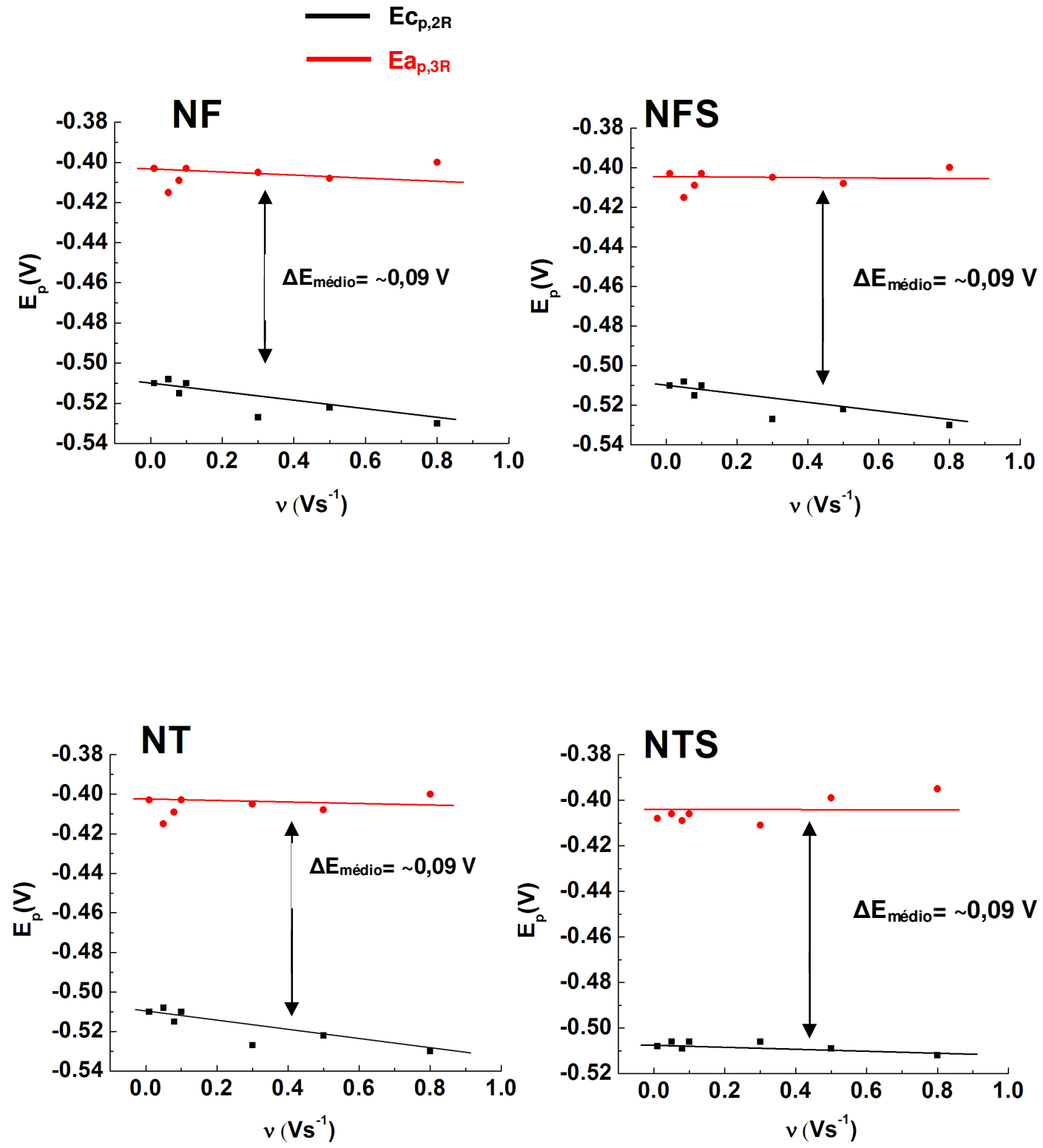

Figura 22- Variação de Ec,p2R e Ea,p3R em pH 10,01 como função de v, usando eletrodo de carbono vítreo, [Composto]=0,5mmol/L. 
Observou-se que as funções de corrente referentes ao pico catódico do radical $\left(\mathrm{Ic}_{\mathrm{p}, 2 \mathrm{R}} / \mathrm{Cv}^{1 / 2}\right)$ mostraram-se independentes da velocidade de varredura para todos os derivados, registrando-se valores constantes e próximos a $0,04 \mathrm{~A} \mathrm{~mol}^{-1} \mathrm{LV}^{1 / 2} \mathrm{~s}^{1 / 2}$ (Figura 23). Este comportamento indica que os processos de adsorção não interferem na redução do par $\mathrm{R}-\mathrm{NO}_{2} / \mathrm{R}-\mathrm{NO}_{2}{ }^{\bullet}$ - sobre a superfície do ECV, diferindo-se de resultados encontrados na literatura para compostos nitroderivados pertencentes à classe de antagonistas de canais de cálcio (nimodipino e nitrendipino), no qual o fenômeno de adsorção foi observado (NUÑEZVERGARA et al., 1993; SQUELLA et al.,1991).
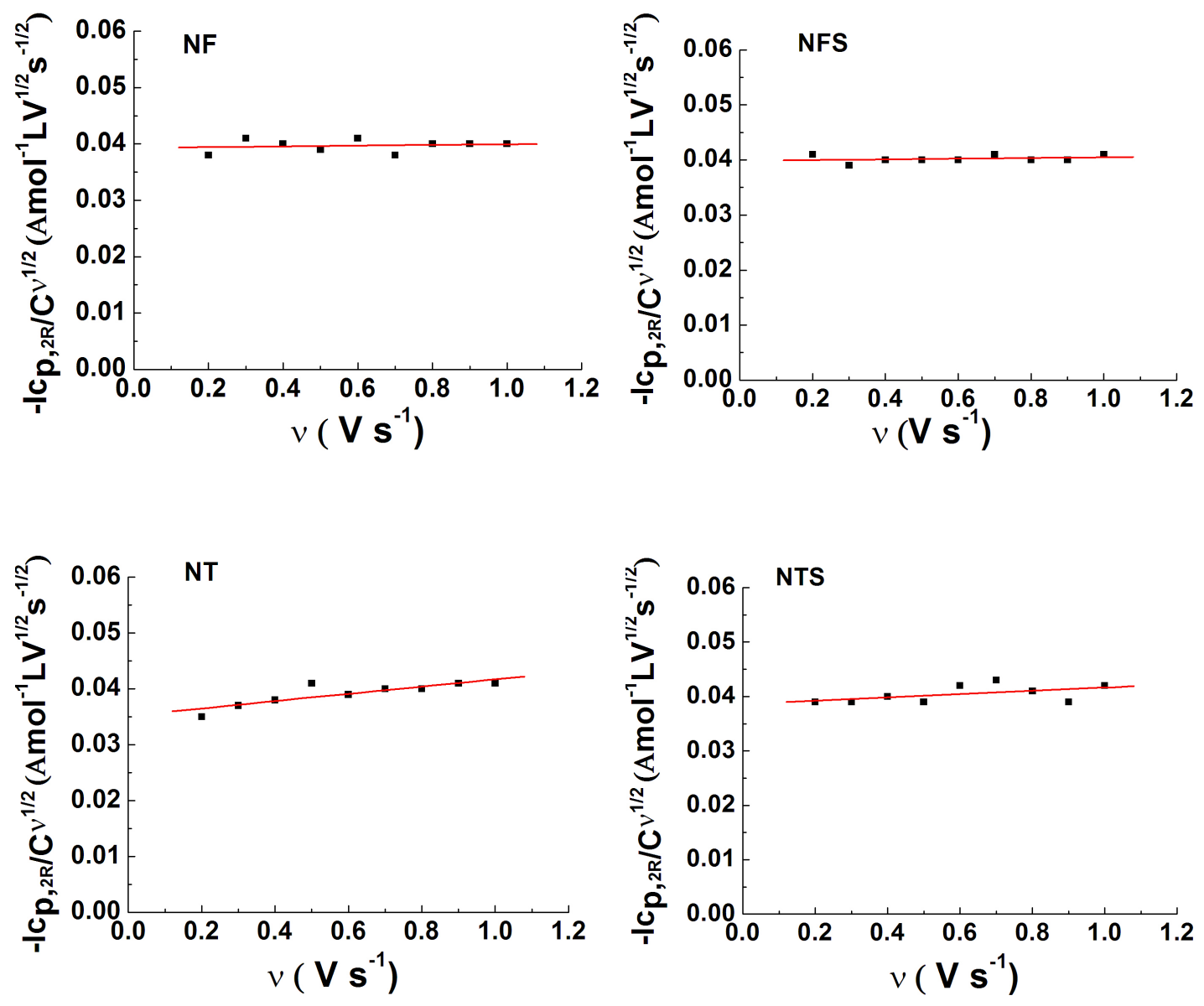

Figura 23- Variação de $\mathrm{Ic}, \mathrm{p}_{\mathrm{R}} / \mathrm{C} v^{1 / 2}$ (função de corrente) como função de $v$. Dados obtidos dos voltamogramas mostrados na Figura 21. 


\subsubsection{Estimativa do número de elétrons envolvidos na redução voltamétrica do nitro radical ânionico $\left(\mathrm{R}-\mathrm{NO}_{2} / \mathrm{R}-\mathrm{NO}_{2}{ }^{-}\right)$de $\mathrm{NF}$ e seus análogos}

Registros da literatura (MANDAL, 2004; JULIÃO et al., 2005; LA-SCALEA et al.,2009) mostram que em meio aquoso-alcalino, e com emprego de tampão BrittonRobinson, o mecanismo de redução do grupo nitro para o primeiro pico de redução indica a formação do derivado nitro radical.

Diante do exposto, determinou-se o número de elétrons (n) envolvidos em meio alcalino, pH 10,0, correspondente ao pico de redução (Ec,p2R) empregando-se VC em diversas velocidades de varredura e mantendo-se constante a concentração da espécie eletroativa. Da inclinação da reta dos gráficos $\mathrm{IC} \mathrm{c}_{\mathrm{p} 2 \mathrm{R}}$ em função de $v^{1 / 2}$ (Figura 24) calculou-se o número de elétrons envolvidos por meio da equação de Randles-Sevick, Tabela 8.
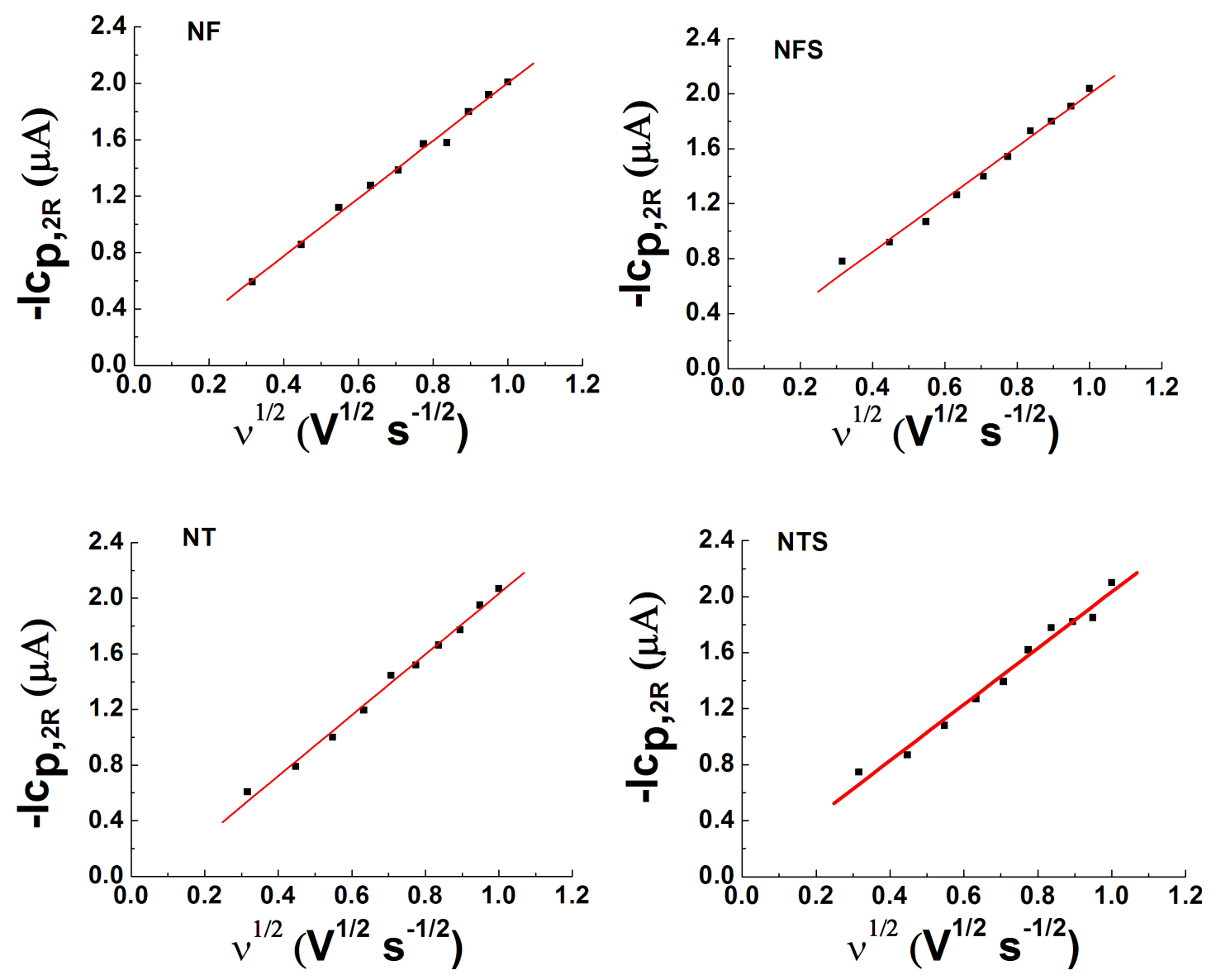

Figura 24- Variação de $\mathrm{lc}, \mathrm{p2R}$ em função de $v^{1 / 2}$. Dados obtidos a partir dos voltamogramas apresentados na Figura 21. [Composto]=0,5mmol/L. 
Tabela 8. Valores de coeficiente de difusão e do número de elétrons (n) dos compostos estudados, bem como as equações de reta em pH 10,01, referentes à redução do pico $\mathrm{Ec}, \mathrm{p} 2 \mathrm{R}$

\begin{tabular}{|c|c|c|c|}
\hline Composto & $D \times 10^{6}\left(\mathrm{~cm}^{2} / \mathrm{s}\right)$ & $n\left(\mathrm{n}\right.$. de elétrons) ${ }^{\mathrm{a}}$ & Eq. da reta ${ }^{b}$ \\
\hline NF & 7,76 & $1,1 \pm 0,1$ & $\begin{array}{c}-I p_{c}=0,043 V^{1 / 2} s^{-1 / 2}+2,047 \mu A \\
R^{2}=0,997\end{array}$ \\
\hline NFS & 7,50 & $1,0 \pm 0,2$ & $\begin{array}{c}-I p_{c}=0,084 V^{1 / 2} s^{-1 / 2}+1,925 \mu A \\
R^{2}=0,994\end{array}$ \\
\hline NT & 7,50 & $1,1 \pm 0,1$ & $\begin{array}{c}-I p_{c}=0,152 V^{1 / 2} s^{-1 / / 2}+2,186 \mu A \\
R^{2}=0,994\end{array}$ \\
\hline NTS & 7,26 & $1,1 \pm 0,1$ & $\begin{array}{c}-I p_{c}=0,024 V^{1 / 2} s^{-1 / 2}+2,010 \mu A \\
R^{2}=0,991\end{array}$ \\
\hline
\end{tabular}

a- valores médios a partir de 5 medidas.

b- equações de reta correspondentes às curvas da Figura 24 e relacionado a uma determinada medida

Portanto, os resultados obtidos mostram claramente que um elétron está envolvido no processo eletródico correspondente ao pico de redução de Ec,p2R, confirmando o processo de formação do nitro radical controlado por difusão. Os resultados obtidos estão de acordo com dados reportados na literatura para outros nitro-heterocíclicos (SQUELLA et al.,1991; NUÑEZ-VERGARA et al., 1993; SQUELLA et al.,1996 ; SQUELLA et al.,2005; LA-SCALEA et al.,2009).

\subsubsection{Avaliação dos parâmetros que podem influenciar as razões de corrente de NF e análogos}

Estudos por VC foram realizados a fim de se estabelecer os parâmetros que podem influenciar os resultados das razões de corrente $\left(\mathrm{l}_{\mathrm{p}, 3 \mathrm{R}} / \mathrm{l}_{\mathrm{p}, 2 \mathrm{R}}\right)$ que foram calculados conforme item 2.2.4.6.2. Este parâmetro voltamétrico é o mais utilizado para estudos eletroquímicos sobre a estabilização cinética do nitro radical 
(SQUELLA et al.,1991; VERGARA et al.,1993; CARBAJO et al.,2002; MANDAL et al., 2004; BOLLO et al.,2004; LA-SCALEA et al.,2009). Segundo dados reportados na literatura a razão de corrente apresenta dependência do $\mathrm{pH}$, sofre influência da velocidade de varredura e da concentração da espécie eletroativa (SYMONS et al., 1991 ; TOCHER \& EDWARDS, 1994; TOCHER, 1997; LA-SCALEA et al., 1998).

\subsubsection{Estudo do efeito do $\mathrm{pH}$}

Os estudos foram centralizados na estabilização do nitro radical em meio aquoso, considerando a faixa de $\mathrm{pH}$ entre 7,41 e 12,0. A mudança de $\mathrm{pH}$ afeta ligeiramente os voltamogramas cíclicos correspondentes ao par redox $\mathrm{R}-\mathrm{NO}_{2} / \mathrm{R}-\mathrm{NO}_{2}{ }^{\bullet}$. . A partir dos resultados apresentados na Figura 25, observa-se que os valores do potencial de pico catódico, Ec,p2R, foram pouco alterados com aumento do $\mathrm{pH}$. A Figura 26 mostra que a estabilidade do radical, avaliada por $\mathrm{la}_{\mathrm{p}, 3 \mathrm{R}} / \mathrm{lc}_{\mathrm{p}, 2 \mathrm{R}}$, para os bioisósteros apresenta perfis semelhantes, no qual entre $\mathrm{opH}$ 10,01 e 12,06, os valores de razão de corrente atingiram valor constante e próximos à unidade. Consequentemente pode-se deduzir que a estabilidade do nitro radical aumenta em meio alcalino devido à dificuldade do processo de protonação. Estes resultados são compatíveis com dados reportados na literatura (SYMONS et al., 1991; LA-SCALEA et al., 2009). Adicionalmente, segundo dados da literatura (ZUMAN et al., 1992) os valores de $\mathrm{la}_{\mathrm{p}, 3 \mathrm{R}} / \mathrm{l}_{\mathrm{p}, 2 \mathrm{R}} \neq 1$ podem indicar a ocorrência de uma reação química com o envolvimento de prótons anterior ao processo de transferência de carga, sugerindo a estabilização das espécies protonadas indicadas pelo par redox $\mathrm{R}-\mathrm{NO}_{2} \mathrm{H}^{+} / \mathrm{R}-\mathrm{NO}_{2} \mathrm{H}^{\bullet}$. 

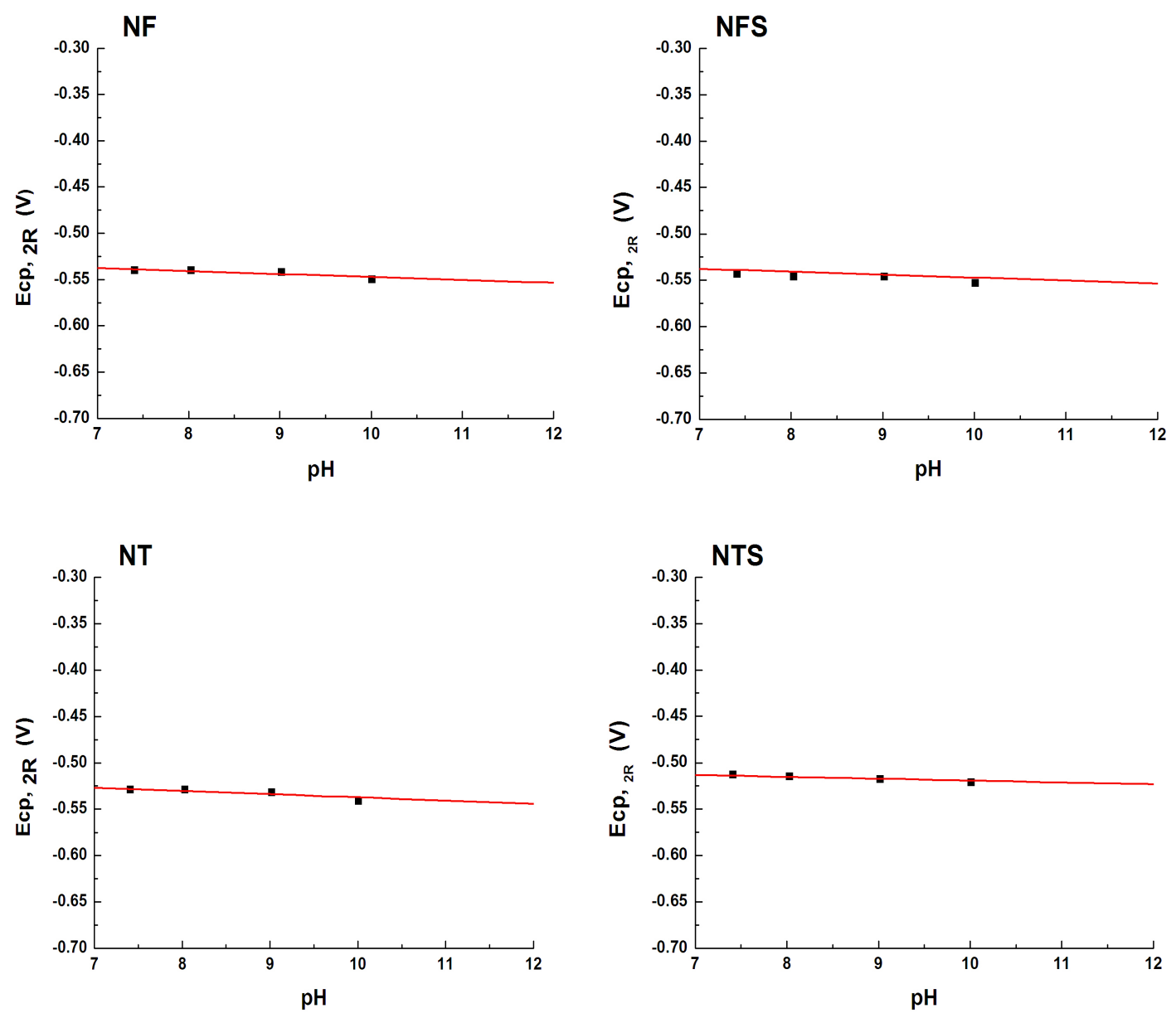

Figura 25- Efeito do $\mathrm{pH}$ nos valores de $\mathrm{Ec}, \mathrm{p} 2 \mathrm{R}$ para o par redox $\mathrm{R}-\mathrm{NO}_{2} / \mathrm{R}-\mathrm{NO}_{2}{ }^{\bullet-}$ gerado eletroquimicamente. [Composto] $=0,50 \mathrm{mmol} / \mathrm{L} ; \mathrm{v}=1,0 \mathrm{~V} \mathrm{~s}^{-1}$; $\mathrm{E}_{\lambda}=-0,7 \mathrm{~V}$.

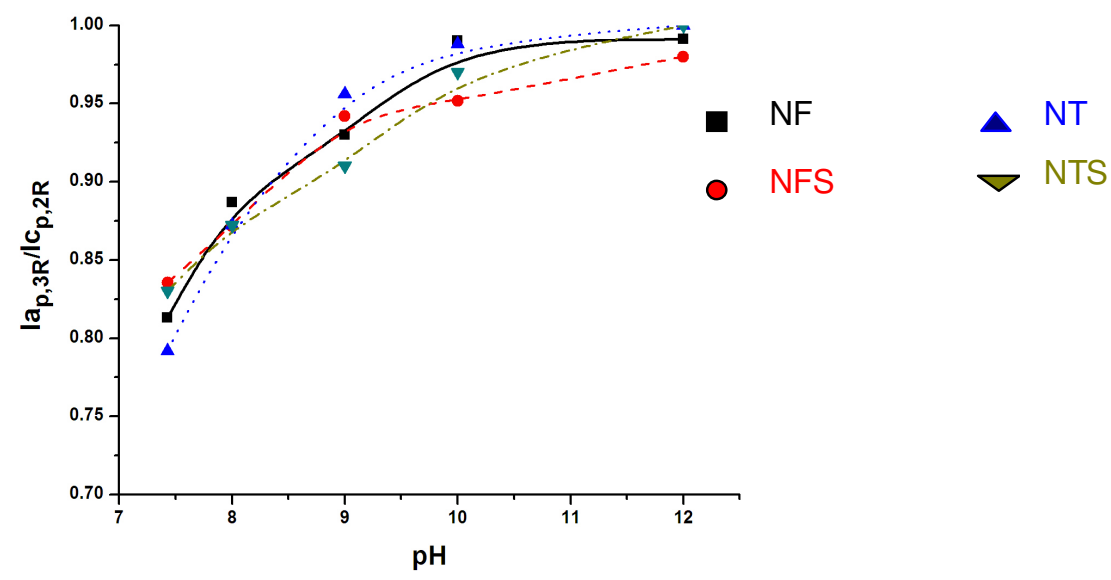

Figura 26- Efeito do $\mathrm{pH}$ nos valores de $\mathrm{la}_{\mathrm{p}, 3 \mathrm{R}} / \mathrm{ll}_{\mathrm{p}, 2 \mathrm{R}}$. [Composto] $=0,50 \mathrm{mmol} / \mathrm{L}$, $v=1,0 \mathrm{Vs}^{-1}$. $\mathrm{E}_{\text {inicial }}=-0,2 \mathrm{~V},-0,60 \mathrm{~V}<\mathrm{E}_{\lambda}<-0,70 \mathrm{~V}, \mathrm{E}_{\text {final }}=-0,2 \mathrm{~V}$ 


\subsubsection{Efeito da velocidade de varredura}

De acordo com a Figura 27 verifica-se que com o aumento da velocidade de varredura as razões de corrente variaram a valores crescentes e segundo observações experimentais de alguns autores (NICHOLSON \& SHAIN, 1964; NUÑEZ-VERGARA et al., 1993, 1995) isto indica etapa de transferência de carga reversível seguida de reação química irreversível de desproporcionamento, caracterizando-se como mecanismo $\mathrm{E}_{\mathrm{r}} \mathrm{C}_{\mathrm{i}}$ representada pela reação 9:

$$
2 \mathrm{R}^{-\mathrm{NO}_{2}}{ }^{-}{ }^{-}+2 \mathrm{H}^{+}=\mathrm{R}-\mathrm{NO}_{2}+\mathrm{R}-\mathrm{NO}+\mathrm{H}_{2} \mathrm{O}
$$

Observa-se que os valores de $\mathrm{la}_{\mathrm{p}, 3 \mathrm{R}} / \mathrm{lc}_{\mathrm{p}, 2 \mathrm{R}}$ (Figura 27) são diferentes de $1 \mathrm{em}$ toda faixa de $\mathrm{pH}$ estudada $(8,03 \leq \mathrm{pH} \leq 12,06)$ e isto pode indicar a existência de uma reação química acoplada. Entretanto, mais uma vez, nota-se que os maiores valores de $\mathrm{la}_{\mathrm{p}, 3 \mathrm{R}} / \mathrm{l}_{\mathrm{p}, 2 \mathrm{R}}$ foram obtidos em meio mais alcalino, o que indica a maior estabilidade do nitro radical neste meio reacional.

Em pH 8,03 nota-se que os valores de $\mathrm{la}_{\mathrm{p}, 3 \mathrm{R}} / \mathrm{lc}_{\mathrm{p}, 2 \mathrm{R}}$ tendem a unidade com o aumento da velocidade de varredura. Os análogos contendo enxofre em sua estrutura sofreram ligeiro aumento das razões de corrente em velocidades de varredura crescentes. Entretanto, em estudo com NF verifica-se comportamento pouco distinto em relação aos demais análogos, na qual se observa que em velocidades de varredura mais baixas $(0,0 \leq \log v \leq 0,20)$ houve um aumento significativo nos valores de $\mathrm{la}_{\mathrm{p}, 3 \mathrm{R}} / \mathrm{lc}_{\mathrm{p}, 2 \mathrm{R}}$, e posteriormente $\mathrm{o}$ comportamento foi semelhante aos demais compostos. Neste sentido, pode-se inferir que nesta condição experimental os compostos apresentam comportamento semelhante quanto à estabilidade do nitro radical.

Em pH 9,02 nota-se comportamento pouco distinto em relação ao $\mathrm{pH} 8,03$, onde os valores de $\mathrm{la}_{\mathrm{p}, 3 \mathrm{R}} / \mathrm{l}_{\mathrm{p}, 2 \mathrm{R}}$ para os compostos com núcleo furânico tendem a certo patamar com o aumento da velocidade de varredura e os compostos com núcleo tiofênico em velocidades de varredura maiores $(0,30 \leq \log v \leq 0,50)$ tiveram uma queda acentuada nos valores de $\mathrm{la}_{\mathrm{p}, 3 \mathrm{R}} / \mathrm{l}_{\mathrm{p}, 2 \mathrm{R}}$. No entanto, os análogos contendo 0 anel furânico apresentaram os menores valores de $l a_{p, 3 R} / l_{p, 2 R}$ em velocidades menores de varredura $(0,0 \leq \log v \leq 0,30)$. Neste caso o tempo da medida 
voltamétrica pode não estar sendo suficiente para a re-oxidação completa do nitro radical formado.

Já em pH 10,01 vê-se uma ligeira tendência de queda dos valores de $\mathrm{Ia}_{\mathrm{p}, 3 \mathrm{R}} / \mathrm{l}_{\mathrm{p}, 2 \mathrm{R}}$ para todos os compostos com exceção do análogo NTS, que tende a valores constantes e apresenta os maiores valores de $1 a_{p, 3 R} / l_{p, 2 R}$, o que pode indicar que para este análogo a reação de cinética de decomposição ocorra de forma menos facilitada em relação aos outros análogos.

Ademais, em pH 12,01 vê-se uma tendência de queda nos valores das razões de corrente para todos os compostos. Nesta condição experimental os compostos não apresentaram diferenças significativas quanto aos valores das razões de corrente, no entanto o análogo NTS apresentou os maiores valores de razão de corrente.

É importante destacar que para o cálculo da razão de corrente levou-se em consideração que os valores de $\mathrm{I}_{\lambda}$ fossem numericamente menores que os valores da corrente catódica (entre 97 e 98\% de Ic,p2R), buscando minimizar a influência da segunda onda catódica correspondente à formação do derivado hidroxilamínico.

De acordo com a observação de que os valores de la, 1 33R $/ / c_{, p 2 R}$ são diferentes de 1 e que sugerem uma etapa de transferência de carga seguida de reação química irreversível, investigou-se a relação entre o potencial de pico catódico $\left(\mathrm{Ec}_{\mathrm{p}, 2 \mathrm{R}}\right)$ vs log v, Figura 28.

Nota-se que os valores obtidos para os coeficientes angulares são próximos ao teórico de 0,0195 V (NF-0,0214V; NFS-0,0254V; NT-0,0249V; NTS-0,0230V), o que indica a existência de reação de transferência de carga seguida de reação química irreversível com cinética de segunda-ordem (BONTEMPELLI et al., 1989; NUÑEZ-VERGARA et al., 1993). 

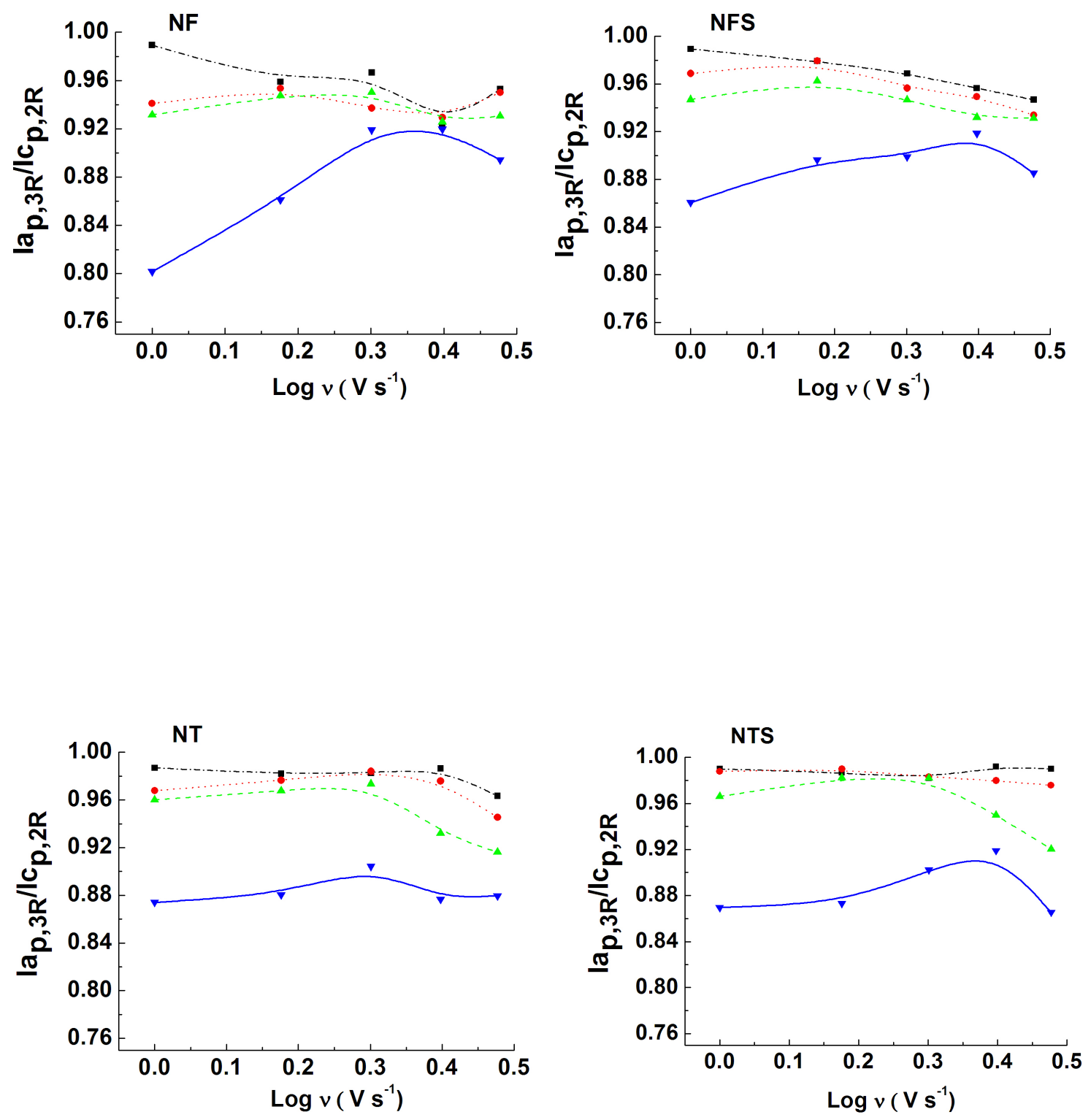

Figura 27- Relação entre as razões de $l a_{p, 3 R} / l_{p, 2 R}$ e log $v$. [Composto] $=0,5 \mathrm{mmol} / \mathrm{L}$

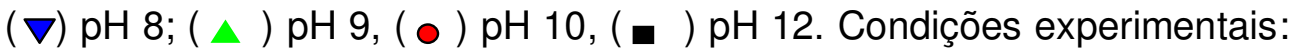
$E_{\text {inicial }}=-0,2 \mathrm{~V},-0,60 \mathrm{~V}<\mathrm{E}_{\lambda}<-0,70 \mathrm{~V}, \mathrm{E}_{\text {final }}=-0,2 \mathrm{~V}$. 

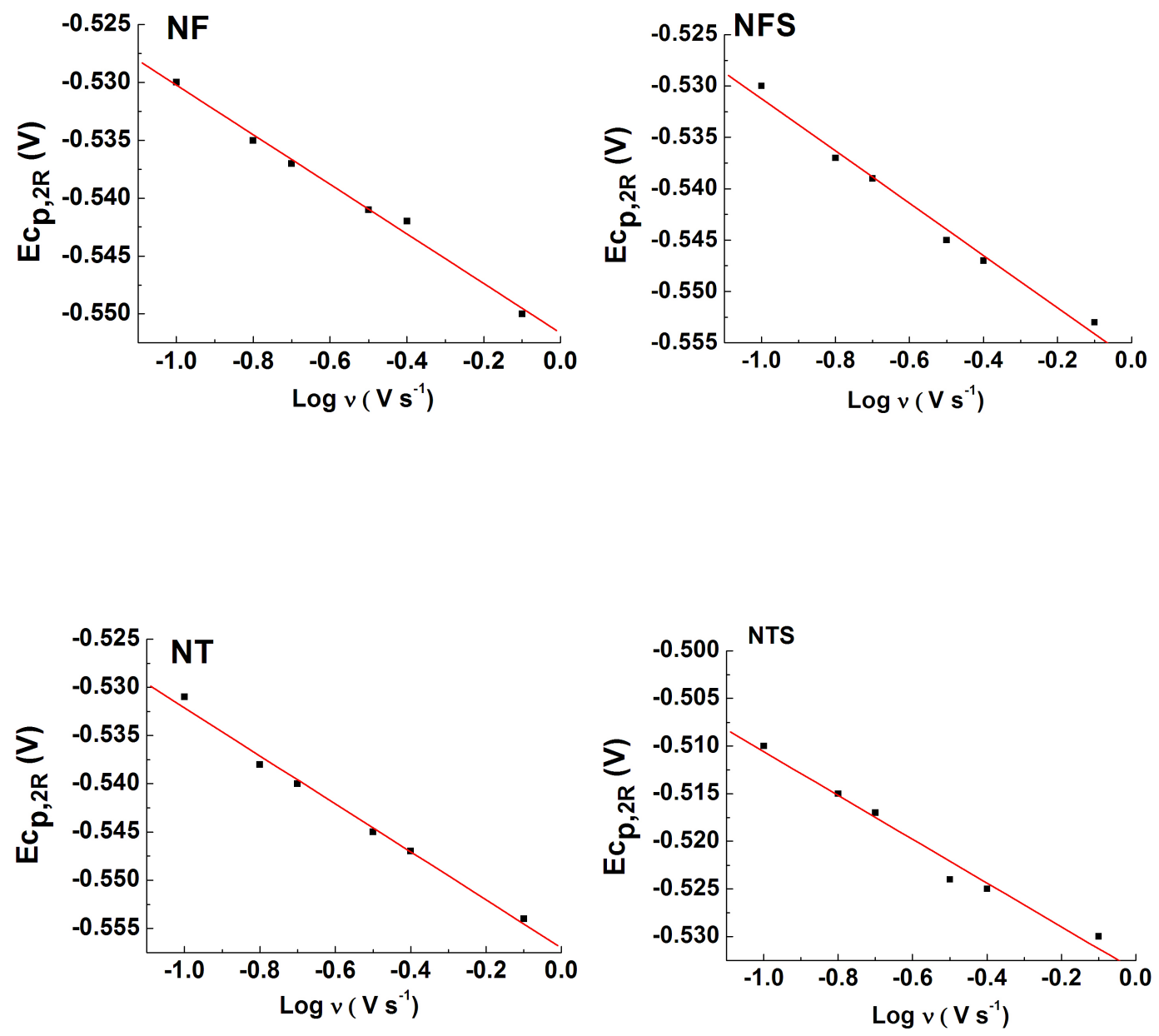

Figura 28 - Dependência de Ec,p2R em função de log v. Dados obtidos em pH 10 usando ECV, velocidade de varredura de $1,0 \mathrm{Vs}^{-1}$. Condições experimentais: $E_{\text {inicial }}=-0,2 \mathrm{~V}, \mathrm{E}_{\lambda_{1}}=-0,70 \mathrm{~V}, \mathrm{E}_{\text {final }}=-0,2 \mathrm{~V}$.

Equações da reta:

(NF) $E p_{c}=-0,552 \mathrm{~V}-0,0214 \mathrm{~V} \mathrm{~s}^{-1}$

$R^{2}=0,997$

(NFS) $\mathrm{Ep}_{\mathrm{c}}=-0,556 \mathrm{~V}-0,0254 \mathrm{~V} \mathrm{~s}^{-1}$

$R^{2}=0,996$

(NT) $E p_{c}=-0,557 \vee-0,0249 V^{-1}$

$R^{2}=0,999$

(NTS) $E p_{c}=-0,534 V-0,0230 \vee s^{-1}$

$R^{2}=0,983$ 


\subsubsection{Efeito da concentração}

Com a finalidade de corroborar com os resultados obtidos sobre a ordem da reação química envolvida, utilizou-se o critério que avalia a dependência de $\mathrm{la}, \mathrm{p3} \mathrm{R} / \mathrm{lc}, \mathrm{p2R}$ em função de diferentes concentrações dos compostos estudados. Se a reação química obedecesse à cinética de primeira-ordem essa relação seria constante com o aumento da concentração dos análogos (NUÑEZ-VERGARA et al., 1993). Entretanto, os resultados obtidos para NF e análogos, as razões de corrente diminuíram de forma semelhante para a mesma faixa de concentração, como mostra a Figura 29. Este critério de diagnóstico satisfaz o requisito de processo homogêneo acoplado ao eletrodo, no qual se tem uma reação química irreversível à uma etapa reversível de transferência de carga (BARD \& FAULKNER, 2001). Neste sentido, o comportamento de NF e análogos sugerem que todos sofrem uma reação química irreversível de desproporcionamento depois da formação do nitro radical, em acordo com a equação 9, confirmando a cinética de segunda-ordem. 

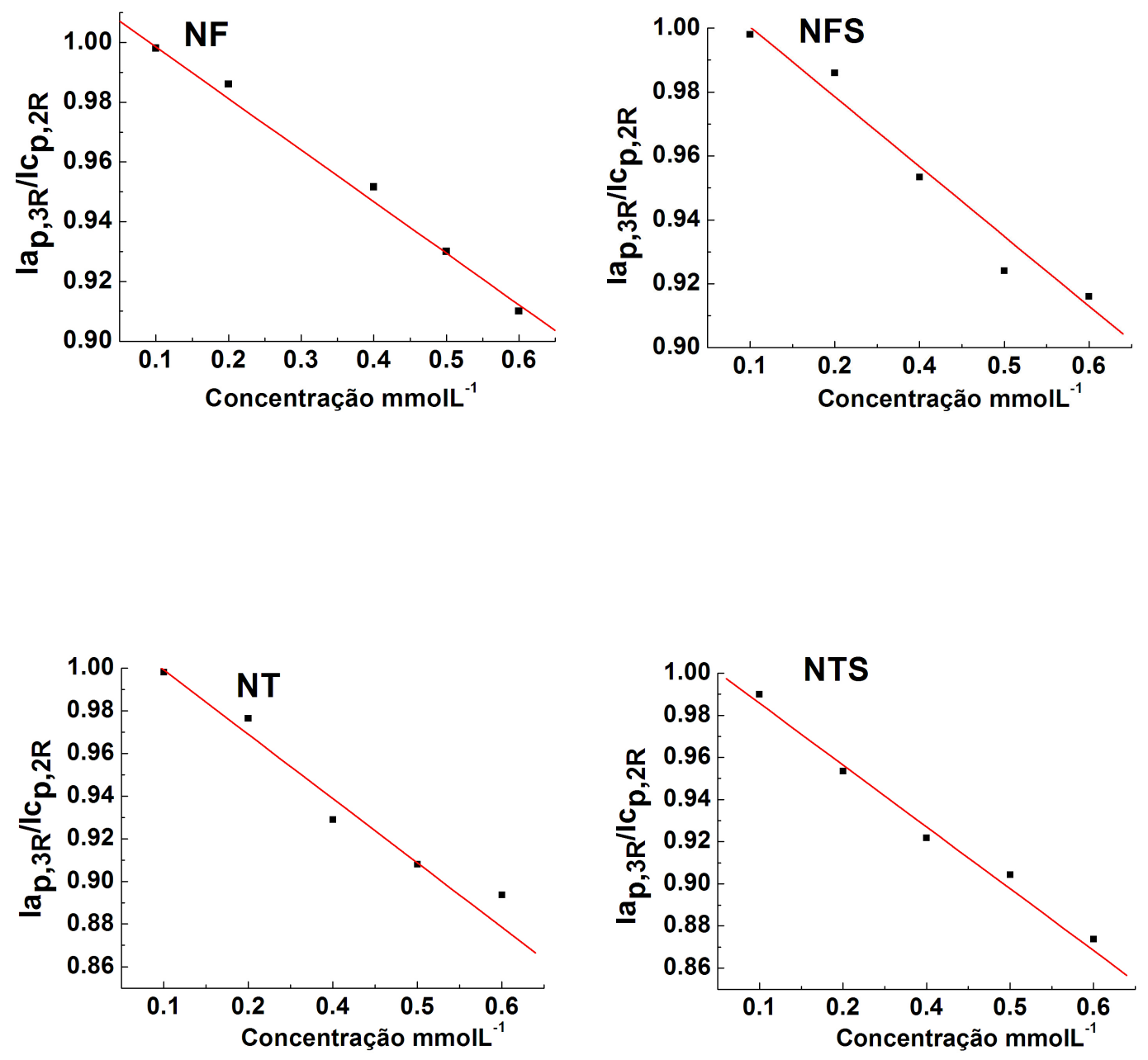

Figura 29-Variação de la,p3R $/ l_{, p 2 R}$ como função da concentração de NF e análogos.

Dados obtidos em pH 10 usando ECV, velocidade de varredura de $1,0 \mathrm{~V} \mathrm{~s}^{-1}$ . Condições experimentais: $\mathrm{E}_{\text {inicial }}=-0,2 \mathrm{~V}, \mathrm{E}_{\lambda_{1}}=-0,70 \mathrm{~V}$, $\mathrm{E}_{\text {final }}=-0,2 \mathrm{~V}$.

Equações da reta:

(NF) $l a_{, p 3 R} / l c_{, p 2 R}=1,02-0,172[N F]$

$R^{2}=0,997$

(NFS) $l \mathrm{a}_{\mathrm{p} \text { p3R }} / \mathrm{lc}, \mathrm{p} 2 \mathrm{R}=1,02-0,22$ [NFS]

$R^{2}=0,985$

(NT) la,p3R $/ / \mathrm{l}, \mathrm{p} 2 \mathrm{R}=1,01-0,293[\mathrm{NT}]$

$R^{2}=0,991$

(NTS) $l \mathrm{a}_{, \mathrm{p} 3 \mathrm{R}} / \mathrm{lc}, \mathrm{p} 2 \mathrm{R}=1,03-0,301[\mathrm{NTS}]$

$R^{2}=0,996$ 


\subsubsection{Cálculo das constantes de velocidade ( $k_{2}$ ) e tempo de meia-vida ( $\left.t_{1 / 2}\right)$}

De acordo com os resultados obtidos que confirmam reação química acoplada à reação eletroquímica é de segunda-ordem, as constantes de velocidade $\left(k_{2}\right)$ foram determinadas seguindo metodologia desenvolvida por OlmsteadNicholson, conforme indicado pelo item 2.2.4.6.3 (OLMSTEAD \& NICHOLSON, 1969). Recentemente, este mecanismo foi empregado por Squella e co-autores para outros compostos nitro-heterocíclicos. A Figura 30 mostra os gráficos, baseados nesta teoria, onde se tem relação linear entre os parâmetros cinéticos, $\varpi$ em função de $\tau$, obtidos em diferentes valores de $\mathrm{pH}$ para NF e análogos. Observa-se que em toda faixa de $\mathrm{pH}$ avaliada todos os compostos apresentaram comportamentos similares e em meio mais alcalino as inclinações das retas foram menos acentuadas indicando os menores valores para $k_{2}$ sugerindo maior estabilidade do nitro radical.

Pelos dados apresentados na Tabela 9 , referentes ao $t_{1 / 2}$, nota-se que a estabilidade do nitro radical é aumentada a valores crescentes de $\mathrm{pH}$ confirmando que o desproporcionamento do $\mathrm{R}_{-\mathrm{NO}_{2}}{ }^{-}$- é mais lento em valores maiores de $\mathrm{pH}$. $\mathrm{Na}$ faixa de $\mathrm{pH}$ entre 8 e 9, os radicais referentes a NF e aos análogos apresentaram estabilidade similares entre si. $\mathrm{Na}$ faixa de $10,0 \leq \mathrm{pH} \leq 12,0$ os compostos com núcleo tiofênico apresentam maior estabilidade referente ao nitro radical, pois apresentaram os menores valores de $k_{2}$.

Com estes aspectos apontados é possível inferir que a reação de desproporcionamento do nitro radical é facilitada com o aumento da acidez do meio, pois este disponibiliza de prótons para doar ao radical formando o intermediário

$\mathrm{R}-\mathrm{NO}_{2} \mathrm{H}^{\bullet}$ facilitada pela rápida reação de protonação entre o conjugado $\mathrm{R}^{-\mathrm{NO}_{2}}{ }^{\bullet-} \mathrm{e}$ a sua forma radicalar neutra, como segue na reação 10 (CARBAJO et al., 2002):

$$
\mathrm{R}-\mathrm{NO}_{2} \mathrm{H}^{\bullet}+\mathrm{R}-\mathrm{NO}_{2}{ }^{\bullet}-\left(+\mathrm{H}^{+}\right) \longrightarrow \mathrm{R}-\mathrm{NO}_{2}+\mathrm{R}-\mathrm{NO}\left(+\mathrm{H}^{+}\right)
$$

Complementarmente, verifica-se que todos os compostos foram facilmente reduzidos em meio aquoso e o nitro radical foi suficientemente estável e detectável pela técnica de VC. Usualmente a detecção do nitro radical requer o uso de meio misto e/ou solventes apróticos (CARBAJO et al., 2002; SQUELLA et al., 2007). Além disso, a geração e observação do nitro radical em meio alcalino também podem 
estar relacionado ao material do eletrodo. Classicamente, emprega-se para estudos deste escopo eletrodos de gota de mercúrio (TOCHER \& EDWARDS, 1994), no entanto eletrodos confeccionados com materiais de carbono vêm merecendo destaque (MANDAL, 2004; JULIÃO et al., 2005, LA-SCALEA et al , 2009). Eletrodo de diamante altamente dopado com boro apresentou as características hidrofóbicas necessárias para a geração e estabilização do nitro radical em meio aquoso (JULIÃO et al., 2005). Entretanto, este trabalho indica claramente que a ativação da superfície do ECV, mediante polimento com diamante, contribuiu para a estabilidade cinética do nitro radical, originando superfície hidrofóbica similar ao registrado com eletrodo de diamante dopado com boro, dificultando da mesma forma a protonação do nitro radical (LA-SCALEA et al., 2009). MANDAL (2004) registrou comportamento semelhante entre ECV e eletrodo de ouro, mostrando que o processo de protonação do nitro radical na superfície do ECV é mais lenta do que ocorre com ouro.

No entanto, não foi possível realizar em $\mathrm{pH} 7,41$, pois os voltamogramas obtidos não se apresentaram bem resolvidos, devido à baixa estabilidade do radical nestas condições. Neste sentido, considerando os resultados obtidos em pH 8,03 e 9,02 pode-se inferir que a estabilidade dos radicais de NF e seus bioisósteros em $\mathrm{pH}$ 7,41 apresentam-se numa mesma ordem de grandeza. Além disso, comparando os valores obtidos de $k_{2}$ para NF e análogos com derivados desenvolvidos por ARGUELLO et al 2006, em meio não aquoso, encontram-se em uma magnitude de grandeza duas vezes menor. Vale ressaltar, que a decomposição do nitro radical é facilitada em meio prótico (CARBAJO et al., 2002). Também, em trabalho desenvolvido anteriormente, comparando os valores obtidos de $k_{2}$ com outro derivado de NF (NFOH) em meio aquoso constatou-se que o nitro radical advindo deste outro análogo é mais estável (LA-SCALEA et al., 2009). No entanto, os radicais de NF e análogos foram mais estáveis do que os derivados estudados por BOLLO et al 2004, na qual incluía o megazol, composto com atividade antichagásica reconhecida, mesmo em meio totalmente aprótico.

Ademais, o nitro radical gerado a partir de NF e bioisósteros é um bom exemplo para estudo de reações de transferência de carga acopladas à reações químicas de desproporcionamento, sendo a VC excelente ferramenta para estudos da estabilidade do referido radical (YAÑEZ et al., 2005; BOLLO et al., 2003; CARBAJO et al., 2002). 

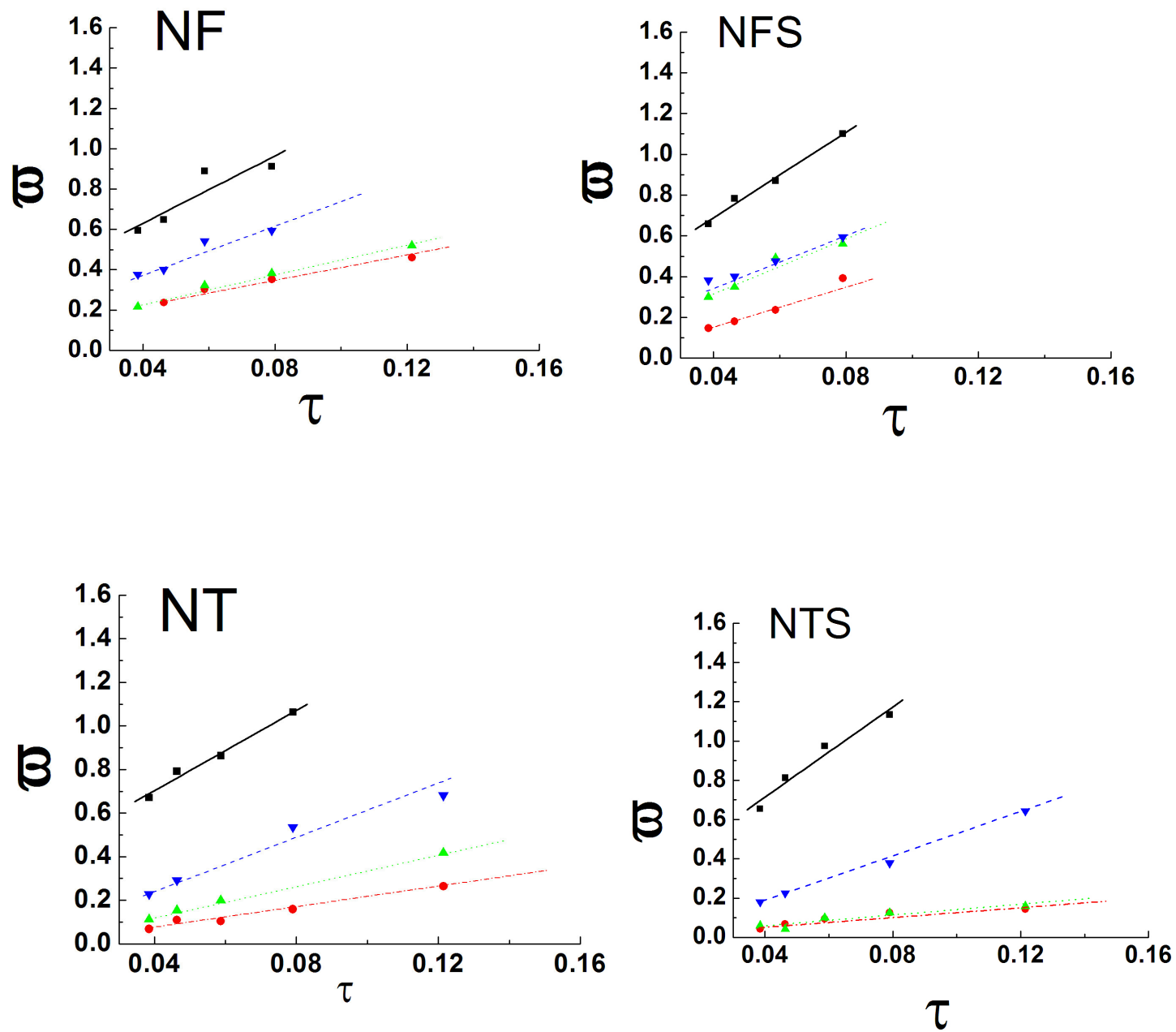

Figura 30- Gráfico dos parâmetros cinéticos, ఐ como função da constante de tempo, $\tau$. [Composto] = 0,50 mmol/L.4 ) pH 8, 12. Condições experimentais: $E_{\text {inicial }}=-0,2 \mathrm{~V},-0,60 \mathrm{~V}<\mathrm{E}_{\lambda}<-0,70 \mathrm{~V}, \mathrm{E}_{\text {final }}=$ $-0,2 \mathrm{~V}$. 
Tabela 9. Valores de $k_{2}$ e $t_{1 / 2}$ para a reação de desproporcionamento do radical aniônico em diferentes valores de $\mathrm{pH}$; [Composto] $=0,5 \mathrm{mmol} / \mathrm{L}$.

\begin{tabular}{|c|c|c|c|c|c|c|c|c|}
\hline \multirow[t]{2}{*}{$\mathrm{pH}$} & \multicolumn{4}{|c|}{$\begin{array}{c}k_{2} \times 10^{+3} \\
\left(\mathrm{~L} \mathrm{~mol}^{-1} \mathrm{~s}^{-1}\right)\end{array}$} & \multicolumn{4}{|c|}{$\begin{array}{l}t_{1 / 2} \\
\text { (s) }\end{array}$} \\
\hline & NF & NFS & NT & NTS & NF & NFS & NT & NTS \\
\hline 8,03 & 16,74 & 20,90 & 18,42 & 22,93 & 0,12 & 0,10 & 0,11 & 0,09 \\
\hline 9,02 & 11,43 & 15,84 & 10,98 & 11,05 & 0,17 & 0,13 & 0,18 & 0,18 \\
\hline 10,01 & 7,07 & 13,29 & 7,22 & 2,29 & 0,28 & 0,15 & 0,28 & 0,87 \\
\hline 12,05 & 5,68 & 13,28 & 4,52 & 2,28 & 0,35 & 0,16 & 0,44 & 0,88 \\
\hline
\end{tabular}




\section{Capítulo 4}

Conclusões

\section{CONCLUSÕES}

- Estudos por espectrofotometria de UV/Vis mostraram que o uso do ultrassom no processo de dissolução de NF e de seus análogos não afetou a estabilidade química dos mesmos.

- Em meio ácido, NF e seus análogos apresentaram comportamento voltamétrico semelhante controlado por difusão, com única onda de redução irreversível ( $E c, p 1)$, e um pico de oxidação $\left(E_{p, 1}\right)$.

- O análogo NTS foi o único a apresentar dois picos de oxidação $\left(\mathrm{Ea}_{, \mathrm{p} 1}\right.$ e Ea,p2 $)$, sendo o segundo correspondente a possível processo adsortivo sobre a superfície do ECV.

- Observou-se que o pico $\mathrm{Ea}_{, \mathrm{p} 1}$ é dependente do pico $\mathrm{Ec}_{\mathrm{c}, \mathrm{p} 1}$, indicando que este pico anódico corresponde à oxidação de hidroxilamina ao derivado nitroso.

- O número de elétrons estimados confirmou o envolvimento de 4 elétrons no processo principal de redução ( $E c, p 1)$ de NF e análogos.

- Os valores de potencial de redução $\mathrm{Ec}_{\mathrm{p} p 1}$ de NF e de seus análogos são dependentes da acidez do meio, sendo deslocados linearmente para valores mais negativos de potencial com aumento do $\mathrm{pH}$.

- Os dois procedimentos de polimento do ECV, com diamante e alumina, não apresentaram efeitos significativamente diferentes sobre o comportamento voltamétrico dos análogos estudados.

- Os estudos por VC indicam que o nitro radical, Ec,p2R, para todos os compostos foram suficientemente estáveis em meio aquoso-alcalino $7,41 \leq$ $\mathrm{pH} \leq 12,01$ no tempo de escala da técnica voltamétrica empregada.

- O pico Ec,p2R apresentou respectivo componente anódico $\left(\mathrm{Ea}_{, \mathrm{p} 3 \mathrm{R}}\right)$, onde $\Delta \mathrm{E}$ $90 \mathrm{mV}$ caracterizando-se como processo quasi-reversível.

- A formação do radical ocorre rapidamente e envolve etapa de um elétron que e é controlada por difusão.

- Todos os resultados de $\mathrm{la}_{\mathrm{p}, \mathrm{p} 3 \mathrm{R}} / \mathrm{lc}_{\mathrm{p} \text {, } 2 \mathrm{R}}$ são diferentes da unidade, onde se 
destaca o efeito da velocidade de varredura, $\mathrm{pH}$ e concentração sobre os resultados da razão de corrente. Isto demonstra o envolvimento de reação química acoplada.

- O aumento da concentração dos nitrocompostos estudados favorece a reação de desproporcionamento do $\mathrm{R}_{-} \mathrm{NO}_{2}{ }^{\bullet-}$.

- Os resultados obtidos indicam que o radical formado tem a tendência em sofrer reação química de segunda-ordem de desproporcionamento, obedecendo ao mecanismo $\mathrm{E}_{\mathrm{r}} \mathrm{C}_{\mathrm{i}}$, na qual indica reação química reversível seguida de reação química irreversível com a participação de prótons.

- A estabilidade do nitro radical é aumentada a valores crescentes de $\mathrm{pH}$, confirmando que a reação de desproporcionamento do $\mathrm{R}-\mathrm{NO}_{2}{ }^{\bullet-}$ é mais lenta em valores maiores de $\mathrm{pH}$.

- Estes resultados até o momento indicam que as modificações moleculares realizadas a partir do NF não introduziram alterações significativas no comportamento voltamétrico de seus bioisósteros.

- Assim, fica evidente a importância do conhecimento do comportamento voltamétrico de nitro-heterocíclicos como ferramenta para estudos de REA e compreensão do mecanismo de ação dos mesmos. 


\section{Capítulo 5}

Perspectivas

\section{PERSPECTIVAS}

- Iniciar estudos voltamétricos para a detecção de possíveis interações entre o nitro radical e aceptores eletrônicos, como, por exemplo, a glutationa e cisteína, com ECV em meio aquoso;

- Estudar outros análogos da classe dos nitro-heterocíclicos; principalmente os derivados hidroximetilados dos biosisósteros aqui apresentados,

- Avaliar a aplicação da voltametria de onda quadrada (VOQ) para o estudo do comportamento voltamétrico dos compostos estudados. Esta técnica além de permitir o uso de concentrações menores de analito, possibilitará melhor definição do registro de formação do nitro radical,

- Possíveis resultados obtidos por VOQ, além destes já obtidos por VC, poderão ser aplicados a futuros estudos de correlação entre estrutura química e a atividade biológica destes compostos potencialmente antichagásicos. 
Capítulo 6

Referências Bibliográficas

\section{REFERÊNCIAS BIBLIOGRÁFICAS}

AGUIRRE, G.; BOIANI, L.; BOIANI, M.; CERECETTO, H.; DI MAIO, R.; GONZÁLEZ, M.; PORCAL, W.; DE NICOLA, A.; PIRO, O.E.; CASTELLANO, E.E.; SANT'ANNA, C.M.R.; BARREIRO, E.J. New potent 5-substitude benzofuroxans as inhibitors of Trypanosoma cruzi grouth: quantitative structure-activity relationship studies. Bioorganic \& Medicinal Chemistry, v.13, n.23, p.6336-6346, 2005.

ABREU, F.C.; FERRAZ, P.A.L.; GOULART, M.O.F. Some applications of electrochemistry in biomedical chemistry. Emphasis on the correlation of electrochemical and bioactive propertiers. Journal of the Brazilian Chemical Society, v.13, n.1, p.19-35, 2002.

AMATO NETO, V. A vida e a obra de Carlos Chagas. Imprensa Médica, v.442, p.82$91,1950$.

ANDRADE, Z.A.; BRENNER, Z. Ação da nitrofurazona (5-nitro-2-furaldeídosemicarbazona) sobre as formas intracelulares do Trypanosoma cruzi na doença de Chagas experimental. Revista do Instituto de Medicina Tropical de São Paulo, v.11, p.222-228, 1969.

ARAYA, J.E.; NEIRA, I.; SILVA, S.; MORTARA, R.A.; MANQUE, P.; CORDERO, E.; SAGUA, H.; LOYOLA, A.; BÓRQUEZ, J.; MORALES, G.; GONZÁLEZ, J. Diterpenóides from Azzorella compacta (Umbelliferae) active on Trypanosoma cruzi. Memórias do Instituto Oswaldo Cruz, v.98, n.3, p.413-418, 2003.

ARAÚJO, A.J.G.; SABROZA, P.J.; SILVA, L.F.R.F. Epidemiologia: situação atual. Disponível em: http://www.fiocruz.br/chagas/cgi/cgilua.exe/sys/start.htm?tpl=home. Acesso em: 29 out. 2009.

ARGUELLO, J.; NUÑEZ-VERGARA, L.J.; BOLLO, J.A.; SQUELLA, J.A. Nitro radical anion formation from nitrofuryl substituted 1,4 - dihydropyridine derivates in mixed and non-aqueous media. Bioelectrochemistry, v.69, p.104-112, 2006.

BARD, A.J.; FAULKNER, L.R. Electrochemical methods: fundamentals and applications. 2.ed. New York: John Wiley, 2001. 833p.

BIAGLOW, J.E.; VARNES, M.E.; ROIZEN'TOWLE, L.; CLARK, E.P.; EPP, E.R.; ASTOR, M.B.; HALL, E.J. Biochemistry of reduction of nitro heterocycles. Biochemical Pharmacology, v.35, n.1, p.77-80, 1986.

BLUMENSTIEL, K.; SCHONECK, R.; YARDLEY, V.; CROFT, S.L.; KRAUFTSIEGEL, R.L. Nitrofuran drugs as common subversive substrates of Trypanosoma 
cruzi lipoamine dehydrogenase and trypanothione reductase. Biochemical Pharmacology, v.58, n.11, p.1791-1799, 1999.

BOLLO, S.; JARA-ULLOA, P.; ZAPATA-TORRES, G.; CUTIÑO, E.; STURM, J.C.; NUÑES-VERGARA, L.J.; SQUELLA, J.A. Voltammetric reduction of 4-nitroimidazole derivatives: influence of the $\mathrm{N}-1$ substitution in protic and aprotic media. Electrochimica Acta, v.55, p.4558-4566, 2010.

BOLLO, S.; NUNES-VERGARA, L.J.; MARTINEZ, C.; CHAUVIERE, G.; PÉRIÉ, J.; SQUELLA, J.A. Voltammetric study of nitro-radical aniônico anion generated from some nitrofuran compounds of pharmacological significance. Electroanalysis, v.15, n.1, p.9-25, 2003.

BOLLO, S.; NUNES-VERGARA, L.J.; CHAUVIERE, G.; PÉRIÉ, J.; SQUELLA, J.A. Electrochemical study of a 4-substituded analogues of megazol. Electroanalysis, v.17, n.2, p.134-139, 2004.

BOND, C.S.; ZHANG, Y.; BERRIMAN, M.; CUNNINGHAM, M.L.; FAIRLAMB, A.H.; HUNTER, W.N. Crystal structure of Trypanosoma cruzi trypanothione reductase in complex with trypaothione and the structure-based discovery of new natural product inhibitors. Structure, v.7, n.1, p.81-89, 1999.

BONTEMPELLI, G.; MAGNO, F.; MAZZOCCHIN, G.A.; SEEGER, R. Linear sweep and cyclic voltammetry. Annali di Chimica, v.79, n.3/4, p.103-216, 1989.

BRAJTER-TOTH, A.; GOYAL, R.N.; WRONA, M.Z.; LACAVA, T.; NGUYEN, N.T.; DRYHURST, G. Electrochemical and enzymic oxidation of biological purines. Bioelectrochemistry and Bioenergetics, v.8, n.4, p.413-435, 1981.

BOLLO, S.; JARA-ULLOA, P.; ZAPATA-TORRES, G.; CUTIÑO, E.; STURM, J.C.; NUÑES-VERGARA, L.J.; SQUELLA, J.A. Voltammetric reduction of 4-nitroimidazole derivatives: Influence of the $\mathrm{N}-1$ substitution in protic and aprotic media. Eletrochimica Acta, v. 55, p. 4558-4566, 2010.

BOLLO, S.; NUNES-VERGARA, L.J.; MARTINEZ, C.; CHAUVIERE, G.; PÉRIÉ, J.; SQUELLA, J.A. Voltammetric Study of Nitro-radical aniônico Anion Generated fromSome Nitrofuran Compounds of Pharmacological Significance. Electroanalysis, Weinhem, v. 15, n. 1, p. 9-25, 2003.

BRETT, A.M.O.; BRETT, A. M. Electrochemistry. Principles, Methods and Applications, Oxford University press, New York, 1996.

BROWN, E.R.; SANDIFER, J.R. Cyclic voltammetry, AC polarography and related techniques. In: ROSSITER, B.W.; HAMILTON, J.F., eds. Physical methods of chemistry. 2.ed. New York: John Wiley, 1986. p.273-432. [v.2: Electrochemical methods].

BURGER, A. Isosterism and bioisosterism in drug design. Progress in Drug Research, v.37, p.287-371, 1991.

CANÇADO, J.R. Criteria of Chagas disease cure. Memórias do Instituto Oswaldo Cruz, v.94, suppl.1, p.331-335, 1999. 
CARBAJO, J.; BOLLO, S.; NUÑES-VERGARA, L.J.; CAMPERO, A.; SQUELLA, J.A. Cyclic voltammetric study of the disproportionation reaction of the nitro radical anion from 4-nitroimidazole in protic media. Journal of Electroanalytical Chemistry, v.531, p.187-194, 2002.

CASTRO, J.A.; MECA, M.M.; BARTEL, L.C. Toxic side effects of drug used to treat Chagas' disease (American Trypanosomíasis). Human \& Experimental Toxicology, v.25, p.471-479, 2006.

CERECETTO, H.; DI MAIO, R.; GONZALEZ, M.; RISSO, M.; SAGRERA, G.; SEOANE, G.; DENICOLA, A.; PELUFFO, G.; QUIJANO, C.; STOPPANI, A.O.; PAULINO, M.; OLEA-AZAR, C.; BASOMBRIO, M.A. Synthesis and antitrypanossoamal evaluation of $E$-isomers of 5-nitro-2furaldehyde and 5nitrothiophene-2-carboxaldehyde semicarbazone derivates: structure-activity relationshaps. European Journal of Medical Chemistry, v.35, p.343-350, 2000.

CHAUVIÉRE, G.; BOUTEILLE, B.; BERTINEHANGA, B.; ALBUQUERQUE, C.N.; CROFT, S.L.; DUMAS, M.; PERIÉ, J. Synthesis and biological activity of nitro heterocycles analogous to megazol, a trypanocidal lead. Journal of Medicinal Chemistry, v.46, p.427-440, 2003.

CHIBALE, K.; MUSONDA, C.C. The synthesis of parasitic cysteine protease and trypanothione reductase inhibitors. Current Medicinal Chemistry, v.10, p.1863-1889, 2003.

CIAPETTI, P.; GIETHLEN, B. Molecular variations based on isosteric replacements. In: WERMUTH, C.G., ed. The practice of medicinal chemistry. 3.ed. London: Academic Press, 2008. p.290-334.

COURA, J.R.; DIAS, J.C.P. Epidemiology, control and surveillance of Chagas disease - 100 years after its discovery. Memórias do Instituto Oswaldo Cruz, v.104, p.31-40, 2009.

COURA, J.R.; CASTRO, S.L. A critical review on Chagas disease chemotherapy. Memórias do Instituto Oswaldo Cruz, v.97, n.1, p.3-24, 2002.

CRENSHAW, C.A.; GLANGES, E.; STUART, B.H.; PIERCE, J. Nitrofurazone therapy in "middle burns": a review. Current Therapeutic Research, Clinical and Experimental, v.19, n.4, p.487-492, 1976.

DA SILVA, R.P.; SERRANO, S.H.P. Electrochemical oxidation of biological molecules at carbon paste electrodes pre-treated in guanine solutions. Journal of Pharmaceutical and Biomedical Analysis, London, v.33, n.4, p. 735-744, 2003.

DECLERCK, P.J.; DE RANTER, C.J. In vitro reducive activation of nitroimidazoles. Biochemical Pharmacology, v.35, p.59-61, 1986.

DIAS, L.C.; DESSOY, M.A.; SILVA, J.J.N.; THIEMANN, O.H.; OLIVA, G.; ANDRICOPULO, A.D. Quimioterapia da doença de Chagas: estado da arte e perspectivas no desenvolvimento de novos fármacos. Química Nova, v.32, n.9, p.2444-2457, 2009. 
DIAS, J.C.P.; SILVEIRA, A.C.; SCHOFIELD, C.J. The impact of Chagas control in Latin América: a review. Memórias do Instituto Oswaldo Cruz, v.97, p.603-612, 2002.

DIAS, J.C.P. Epidemiologia. In: BRENER, Z.; ANDRADE, Z.; BARRAL-NETO, M., eds. Trypanosoma cruzi e doença de Chagas. 2.ed. Rio de Janeiro: Guanabara Koogan, 2000. p.48.

DOCAMPO, R.; MORENO, S.N.J. Biochemical toxicology of antiparasitic compounds used in the chemotherapy and chemoprophylaxis of American trypanosomes. Reviews in Biochemical Toxicology, v.7, p.159-204,1985.

DODD, M.C.; STILLMAN, W.B.; ROYS, M.; CROSBY, C. The in vivo bacteriostatic action of some simple furan derivates. Journal of Phamacology and Experimental Therapeutics, v.82, n.1, p.11-18, 1944.

DU, X.; GUO, C.; HANSELL, E.; DOYLE, P.S.; CAFFREY, C.R.; McKERROW, T.J.H.; COHEN, F.E. Synthesis and sctruture-activity relationship study of potent trypanocidal thio semicarbazona inhibitors of the trypanosomal cysteine protease cruzain. Journal of Medicinal Chemistry, v.45, p.2695-2777, 2002.

EDWARDS, D.I. Nitroimidazoles drugs-action and resistance mechanisms. I. Mechanisms of action. Journal of Antimicrobial Chemotherapy, v.31, n.1, p.9-20, 1993.

ENGELS, D.; SAVIOLI, L. Reconsidering the underestimated burden caused by neglected tropical diseases. Trends in Parasitology, v.22, p.363-366, 2006.

GELB, M.H.; HOL, W.G. Drugs to combat tropical protozoan parasites. Science, v.297, p.343-344, 2002.

GIRAULT, S.; DAVIOUD-CHARVET, E.; MAES, L.; DUBREMETZ, J.F.; DEBREU, M.A.; LANDRY, V.; SERGHERAERT, C. Potent and specific inhibitors of trypanothione reductase from Trypanosoma cruzi: bis(2-aminodiphenylsulfides) for fluorescent labeling studies. Bioorganic \& Medicinal Chemistry, v.9, n.4, p.837-846, 2001.

GOLDMAN, P.; KOCH, R.L.; YEUNG, T.C.; CHRYSTAL, E.J.T.; BEALIEU Jr., B.B.; McLAFFERTY, M.A.; SUDLOW, G. Comparing the reduction of nitroimidazoles in bacteria and mammalin tissues and relating it to biological activity. Biochemical Pharmacology, v.35, n.1, p.43-51, 1986.

GOOMANN, L.S.; HARDMANN, J.G.; LIMBIRD, L.E.; GILMAN, A.G. Goomann \& Gilman's the pharmacological basis of therapeutics. 9.ed. New York: McGraw-Hill, 1996. 1905p.

HARRIS, D.C. Análise química quantitativa. 5.ed. Rio de Janeiro: LTC, 2001. p.403420.

HENDERSON, G.B.; ULRICH, P.; FAIRLAMB, A.H.; ROSENBEERG, I.; PEREIRA, M.; SELA, M.; CERAMI, A. Subversive substrates for the enzyme trypanothione dissulfide reductase: alternative approach to chemotherapy of Chagas disease. 
Proceedings of the National Academy of Sciences of the United States of America, v.85, p.5374-5378, 1988.

HOLLOWAY, G.A.; BAELL, J.B.; FAIRLAMB, A.H.; NOVELLO, P.M.; PARISOT, J.P.; RICHARDSON, J.; WATSON, K.G.; STREET, I.P. Discovery of 2iminobenzimidazoles as a new class of trypanothione reductase inhibitor by highthroughput screening. Bioorganic \& Medicinal Chemistry Letters, v.17, p.1422-1427, 2007.

HORROCKS, S.M.; JUNG, Y.S.; HUWE, J.K.; HARVEY, R.B.; RICKE, S.M.F.; CARSTENS, G.E.; CALLAWAY, T.R.; ANDERSON, R.C.; RAMLACHAN, N.; NISBET, D.J. Effects of short-chain nitrocompounds against Camylobacter jejuni and Campylobacter coli in vitro. Journal of Food Science, v.72, n.2, p.M50-M55, 2007.

JOCKERS-SCHERUBL, M.C.; SCHIMER, R.H.; KRAUTH-SIEGEL, R.L. Trypanothione reductase from Trypanosoma cruzi. catalytic properties of the enzyme and inhibition studies with trypanocidal compounds. European Journal of Biochemistry, v.180, n.2, p.267-272, 1989.

JULIÃO, M.S.S.; ALMEIDA, E.C.; LA-SCALEA, M.; FERREIRA, N.G.; COMPTON, R.G.; SERRANO, S.H.P. Voltammetric behaviour of nitrofurazone at highly boron doped diamond electrode. Electroanalysis, v.17, n.3, p.269-274, 2005.

JULIÃO, M.S.S.; FERREIRA, E.I.; FERREIRA, N.G.; SERRANO, S.H.P. Voltammetric detection of the interactions between $\mathrm{RNO}^{\circ-}$ and electron acceptors in aqueous medium at highly boron doped diamond electrode (HBDEE). Electrochimica Acta, v.51, n.24, p.5080-5086, 2006.

KALCHER, K.; KAUFFMANN, J.M.; WANG, J.; SVANCARA, I.; VYTRAS, K.; NEHHOLD, C.; YANG, Z. Sensors based on carbon paste in electrochemical analysis: a review with particular emphasis on the period 1990-1993. Electroanalysis, v.7, n.1, p.5-22, 1995.

KAVOLDA, R. Environmental eletroanalytical chemistry contemporary trends and prospects. Critical Reviews in Analytical Chemistry, v.30, n.1, p.31-35, 2000.

KAUFFMAN, J.M.; GUILBAUT, G.G. Enzyme electrode biosensors: theory and applications. In: SUELTER, C.H.; KRICKA, L., eds. Bioanalytical applications of enzymes. New York: Wiley, 1992. v.36, p.63-113. (Methods of biochemical analysis, v.36).

KAUFFMAN, J.M.; PEKLI-NOVAK, M.; NAGY, A. The potential of electroanalytical techniques in pharmaceutical analysis. Acta Phamaceutica Hungarica, v.66, n.2, p.57-64, 1996.

KATZUNG, B.G. Farmacologia básica e clínica. 8.ed. Rio de Janeiro: Guanabara Koogan, 2001. cap.52, p.757.

KARAKUS, C.; ZUMAN, P. Polarographic and electrochemical studies of some aromatic and heteroaromatic nitrocompounds. Part 9. Substituints effects on protonation of the radical $\mathrm{ArNO}_{2} \mathrm{H}^{-}$and its reactions with hidroxylamino and nitroso 
compounds in buffered mixtures of water and DMF. Journal of Electroanalytical Chemistry, v.396, p.499-505, 1995.

KOROLKOVAS, A. Essentials of medicinal chemistry. 2.ed. New York: WileyInterscience, 1988. p.579-670.

KOROLKOVAS, A.; FRANÇA, F.F.A.C. Dicionário Terapêutico Guanabara, 2007/2008, 14.ed., Rio de Janeiro: Guanabara Koogan, 2007.

KRAUTH-SIEGEL, R.L.; INHOFF, O. Parasite-specific trypanothione reductase as a drug target molecule. Parasitology Research, v.90, suppl.2, p.S77-S85, 2003.

KRAUTH-SIEGEL, R.L.; BAUER, H.; SCHIRMER, H.R. Dithiol proteins as guardians of the intracellular redox milieu in parasites: old and new drug targets in trypanosomes and malaria-causing plasmodial. Angewandte Chemie, International Edition, v.44, p.690-715, 2005.

LANA, M.; TAFURI, W.L. Trypanossoma cruzi e doença de Chagas. In: NEVES, D.P. Parasitologia humana. 11.ed. São Paulo: Atheneu, 2005. cap.11, p.85-108. (Biblioteca médica).

LA-SCALEA, M.; TROSSINI, G.H.G.; MENEZES, C.M.S.; CHUNG, M.C.; FERREIRA, E.I. Eletrochemical reduction using glassy carbon electrode in aqueous medium of a potential anti-Chagas drug: hidroxymethylnitrofurazone (NFOH). Journal of the Electrochemical Society, v.156, n.7, p.F93-F97, 2009.

LA-SCALEA, M.; MENEZES, C.M.S.; JULIÃO, M.S.S.; CHUNG, M.C.; SERRANO, S.H.P.; FERREIRA, E.I. Voltammetric behavior of nitrofurazone and its hydroxymethyl prodrug with potencial anti-Chagas activity. Journal of the Brazilian Chemical Society, v.16, p.774-782, 2005.

LA-SCALEA, M.; MENEZES, C.M.S.; FERREIRA, E.I. Molecular volume calculation using AM1 semi-empirical method toward diffusion coefficients and electrophoretic mobility estimates in aqueous solution. Journal of Molecular Structure, v.730, p.111121, 2005.

LA-SCALEA, M. Comportamento voltamétrico e mecanismo de ação biológico de nitroimidazóis. Revista de Farmácia e Bioquímica da Universidade de São Paulo, v.34, n.2, p.58-62, 1998.

LEMKE, T.L.; WILLIAMS, D.A., eds. Foye's principles of medicinal chemistry. 6.ed. Philadelphia: Lippincott Williams \& Wilkins, 2008. 1377p.

LEON, L.E.; SAWYER, D.T. Simultanoues determination of iron (II) and Iron (III) at micromolar concentrations by differential pulse polarography. Analytical Chemistry, v.53, n.4, p.706-709, 1981.

LIMA, L.M.; BARREIRO, J.E. Bioisosterism: a useful strategy for molecular modification and drug design. Current Medical Chemistry, v.12, p.23-49, 2005.

LURIE, J. Handbook of analytical chemistry. Moscow: Mir Publishers, 1978. 488p. 
MAEGAWA, F.A.B.; DAMERAU, E.F.; BELTRAME, I.T.; LOPES, A.; MACHADO, P.E.; STEINDEL, M.; GRISARD, E.C. Authoctonous Chagas' disease in Santa Catarina, Brazil: report of the first case of digestive tract involvement. Revista da Sociedade Brasileira de Medicina Tropical, v.36, p.609-612, 2003.

MAYA, J.D.; CASSELS, B.K.; ITURRIAGA-VÁSQUEZ, P.; FERREIRA, J.; FAÚNDEZ, M.; GALANTI, N.; FERREIRA, A.; MORELLO, A. Mode of action of natural and synthetic drugs against Trypanosoma cruzi and their interaction with the mammalian host. Comparative Biochemistry and Physiology. Part A, Moleculat \& Integrative Physiology, v.146, n.4, p.601-620, 2007.

MANDAL, P.C. Reactions of the nitro radical anion of metronidazole in aqueous and mixed solvent: a Cyclic Voltammetric Study. Journal of Electroanalytical Chemistry, v.570, p.55-61, 2004.

MARTYN, D.C.; JONES, D.C.; FAIRLAMB, A.H.; CLARDY, J. High-throughput screening affords novel and selective trypanothione reductase inhibitors with antitrypanosomal activity. Bioorganic \& Medicinal Chemistry Letters, v.17, p.1280-1283, 2007.

MOLINSPIRATION. Disponível em: http://www.molinspiration.com/. Acesso em: 20 jul. 2009.

MONTEAGUDO, J.C.G.; FONSECA, J.M.L.; CRESPO, M.A. Mechanism of the polarographic reduction of a new 5-nitrofuran derivate with antibacterial activity. Pharmazie, v.47, n.2, p.98-101, 1992.

MORALES, A.; RICHTER, P.; TORAL, M.I. Polarographic behaviour an determination of nitrofuratoin, chloramphenicol and related compounds. Analyst, v.109, p.663-636, 1984.

MORALES, A.; RICHTER, P.; TORAL, M.I. Voltammetric behaviour of nitrofurazone, furazolidone and other nitro-derivates of biological importance. Analyst, v.112, p.965970, 1987.

MORENO, S.N.J. The reductive metabolism of nifurtimox and benznidazole in Crithidia fasciculata is similar to that in Trypanosoma cruzi. Comparative Biochemistry and Physiology, Part C: Pharmacology, Toxicology \& Endocrinology, v.91C, n.2, p.321-325, 1988.

NUÑEZ-VERGARA, L.J.; BOLLO, S.; ALVAREZ, A.F.; SQUELLA, J.A.; BLAZQUEZ, $M$. Nitro radical formation from nimodipine. Journal of Electroanalytical Chemistry, v.345, p.121-134, 1993.

NUÑEZ-VERGARA, L.J.; ALDUNATE, J.; LETELIER, M.E.; BOLLO, S.; REPETTO, Y.; MORELLO, A.; SPENCER, P.L.; SQUELLA, J.A. Nitro radical formation from nifurtimox II: electrochemical evidence. Bioelectrochemistry and Bioenergetics, v.38, p.355-358, 1995.

NUÑEZ-VERGARA, L.J.; ORTIZ, M.E.; BOLLO, S.; SQUELLA, J.A. Electrochemical generation and reactivity of free radical redox intermediates from ortho- and meta- 
nitro substituted 1,4 dihydropyridines. Chemico-Biological Interactions, v.106, n.1, p.1-14,1997.

NICHOLSON, R.S.; SHAIN, I. Theory of stationary electrode polarography, single scan and syclic methods applied to reversible, irreversible and kinetics systems. Analytical Chemistry, v.36, p.706-723, 1964.

OLIVEIRA, R.B.; ZANI, C.L.; FERREIRA, R.S.; LEITE, R.S.; ALVES, M.A.; SILVA, T.H.A.; ROMANHA, A.J. Síntese, avaliação biológica e modelagem molecular de arilfuranos como inibidores da tripanotiona redutase. Química Nova, v.31, n.2, p.261267, 2008.

OLMSTEAD, M.L.; HAMILTON, R.; NICHOLSON, R.S. Theory of cyclic voltammetry for a dimerization reaction initiated electrochemically. Analytical Chemistry, v.41, n.6, p.862-864, 1969.

PATANI, G.A.; LAVOIE, E.J. Bioisosterism: a rational approach in drug design. Chemical Reviews, v.96, p.3147-3176, 1996.

PESSOA, S.B.; MARTINS, A.V. Parasitologia médica. 11.ed. Rio de Janeiro: Guanabara Koogan, 1988. cap.14, p.175-176.

RAETHER, W.; HANEL, H. Nitroheterocyclic drugs with broad spectrum activity. Parasitology Research, v.90, suppl.1, p.S19-S39, 2003.

ROFFEL, B.; VAN DE GRAFF, J.J. The diffusion coefficient of ions in aqueous ferricyanide of potassium chloride with and without addition of poliethylene oxide. Journal of Chemical \& Engineering Data, v.22, p.3, p.300-302, 1977.

ROJAS, A.; VINHÂES, M.; RODRIGUEZ, M.; MONROY, Y.; PERSAUD, N.; AZNAR, C.; NÁQUIRA, C.; HIWAT, H.; BENITEZ, J. Implementação da iniciativa intergovernamental de vigilância e prevenção da doença de Chagas na Amazônia. Revista da Sociedade Brasileira de Medicina Tropical, v.38, p.82-89, 2005. [Reunião Internacional sobre Vigilância e Prevenção da Doença de Chagas na Amazônia].

ROZENSKI, J.; DE RANTER, C.J.; VERPLANKEN, H. Quantitative structure-activity relationships for antimicrobial nitroheterocyclic drugs. Quantitative Structure-Activity Relationships, v.14, n.2, p.134-141, 1995.

Secretaria de vigilância em Saúde de Santa Catarina (SVS), 13/2/2005; Secretaria de vigilância em Saúde do Pará (SVS), 31.03.2005, Brasil, http://dtr2001.saude.gov.br/svs.Nota Técnica -4/4/05, acessado em 02/2009

SERRANO, S.H.P.; BARROS, R.C.M.; JULIÃO, M.S.S.; PAULA, F.R. Biological electrochemical applications on diamond electrodes: solving old problems and opening new possibilities. In: SQUELLA, J.A.; BOLLO, S., eds. Electroanalytical aspects of biological significance compounds. Kerala: Transworld Research Network, 2006. cap.3, p.51-71.

SERRANO, S.H.P.; MACHADO, S.A.S.; GIL, E.S. Métodos eletroquímicos. In: GIL, E.S.; ORLANDO, R.M.; MATHIAS, R.; SERRANO, S.H.P., eds. Controle físico- 
químico de qualidade de medicamentos. Campo Grande: UNIDERP, 2005. cap.2.2, p.363-399.

SQUELLA, J.A.; LETELIER, M.E.; LINDERMEYER, L.; NUÑES-VERGARA, L.J. Redox behaviour of nifuroxazide: generation of the one-electron reduction product. Chemico-Biological Interactions, v.99, n.1/3, p.227-238, 1996.

SQUELLA, J.A.; BOLLO, S.; NUNES-VERGARA, L.J. Recent developments in the electrochemistry of some nitro compounds of biological significance. Current Organic Chemistry, v.9, n.6, p.565-581, 2005.

SQUELLA, J.A.; NUÑES-VERGARA, L.J.; CAMPERO, A.; MARAVER, J.; JARAULLOA, P.; CARBAJO, J. Eletrochemical reduction of 2- nitroimidazole in aqueous mixed medium. Journal of the Electrochemical Society, v.154, n.4, p.F77-F81, 2007.

SYMONS, T.; TOCHER, J.H.; TOCHER, D.A.; EDWARDS, I. Electrochemical studies of nitroheterocyclic compounds of biological interest. VII. Efect of electrode material. Free Radical Research Communications, v.14, p.33-40, 1991.

TAVARES, L.C.; CHISTÉ, J.J.; SANTOS, M.G.B.; PENNA, T.C.V. Synthesis and biological activity of nifuroxazide and analogs. II. Bolletino Chimico Farmaceutico, v.138, n.8, p.432-436, 1999.

TOCHER, J.H. Reductive activation of nitroheterocyclic compounds. General Pharmacology, v.28, n.4, p.485-487, 1997.

TOCHER, J.H.; EDWARDS, D.I. Evidence for the direct interaction of reduced nitroimidazole derivates with DNA bases. Biochemical Pharmacology, v.48, n.6, p.1084-1089, 1994.

TROSSINI, G.H.G. Antichagásicos potenciais: busca racional de compostos com ação seletiva pela cruzaína. São Paulo, 2008. 289p. Tese de Doutorado - Faculdade de Ciências Farmacêuticas - Universidade de São Paulo.

URBINA, J.A.; CONCEPCION, J.L.; CALDERA, A.; PAYARES, G.; SANOJA, C.; OTOMO, T.; HIYOSHI, $\mathrm{H}$. Chemotherapy of Chagas disease. Current Pharmaceutical Design, v.8, p.278-295, 2002.

URBINA, J.A.; DOCAMPO, R. Specific chemotherapy of Chagas disease: controversies and advances. Trends in Parasitology, v.19, p.495-501, 2003.

VIODÉ, C.; BETTACHE, N.; CENAS, N.; KRAUTH-SIEGEL, R.L.; CHAVIÉRE, G.; BAKALARA, N.; PÉRIE, J. Enzimatic reduction studies of nitroheterocycles. Biochemical Pharmacology, v.57, n.5, p.549-557, 1999.

YAÑEZ, C.; PEZOA, J.; RODRIGUES, M.; NUÑES-VERGARA, L.J.; SQUELLA, J.A. Voltammetric behavior of a 4-nitroimidazole derivates nitro radcial anion formation and stability. Journal of the Electrochemical Society, v.152, n.6, p.J46-J51, 2005.

VETTORAZZI, N.; OTERO, L.; SERENO, L. Modified glassy carbon electrodes obtained by electrochemical treatment: effects on the heterogeneous electron 
transfer kinetics of an adsorbed aromatic amine. Electrochimica Acta, v.44, p.345352, 1998.

VIODÉ, C.; BETTACHE, N.; CENAS, N.; KRAUTH-SIEGEL, R.L.; CHAUVIÉRE, G.; BAKALARA, N.; PERIÉ, J. Enzimatic reduction studies of nitroheterocycles. Biochemical Pharmacology, v.57, p.549-557, 1999.

WANG, J. Analytical electrochemistry. 2.ed. New York: Wiley-VHC, 2000. p.1-124.

WERMUTH, C.G. In: Molecular variations based on isosteric replacements, ed. The practice of medicinal chemistry. 2 ed. London: Academic press, 2008a. p. 191-210.

WILKE, C.R.; CHANG, P. Correlation of diffusion coefficients in dilute solutions. AlChe Journal, v.1, n.2, p.264-270, 1955.

WHO, in: http://www.who.int/tdr/diseases/chagas/files/chagas-postes.pdf. Acessado em 25/04/2011.

WHO, in: http://apps.who.int/tdr/publications/tdr-research-publications/reporteenfermedad-chagas/pdf/swg chagas.pdf, 2008.

ZHAO, Q.J.; HU, H.G.; LI, Y.W.; SONG, Y.; CAI, L.Z.; WU, Q.Y.; JIANG, Y.Y. Design, synthesis and antifungal activities of novel $1 \mathrm{H}$-triazole derivatives based on the structure of the active site of fungal lanosterol 14a-demetilase (CYP51). Chem. Biodiversity, v.4, p.1472-79, 2007.

ZHANG, H.; COURY, L.A. Effects of high-intensity ultrasound on glassy carbon electrodes. Anal. Chem., v.65, p.1552-1556, 1993.

ZINGALES, B.; COLLI, W. Trypanosoma cruzi- interactions with host cells. Curr. Top. Microbiol., v.17, p.129-152, 1985.

ZUMAN, P.; FIJALEK, Z.; DUMANOVIC, D.; SUZNEJEVIC, D. Polarographic and eletrochemical studies of some aromatic and heterocyclic nitro compounds. Part I: General mechanism aspects. Electroanalysis, v.4, p.783-794, 1992. 


\subsection{CURRICULM VITAE}

\section{DADOS PESSOAIS}

Nome: Charles de Lima Brito

Local e data de nascimento: São Paulo-SP, 15-06-1978

\section{EDUCAÇÃO}

Ensino Fundamental: Escola de $1^{\circ}$ e $2^{\circ}$ grau Frei Paulo Luig, 1992.

Ensino médio: Escola de $2^{\circ}$ grau Oswaldo Catalano, 1995.

ENSINO SUPERIOR: Universidade Presbiteriana Mackenzie, 2002.

Graduação em química bacharelado

\section{FORMAÇÃO COMPLEMENTAR}

Mini-curso: Planejamento de candidatos a novos fármacos

Simpósio Brasileiro de Química, SBQ, Brasil, 2010.

Workshop: Interfaces entre a Química e a Biologia nas áreas de produtos Naturais e Química

Simpósio Brasileiro de Química, SBQ, Brasil, 2010.

Difusão: Biônica-ponte entre a natureza e evolução

Universidade de São Paulo, USP, Brasil, 2008. 


\section{TRABALHOS EM CONGRESSO}

Evento: XV Simpósio Brasileiro de Eletroquímica;

Título: Comportamento de dois derivados nitrotiofênicos com potencial leismanicida;

Autores: Brito, C.L., Rando, D. G., La-Scalea-M, Ferreia, E.I.;

Local: Universidade Estadual de Londrina-PR ; Data: 04-07 de dezembro de 2005.

Evento: XLII Congresso da Sociedade Brasileira de Medicina Tropical, do I Encontro Tropical dos Países de Língua Portuguesa, do II Encontro Brasileiro de Coccidioidomicose, do Fórum de Propriedade Intelectual e Tratamento do HIV/AIDS e de Doenças Infecciosas e Negligenciadas, do Fórum da Malária do Programa Índia/Brasil, Instituto de Investigação, Imunologia: Imunologia as Retroviroses do Fórum Fome e Doenças Tropicais e da Reunião de Biotecnologia Aplicada às Doenças Tropicais.

Título: Emprego de agentes moduladores da resistência e isolados brasileiros de Plasmodium falciparum resistentes à cloroquina: 2 . Análise comparativa da interação com grupo Heme,

Co-autores: Brito, C.L., Menezes, C.M., La-Scalea-M, Ferreia, E.I.;

Local: Universidade Federal do Piauí-PI ; Data: 04-08 de março de 2006.

Evento: 29. Simpósio Brasileiro de Química- SBQ;

Título: Comportamento voltamétrico de decomposição de nitrotiofênicos com atividade leishmanicida potencial;

Autores: Brito, C.L.,Rando, D. G., La-Scalea-M, Ferreia, E.I.

Local: Águas de Lindóia- SP, maio de 2006.

Evento: XXXI Semana Farmacêutica da Faculdade de Ciências Farmacêuticas da USP;

Título: Planejamento molecular de análogos do nitrofural à ativdade antichagástica potencial.

Autores: Trossini, G.G., Brito, C.L., La-Scalea, M., .T., Paula, F.R., Menezes, C.M., Ferreia, E.l;

Local: Universidade de São Paulo, outubro de 2006. 
Evento: 30. Simpósio Brasileiro de Química- SBQ.

Título: Avaliação de parâmetros físico-químicos de bioisósteros do nitrofural (NF) com potencial atividade antichagásica.

Autores: Brito , C.L.,Trossini,G.G., La-Scalea-M, Menezes, C.M.S., Ferreira, E.I ; Local: Águas de Local: Lindóia- SP, maio de 2007.

Evento: XXXII Semana Farmacêutica da Faculdade de Ciências Farmacêuticas da USP.

Título: Estudo de docking e atividade de inibição da cruzipaína de análogos de nitrofural com atividade antichagásica.

Autores:, Trossini, G.G., Brito, C.L., Romeiro, N.L., Malvezzi, A., Amaral, A.., Fraga, C., Barreiro, E. J., .T., Ferreia, E.I.

Local: Universidade de São Paulo, outubro de 2007.

Evento: 31. Simpósio Brasileiro de Química- SBQ.

Título: Estudo do comportamento voltamétrico de bioisósteros do nitrofural potencialmente antichagásicos.

Autores: Brito , C.L.,Trossini, G.G.,La-Scalea-M, Ferreia, E.I.

Local: Águas de Lindóia- SP, maio de 2008.

Evento: XXXIV Semana Farmacêutica da Faculdade de Ciências Farmacêuticas da USP.

Título: Estimate of the number of involved electrons in the voltammetric reduction of potentially antichagasic bioisosters of nitrofurazone.

Autores: Brito , C.L.,Trossini, G.G.,La-Scalea-M, Ferreia, E.I.

Local: Universidade de São Paulo, outubro de 2009.

Evento: 33. Simpósio Brasileiro de Química- SBQ.

Título: Efeito do $\mathrm{pH}$ e polimento em ECV sobre a redução de redução de bioisósteros de NF potencilamente antichagásicos.

Autores: Brito , C.L.,Trossini, G.G., La-Scalea-M, Ferreia, E.I.

Local: Águas de Lindóia- SP, maio de 2010. 
Evento: XXXIV Semana Farmacêutica da Faculdade de Ciências Farmacêuticas da USP

Título: Effect of $\mathrm{pH}$ and glassy carbon electrode (GCE) polishing on reduction of $\mathrm{NF}$ bioisosters potentially active as antichagasic agents.

Autores: Brito , C.L.,Trossini, G.G.,La-Scalea-M, Ferreia, E.I.

Local: Universidade de São Paulo, outubro de 2010.

Evento: XVIII Simpósio Brasileiro de Eletroquímica e Eletronalítica (SIBEE)

Título: Estudo Eletroquímico da Geração do Nitro radical Aniônico em meio aquoso a partir de análogos do Nitrofural com Potencial Atividade Antichagásica.

Autores: Brito , C.L.,Trossini, G.G.,La-Scalea-M, Ferreia, E.I.

Local: Bento Gonçalves-Rio Grande do Sul, setembro de 2011.

\section{ARTIGOS PUBLICADOS EM PERIÓDICOS}

PANCOTE, C. G. ; BRANDT, C. A. ; BRITO, C.L.; P., S. A. C. M. ; SILVEIRA, M. A. B. . synthetic method of beta-enamino ester using ultrasound. synthesis, v. 10, p. 1557-1559, 2004.

GRILLO, R. ; MELO, N. F. S. de ; BRITO, C. L. ; TROSSINI, G. H. G. ; MENEZES,

C. M. S. ; FERREIRA, E. I. ; MORAES, C. L. ; FRACETO, L. F. .Caracterização físico-química de complexo de inclusão entre hidroximetilnitrofurazona e hidroxipropil-beta-ciclodextrina. Química Nova, v. 31, p. 290-295, 2008

\section{ARTIGOS EM ELABORAÇÃO A PARTIR DESTA DISSERTAÇÃO}

Brito, C.L.; Trossini, G.H.G.;.Ferreira, E.I.; La-Scalea, M.A. Eletrochemical reduction of nitrofurazone analogues and the number of electrons estimate.

Brito, C.L.; Trossini, G.H.G.; Ferreira, E.I.; La-Scalea, M.A. Nitro radical formation from analogues of nitrofurazone aqueous with potential activity antichagasic. 


\title{
7.2 FICHA DO ALUNO
}

Fanus - Sistema Administrativo da Pós-Graduação

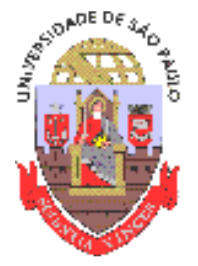

\author{
Universidade de São Paulo \\ Faculdade de Ciências Farmacêuticas \\ Documento sem validade oficial
}

FICHA DO ALUNO

9138 - 3575863/1 - Charles de Lima Brito

charles.brito@uol.com.br

Data de Nascimento:

15/06/1978

Cédula de Identidade:

RG - 23.244.580-1 - SP

Local de Nascimento:

Estado de São Paulo

Nacionalidade:

Brasileira

Graduação:

Bacharel em Química - Universidade Mackenzie - São Paulo - Brasil 2002

Curso:
Programa:
Área:
Data de Matrícula:
Início da Contagem de Prazo:
Data Limite:
Orientador:
Proficiência em Línguas:
Data de Aprovação no Exame de
$\quad$ Qualificação:
Mestrado
Fármaco e Medicamentos
Insumos Farmacêuticos
$02 / 02 / 2009$
$02 / 02 / 2009$
$02 / 08 / 2011$
Prof(a). Dra Elizabeth Igne Ferreira email: elizabeth.igne@gmail.com
Inglês, Aprovado em 02/02/2009

28-01-2011

Data do Depósito do Trabalho:

Título do Trabalho:

Data Máxima para Aprovação da Banca:

Data de Aprovação da Banca:

Data Máxima para Defesa:

Data da Defesa:

Resultado da Defesa:

Histórico de Ocorrências:

Ingressou no Mestrado em 02/02/2009

Matrícula de Acompanhamento em 
Última ocorrência: Matrícula de Acompanhamento em 25/07/2010

Impresso em: 24/07/11

Fanus - Sistema Administrativo da Pós-Graduação

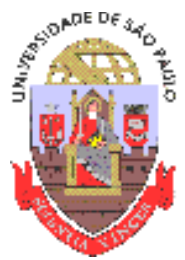

\author{
Universidade de São Paulo \\ Faculdade de Ciências Farmacêuticas \\ Documento sem validade oficial
}

FICHA DO ALUNO

9138 - 3575863/1 - Charles de Lima Brito

\begin{tabular}{|c|c|c|c|c|c|c|c|c|c|}
\hline Sigla & $\begin{array}{l}\text { Nome da } \\
\text { Disciplina }\end{array}$ & Início & Término & Carga Horária & Cred. & Freq. & Conc. & Exc. & Situação \\
\hline $\begin{array}{c}\text { FBF5704- } \\
5 / 2\end{array}$ & $\begin{array}{l}\text { Análise } \\
\text { Espectrométric } \\
\text { a de Fármacos }\end{array}$ & 02/03/2009 & $14 / 06 / 2009$ & 150 & 10 & 100 & B & $\mathrm{N}$ & Concluída \\
\hline $\begin{array}{c}\text { FBF5705- } \\
4 / 1\end{array}$ & $\begin{array}{c}\text { Planejamento } \\
\text { Fármacos }\end{array}$ & le $24 / 04 / 2009$ & 02/07/2009 & 90 & 6 & 100 & A & $\mathrm{N}$ & Concluída \\
\hline $\begin{array}{c}\text { FBF5786- } \\
2 / 1\end{array}$ & $\begin{array}{l}\text { Metodologias } \\
\text { Modelagem } \\
\text { Molecular } \\
\text { Planejamento } \\
\text { de Fármacos }\end{array}$ & 15/09/2009 & $16 / 11 / 2009$ & 90 & 6 & 100 & $A$ & $\mathrm{~N}$ & Concluída \\
\hline $\begin{array}{c}\text { QFL5713- } \\
6 / 1\end{array}$ & $\begin{array}{l}\text { Química } \\
\text { Eletroanalítica } \\
\text { Fundamentos } \\
\text { Aplicações } \\
\text { Ambientais } \\
\text { Clínicas } \\
\text { (Instituto d } \\
\text { Química } \\
\text { Universidade } \\
\text { de São Paulo) }\end{array}$ & $\begin{array}{l}- \\
\text { e } \\
\text { e } 30 / 09 / 2009 \\
-\end{array}$ & $02 / 12 / 2009$ & 90 & 6 & 100 & A & $\mathrm{N}$ & Concluída \\
\hline $\begin{array}{c}\text { FBF5777- } \\
2 / 2\end{array}$ & $\begin{array}{l}\text { Tópicos Gerais d } \\
\text { Fármaco } \\
\text { Medicamentos }\end{array}$ & e 01/03/2010 & $13 / 06 / 2010$ & 45 & 3 & 93.3 & A & $\mathrm{N}$ & Concluída \\
\hline
\end{tabular}

